\title{
Interactions between the atmosphere, cryosphere, and ecosystems at northern high latitudes
}

Michael Boy $^{1}$, Erik S. Thomson ${ }^{2}$, Juan-C. Acosta Navarro ${ }^{3}$, Olafur Arnalds ${ }^{4}$, Ekaterina Batchvarova ${ }^{5,6}$, Jaana Bäck ${ }^{7}$, Frank Berninger $^{7}$, Merete Bilde ${ }^{8}$, Zoé Brasseur $^{1}$, Pavla Dagsson-Waldhauserova ${ }^{4,9,10}$, Dimitri Castarède ${ }^{2}$, Maryam Dalirian $^{11}$, Gerrit de Leeuw ${ }^{12}$, Monika Dragosics ${ }^{13}$, Ella-Maria Duplissy ${ }^{1}$, Jonathan Duplissy ${ }^{1}$, Annica M. L. Ekman ${ }^{14}$, Keyan Fang ${ }^{15}$, Jean-Charles Gallet ${ }^{16}$, Marianne Glasius ${ }^{8}$, Sven-Erik Gryning ${ }^{5}$, Henrik Grythe ${ }^{11,17}$, Hans-Christen Hansson ${ }^{11}$, Margareta Hansson ${ }^{18}$, Elisabeth Isaksson ${ }^{16}$, Trond Iversen ${ }^{19}$, Ingibjorg Jonsdottir ${ }^{13}$, Ville Kasurinen ${ }^{1,7}$, Alf Kirkevåg ${ }^{19}$, Atte Korhola ${ }^{20}$, Radovan Krejci ${ }^{11}$, Jon Egill Kristjansson ${ }^{21, \dagger}$, Hanna K. Lappalainen ${ }^{1,12,22}$, Antti Lauri ${ }^{1}$, Matti Leppäranta ${ }^{1}$, Heikki Lihavainen ${ }^{12}$, Risto Makkonen ${ }^{1}$, Andreas Massling ${ }^{23}$, Outi Meinander ${ }^{12}$, E. Douglas Nilsson ${ }^{11}$, Haraldur Olafsson ${ }^{9,24}$, Jan B. C. Pettersson ${ }^{2}$, Nønne L. Prisle ${ }^{25}$, Ilona Riipinen ${ }^{11}$, Pontus Roldin ${ }^{26}$, Meri Ruppel ${ }^{20}$, Matthew Salter ${ }^{11}$, Maria Sand $^{27}$, Øyvind Seland ${ }^{19}$, Heikki Seppä ${ }^{28}$, Henrik Skov ${ }^{23}$, Joana Soares ${ }^{12,29}$, Andreas Stohl ${ }^{17}$, Johan Ström ${ }^{11}$, Jonas Svensson $^{12}$, Erik Swietlicki ${ }^{26}$, Ksenia Tabakova ${ }^{1}$, Throstur Thorsteinsson ${ }^{13,30}$, Aki Virkkula ${ }^{1,12}$, Gesa A. Weyhenmeyer ${ }^{31}$, Yusheng Wu ${ }^{1}$, Paul Zieger ${ }^{11}$, and Markku Kulmala ${ }^{1}$

${ }^{1}$ Institute for Atmospheric and Earth System Research/Physics, University of Helsinki, P.O. Box 64, 00014 Helsinki, Finland

${ }^{2}$ Department of Chemistry and Molecular Biology, Atmospheric Science,

University of Gothenburg, 41296 Gothenburg, Sweden

${ }^{3}$ Earth Science Department Barcelona Supercomputing Center (BSC), Barcelona, Spain

${ }^{4}$ Agricultural University of Iceland, Faculty of Agricultural and Environmental Sciences, Hvanneyri, Iceland

${ }^{5}$ DTU Wind Energy, Technical University of Denmark, Risø Campus, Roskilde, Denmark

${ }^{6}$ Bulgarian Academy of Sciences, National Institute of Meteorology and Hydrology, Sofia, Bulgaria

${ }^{7}$ Institute for Atmospheric and Earth System Research/Forest, University of Helsinki, P.O. Box 27, 00014 Helsinki, Finland

${ }^{8}$ Department of Chemistry, Aarhus University, Langelandsgade 140, 8000 Aarhus C, Denmark

${ }^{9}$ University of Iceland, Department of Physical Sciences, Reykjavik, Iceland

${ }^{10}$ Faculty of Environmental Sciences, Czech University of Life Sciences, Prague, Czech Republic

${ }^{11}$ Department of Environmental Science and Analytical Chemistry, Stockholm University, 10691 Stockholm, Sweden

${ }^{12}$ Finnish Meteorological Institute, Climate Research Programme, Helsinki, Finland

${ }^{13}$ University of Iceland, Institute of Earth Sciences, Reykjavik, Iceland

${ }^{14}$ Department of Meteorology and Bolin Centre for Climate Research, Stockholm University, Stockholm, Sweden

${ }^{15}$ Institute of Geography, Key Laboratory of Humid Subtropical Eco-geographical

Process, Fujian Normal University, Fujian, China

${ }^{16}$ Norwegian Polar Institute, FRAM - High North Research Centre on Climate and the Environment, 9296 Troms $\varnothing$, Norway

${ }^{17} \mathrm{NILU}$ - Norwegian Institute for Air Research, Kjeller, Norway

${ }^{18}$ Department of Physical Geography, Stockholm University, 10691 Stockholm, Sweden

${ }^{19}$ Norwegian Meteorological Institute, Oslo, Norway

${ }^{20}$ University of Helsinki, Environmental Change Research Unit (ECRU), Ecosystems and Environment Research Programme, Faculty of Biological and Environmental Sciences, P.O. Box 65, University of Helsinki, 00014 Helsinki, Finland

${ }^{21}$ Department of Geosciences, University of Oslo, Oslo, Norway

${ }^{22}$ Tyumen State University, Department of Cryosphere, 625003 Tyumen, Russia

${ }^{23}$ Aarhus University, Arctic Research Center, Climate, Department of Environmental Science,

Arctic Research Centre, Frederiksborgvej 399, 4000 Roskilde, Denmark

${ }^{24}$ Icelandic Meteorological Office, Reykjavik, Iceland

${ }^{25}$ University of Oulu, Nano and Molecular Systems Research Unit, P.O. Box 3000, 90014, University of Oulu, Oulu, Finland

${ }^{26}$ Lund University, Department of Physics, Division of Nuclear Physics, P.O. Box 118, 22100 Lund, Sweden 
${ }^{27}$ Center for International Climate and Energy Research - Oslo (CICERO), Oslo, Norway

${ }^{28}$ Department of Geosciences and Geography, University of Helsinki, Helsinki, Finland

${ }^{29}$ Air Quality Research Division, Environment and Climate Change Canada, Toronto, M3H 5T4, Canada

${ }^{30}$ University of Iceland, Environment and Natural Resources, Reykjavik, Iceland

${ }^{31}$ Department of Ecology and Genetics/Limnology, Uppsala University, Uppsala, Sweden

$\dagger$ deceased August 2016

Correspondence: Michael Boy (michael.boy@helsinki.fi) and Erik S. Thomson (erik.thomson@chem.gu.se)

Received: 17 July 2018 - Discussion started: 3 August 2018

Revised: 22 December 2018 - Accepted: 16 January 2019 - Published: 14 February 2019

\begin{abstract}
The Nordic Centre of Excellence CRAICC (Cryosphere-Atmosphere Interactions in a Changing Arctic Climate), funded by NordForsk in the years 2011-2016, is the largest joint Nordic research and innovation initiative to date, aiming to strengthen research and innovation regarding climate change issues in the Nordic region. CRAICC gathered more than 100 scientists from all Nordic countries in a virtual centre with the objectives of identifying and quantifying the major processes controlling Arctic warming and related feedback mechanisms, outlining strategies to mitigate Arctic warming, and developing Nordic Earth system modelling with a focus on short-lived climate forcers (SLCFs), including natural and anthropogenic aerosols.

The outcome of CRAICC is reflected in more than 150 peer-reviewed scientific publications, most of which are in the CRAICC special issue of the journal Atmospheric Chemistry and Physics. This paper presents an overview of the main scientific topics investigated in the centre and provides the reader with a state-of-the-art comprehensive summary of what has been achieved in CRAICC with links to the particular publications for further detail. Faced with a vast amount of scientific discovery, we do not claim to completely summarize the results from CRAICC within this paper, but rather concentrate here on the main results which are related to feedback loops in climate change-cryosphere interactions that affect Arctic amplification.
\end{abstract}

\section{Introduction}

Near-surface climate warming in the Arctic has proceeded at approximately twice the global average rate since 1980 . This extraordinary rate of warming has been recognized since the late 1990s (Serreze et al., 2000) and has accelerated even since then (Bekryaev et al., 2010), leading to extreme events in 2016 when October-December temperatures in large parts of the Arctic were more than $5^{\circ} \mathrm{C}$ above normal and daily anomalies exceeded $16^{\circ} \mathrm{C}$ in many locations (Simpkins, 2017). The warming has caused notable changes in the Arctic cryosphere: Arctic sea-ice area has decreased in all seasons (Wadhams, 2016; Johannessen et al., 2019), glaciers have been retreating (Dowdeswell et al., 1997; AMAP, 2017, and references therein), Arctic fresh waters have rapidly warmed (O'Reilly et al., 2015), Arctic soils and permafrost are warming (AMAP, 2017, and references therein), and precipitation and river discharges into the Arctic Ocean are increasing (McCelland et al., 2004; Zhang et al., 2013). These changes have dramatic impacts on the ecology and societies of the Arctic and via global climate effects are connected to changes across the planet. Underlining these interconnected changes is the urgent need for a better understanding of the processes contributing to climate change (AMAP, 2017).

It is commonly accepted that increasing concentrations of anthropogenic greenhouse gases (GHGs) predominantly cause the rising global temperatures and are moderated by effects of aerosols and land-use change (IPCC, 2013). The enhanced warming in the Arctic, termed Arctic amplification or polar amplification when also considering the Antarctic, is understood to be the result of feedback processes acting specifically at high latitudes and primarily involving sea ice and snow cover (e.g. Bekryaev et al., 2010) and changes in the atmospheric temperature lapse rate, which at high latitudes tends to be opposite to those elsewhere (Pithan and Mauritsen, 2014). The general idea is that an initial warming (e.g. caused by increased greenhouse gases) reduces the extent of the highly reflective and heat-flux-damping snow and ice cover, which results in an increased absorption of solar radiation during summer and a larger temperature decrease with altitude (lapse rate) with a reduced loss of long-wave radiation, both contributing to further warming (Pithan and Mauritsen, 2014).

The Arctic is more sensitive to the feedbacks described above than the Antarctic, largely because surface air temperatures in the Arctic are closer to the melting point, at which point the albedo feedbacks are particularly sensitive. However, the relative importance of the different feedback processes (e.g. the role of sea ice vs. snow cover or the seasonal variation of the amplification) is still debated (Hudson, 2011; Perovich and Polashenski, 2012). Furthermore, the implications of Arctic amplification for the mid-latitudes, possibly 
manifested in more frequent extreme weather events, are under discussion (Cohen et al., 2014).

Other feedback processes specific to the Arctic loom and may be triggered by anthropogenically driven global warming. For example, large reservoirs of carbon are stored in boreal wetlands and permafrost areas. Changes in temperature, water table depth, or melting of the permafrost can trigger releases of both methane and carbon dioxide, which can amplify the warming (Chappellaz et al., 1993). Similarly, large amounts of methane are stored in subsea permafrost and methane hydrates, which could be destabilized by oceanic warming, although it is not clear how much of that methane could reach the atmosphere (Shakhova et al., 2010; Myhre et al., 2016). In particular, warming summers reduce the volume of multi-year sea ice in the Arctic Ocean and that may eventually lead to ice-free summer conditions and a largely changed atmosphere-ocean equilibrium state (Eisenmann and Wettaufer, 2009).

Understanding and quantifying the drivers and complex feedbacks in the arctic and northern boreal climate were the main focus of the Cryosphere-Atmosphere Interactions in a Changing Arctic Climate (CRAICC) Nordic Centre of Excellence. With support from NordForsk, CRAICC gathered scientists from different disciplines in a virtual centre of excellence and used their expertise to obtain a holistic understanding of Arctic feedbacks and interactions. CRAICC involved more than 100 researchers from 24 institutions in the Nordic countries and supported $35 \mathrm{PhD}$ students and postdoctoral researchers. To date, CRAICC has produced more than 150 peer-reviewed scientific publications, and this paper provides a summary of the main scientific achievements generated by the centre, with an outlook towards the future. Beyond long-lived greenhouse gases there are other important climate forcers in the Arctic climate system. In particular, short-lived climate forcers (SLCFs) are crucial to Arctic amplification and were one of the main foci in CRAICC.

SLCFs are atmospheric constituents with atmospheric lifetimes (days to weeks) that are substantially shorter than those of long-lived greenhouse gases (decades). Methane, with an intermediate lifetime of about a decade, is also sometimes considered a SLCF. However, CRAICC concentrated on the substances with the shortest lifetimes, which are primarily different types of aerosol particles, and tropospheric ozone (AMAP, 2015). Importantly, these SLCFs are also air pollutants and in general their climate and air quality impacts must be simultaneously assessed (Stohl et al., 2015; Acosta Navarro et al., 2016, 2017). To understand the impact of aerosol particles on the Arctic climate, we need to know their sources, including the sources of aerosol precursors such as volatile organic compounds, and understand the processes leading to their formation, modification, and removal. We also need to understand how aerosols scatter light and affect clouds and how albedo and other physical properties of the cryosphere may change due to aerosol deposition. These topics are extremely broad and cover many different scientific scales and disciplines ranging from biology to atmospheric science, snow physical chemistry, and glaciology.

The overall effect of aerosol particles on the global atmosphere is cooling (Myhre et al., 2013), partly because they scatter sunlight back to space. However, some aerosol particles also absorb solar radiation, which warms the atmosphere. Regionally, the net effect depends both on the optical properties of the aerosol species and the reflectivity (albedo) of the underlying Earth surface. For instance, sulfate aerosol particles primarily scatter light, while black carbon (BC) particles as defined in Andreae and Gelencser (2006) and Bond et al. (2013) are strongly light absorbing. Mineral dust is mainly a light-scattering particle in the atmosphere, but always a light-absorbing particle when deposited on snow or ice (e.g. Bond et al., 2013). The importance of light absorption by aerosol particles is enhanced over highly reflective surfaces, such as snow and ice, and therefore the radiative impact of aerosol particles in the Arctic differs from other parts of the planet not covered by snow (Quinn et al., 2008). Furthermore, when light-absorbing aerosol particles, such as $\mathrm{BC}$ or dust, are deposited on snow or ice, their warming effect is amplified compared to their atmospheric impact because they reduce the snow-ice albedo significantly, which in turn leads to enhanced snow and ice warming and melting (e.g. Flanner, 2013). BC has by far the strongest light absorption and climate warming potential of all aerosol types and is considered the second most important global climate warming agent after carbon dioxide $\left(\mathrm{CO}_{2}\right.$; e.g. Bond et al., 2013). The equilibrium temperature response due to snow darkening by deposited $\mathrm{BC}$ is several times greater than that caused by $\mathrm{CO}_{2}$ (Flanner et al., 2007). Thus, BC potentially has a pronounced role to play in Arctic warming and melting, and as part of CRAICC a particular focus was the investigation of long-term changes in atmospheric BC concentrations, deposition, and climatic impact.

Aerosol particles can also act as condensation nuclei for liquid- and ice-phase hydrometeors and thus have a profound impact on cloud cover, cloud reflectivity, and precipitation (IPCC, 2013). Clouds are an important part of the Arctic energy balance, but due to the strong radiative cooling and limited solar insolation, their effects are different than at lower latitudes. Moreover, Arctic clouds are generally very poorly represented in current Earth system models. Further work is therefore required to understand which processes govern the formation, lifetime, and properties of Arctic clouds, including the composition and sources of the cloud condensation nuclei (CCN) and ice-nucleating particles (INPs) from which these clouds originate. As the Arctic sea ice melts and more open water is exposed, the emissions of sea spray aerosol, dimethyl sulfide (DMS), and organic aerosols within the Arctic are expected to increase (Nilsson et al., 2001; Struthers et al., 2011; Browse et al., 2014). Such emissions will strongly influence the atmospheric aerosol over the entire Arctic region. Consequently, aerosol components have evident and significant effects on the Arctic climate. However, these ef- 


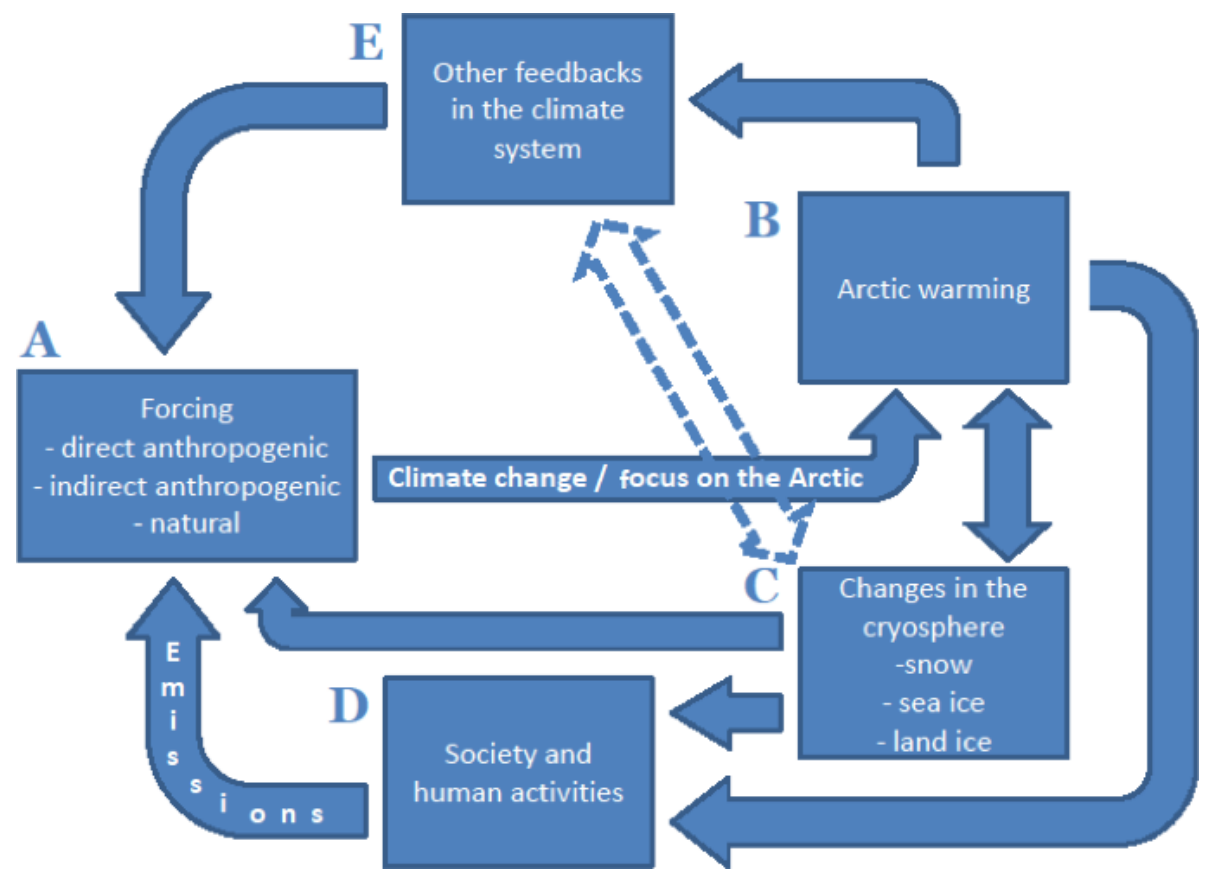

Figure 1. Interlinks and feedbacks in Arctic climate-cryosphere interaction. Capital letters indicate different components of the feedback systems and arrows emphasize the directions of interactions between components (unfilled arrow between component $\mathrm{C}$ and $\mathrm{E}$ indicates a previously undiscovered feedback loop in the system).

fects are often complex or even oppositional in terms of their cooling vs. warming effects (e.g. sulfate vs. BC aerosols from the same industrial emission sources). The direct and indirect effects of aerosols on climate, particularly their feedbacks within the cryosphere and high-latitude ecosystems, have hitherto not been well quantified. Such information is essential for a comprehensive assessment of the relative importance of aerosols in high-latitude climate change.

In this paper we discuss the feedbacks affecting the Arctic and boreal zone which were investigated in CRAICC (Sect. 2). In Sect. 3 we introduce the methods applied to analyse the components of the identified feedback loops and interactions. The main results are presented in Sect. 4 where process, interaction, and feedback analyses are discussed. Section 5 provides a discussion of the legacy of CRAICC, and finally (Sect. 6) we will summarize the outcomes and emphasize necessary future activities.

\section{Feedbacks affecting the Arctic and boreal zones}

Arctic amplification was originally ascribed to the icealbedo feedback mechanism (Arrhenius, 1896); i.e. initial warming induces the melting of highly reflective snow and ice, thus darkening the surface or exposing darker underlying surfaces, with stronger solar absorption properties, which in turn leads to enhanced warming. More recently a suite of causes has been identified as contributing to Arctic amplification (e.g. Serreze and Barry, 2011). These include, but are not limited to, loss of sea ice, changes in atmospheric and oceanic heat flux convergence, changes in cloud cover and water vapour content, and several pathways that link Arctic change to mid-latitude weather (Cohen et al., 2014).

The main goals of the CRAICC project were to quantify the feedback loops identified in the climate changecryosphere interaction scheme affecting Arctic amplification and pictured in Fig. 1. Climate change, cryosphereatmosphere interactions, and development in society cannot be understood separately but are linked via complex feedback mechanisms. The close cooperation between experts in many scientific areas allowed the CRAICC consortium to quantify crucial feedback loops, discover a new feedback loop, and address the potential impact of the components "society and human activities" and "other feedback mechanisms in the Arctic". These inputs are compared to the traditional so-called snow-ice-albedo feedback, involving "forcing", "Arctic warming", and "changes in the cryosphere" (loop A $\rightarrow B \rightarrow C$ ). In this chapter, we will explain the main feedback mechanisms, which have been further investigated and partly quantified in CRAICC. Special attention has been paid to studying the processes and feedbacks that are linked to single components in Fig. 1, including e.g. Iceland as a dust source, the emission of volatile organic compounds from boreal lakes, and the effect of $\mathrm{BC}$ deposition on Arctic snow properties.

Within the modern climate, increased burdens of particulate sulfate increase the scattering of incoming solar radiation 
and thus counterbalance the warming effect of increased levels of greenhouse gases. BC is a species that absorbs incoming solar radiation, and increased $\mathrm{BC}$ burdens tend to directly augment the warming effect of greenhouse gases. In addition to direct scattering and/or absorbing effects, airborne particles also have a potentially important effect on atmospheric cloud cover by playing crucial roles in cloud droplet and ice cloud formation. Within CRAICC the feedback loops initiated by airborne particles vis à vis changes in anthropogenic emissions (loops $\mathrm{D} \rightarrow \mathrm{A} \rightarrow \mathrm{B}, \mathrm{D} \rightarrow \mathrm{E} \rightarrow \mathrm{A}$ in Fig. 1) have been investigated intensively with cooperation between several research groups.

The climatic impact of dust, especially that from northern high-latitude mineral dust sources, has received very little attention. Northern high-latitude mineral dust sources, which are often ignored in models and dust effect studies, differ from those in warmer climates and require different parameterization schemes (Bullard et al., 2016). A number of recent studies on high-latitude dust have demonstrated its importance as a substantial contributor to the total Arctic dust load (Bullard et al., 2016; Meinander, 2016; Groot Zwaaftink et al., 2016; Baddock et al., 2017; Wittmann et al., 2017). However, uncertainties remain large and an assessment of the impacts of high-latitude dust on the cryosphere is still missing. In particular, the impacts of climate change on high-latitude dust emissions and potential climate feedbacks are poorly constrained, although reduced snow cover and glacier retreat could both lead to more dust production. The long-term variability of dust events (SYNOP codes from 1949-2011) showed an increase in dust frequency in NE Iceland (towards the Arctic) in the 1990s and 2000s (Dagsson-Waldhauserova et al., 2013). Given these open questions, CRAICC scientists studied the "dust-albedo feedback loop" with a focus on dust emitted from Iceland (loop C $\rightarrow$ A $\rightarrow$ B in Fig. 1).

Unlike dust, Arctic sea ice has been decreasing in summer extent and the volume of multi-year ice (Wadhams, 2016; Johannessen et al., 2019). The ice-albedo feedback is partly responsible, but also the warming Arctic land areas and increasing heat input from rivers seem to have added sensible heat into the marine system. As the Arctic sea ice melts, exposing more open water and creating more wave breaking and bubbles, the emissions of sea spray aerosol (sea salt and primary organic aerosols; Norris et al., 2011), DMS, and secondary organic aerosol precursors within the Arctic are expected to increase (Nilsson et al., 2001; Struthers et al., 2011; Browse et al., 2014). These increases will influence atmospheric aerosol concentrations and therefore also cloud formation in the Arctic region. Thus, CRAICC has investigated the impact of increasing ice-free open water on the emissions of sea spray aerosol and the influences on aerosol composition and concentration in and for the Arctic region (loops $\mathrm{B} \rightarrow \mathrm{C} \rightarrow \mathrm{A}$ and $\mathrm{E} \rightarrow \mathrm{A}$ in Fig. 1).

Seasonal snow is another important frozen surface for radiative fluxes in the Arctic due to its very high albedo. Snow grain size is a primary physical factor defining snow albedo variations (Domine et al., 2006), and air temperature can affect such snow properties; at higher temperatures snow grains undergo metamorphosis and become larger (e.g. Flanner and Zender, 2006). Larger snow crystals increase the probability that photons are absorbed due to the increased optical path within the ice crystals. The result is enhanced snowmelt and a decrease in the surface albedo, which directly leads to stronger absorption of solar radiation. Thus, temperature changes in high latitudes augment positive snow-albedo feedbacks and affect Arctic climate. CRAICC has studied the effect of air temperature on snow albedo using long-term satellite records on snow cover, surface albedo, and air temperature reanalysis data (loop $\mathrm{B} \rightarrow \mathrm{C} \rightarrow \mathrm{A}$ in Fig. 1).

Aerosol particles and other impurities in snow, including $\mathrm{BC}$, organic carbon (OC), dust, and microbes, also affect snow albedo and melt. Snowmelt further decreases snow albedo, and an intensive melt can cause the diurnal albedo, which is dependent on the solar zenith angle (SZA), to become SZA asymmetric (Pirazzini, 2004; Meinander et al., 2013). Impurities can also affect snow physical properties, including density (Meinander et al., 2014), while thick dust layers have been found to insulate, thus preventing snowmelt and ice melt (Dragosics et al., 2016). Therefore, the albedo effect of impurities in snow is best detected at wavelengths at which ice absorption is theoretically the smallest and impurity absorption the largest. For example, some impurities absorb strongly at wavelengths in the UV part of the solar spectrum (e.g. Peltoniemi et al., 2015), where the absorption by ice is small. Research on albedo decline due to lightabsorbing impurities of $\mathrm{BC}, \mathrm{OC}$, and dust in snow has been included in CRAICC (loops $\mathrm{C} \& \mathrm{D} \rightarrow \mathrm{A} \rightarrow \mathrm{B}$ in Fig. 1).

\section{Methods to analyse the components of the feedback loops and interactions}

CRAICC scientists have used and integrated a large number of state-of-the-art methods covering the spectrum from laboratory studies to field measurements and modelling to quantify the feedback loops presented above. Existing instrumentation and methods have been used and significant new techniques have been developed as part of the CRAICC project. In this chapter, we give an overview of the most important methods used within CRAICC for elucidating Arctic processes and feedback loops affecting Arctic amplification in the past, present, and future.

\subsection{Historical and paleo-data}

One useful way to analyse the identified feedback loops and their components is to examine historical records. The climatic history of the Earth includes both distinct warm and cold climatic periods, and understanding the climate system during these past climates can offer insight into present and 
future feedback processes. One such useful climatic period is the Holocene thermal maximum about 5000 to $10000 \mathrm{yr} \mathrm{BP}$, when the geologic records indicate that the Arctic treeline advanced to the tundra and Arctic sea-ice extent was reduced compared to the present (Zhang et al., 2017). This period is thus an analogue for the current Arctic greening and seaice loss. Such historical records are also useful because they provide a critically important baseline against which current changes can be compared. This is true for climate variables, like temperature, which can be reconstructed from stable isotopes trapped in ice and sediments, and also for many forcing factors (Zhang et al., 2017). In CRAICC, novel studies included compiling long-term $\mathrm{BC}$ records, which help to assess whether current $\mathrm{BC}$ variations are unique in a historical context.

\subsubsection{Methods to study vegetation-climate interactions in the past}

Vegetation plays an important role in mitigating climate change by absorbing atmospheric carbon dioxide, reducing planetary albedo, and influencing the aerosol composition of the atmosphere. Feedbacks between vegetation and climate are particularly conspicuous in the Arctic region because secondary organic aerosol (SOA) from vegetation constitutes a considerable proportion of the atmospheric composition. In addition, increasing vegetation cover reduces surface albedo and leads to more absorption of solar radiation. This process, called "Arctic greening", has intensified over the past few decades, resulting in increased Arctic plant productivity that is coincident with increases in Arctic surface air temperatures. Tools to study historical vegetation changes include dynamic vegetation modelling, the use of plant fossils, and other proxy data and proxy modelling comparisons.

The Lund-Potsdam-Jena General Ecosystem Simulator (LPJ-GUESS) is one important dynamic vegetation model for studying past vegetation-climate feedbacks and is an updated version of the LPJ Dynamic Global Vegetation Model (LPJ-DGVM) (Smith et al., 2001). LPJ-GUESS is one of the most widely used models to simulate past vegetation dynamics from landscape to global scales using a forest gap model scheme (Sitch et al., 2003; Smith et al., 2001). The LPJ-GUESS consists of a number of equations describing the biogeography, biogeochemistry, and biophysical processes of ecosystems. The biogeographic features of vegetation are mechanistically represented by plant functional types (PFTs), which are distinguished by different bioclimatic limitations. In the Arctic, boreal forests are generally formed by one or two dominant species, and the PFTs can be individual species, meaning that LPJ-GUESS can simulate vegetation dynamics at species or community levels.

The LPJ-GUESS model not only simulates vegetation growth but also interactions with other components of the climate system, which helps to quantify feedback loops. The model simulates the biophysical and biogeochemical pro- cesses of energy and matter exchange between the atmosphere, soil, and biosphere (Hickler et al., 2012; Sitch et al., 2003), which in turn modulate net primary productivity, vegetation structure and composition, and the carbon and nitrogen soil and litter budgets, including soil water. The model has been applied in various investigations, such as carbon cycle studies and investigations of fire occurrence and aerosol changes (e.g. Fang et al., 2015; Schurgers et al., 2009).

Pollen data are the most widely used vegetation proxy for climate reconstructions. Species apportionment of pollen is used as an indicator of historical vegetation composition, and the chronologies of pollen data are determined by dating surrounding sediments. However, caution must be exercised when analysing pollen data because pollen undergoes significant aeolian transport and its presence does not always prove the local presence of the coinciding plant species. Therefore, it is also useful to use pollen accumulation rate records to investigate species presence and abundance. For example, threshold data above 500 and above 300 grains $\mathrm{cm}^{-2} \mathrm{yr}^{-1}$ are employed as indicators of the local presence of Pinus and Picea forests, respectively (Hicks, 2006; Seppä and Hicks, 2006). Macrofossil and megafossil records are large remains of plants and can be found in small lakes and ponds in the Arctic areas. The presence of such fossil records is a robust indicator of the presence of local sources. Furthermore, due to the carbon composition of macrofossils and megafossils, their ages can often be determined using radiocarbon dating methods.

Quantitative representations of vegetation structure and function, as well as interactions with other process-based model components, allow for the quantification of feedback loops that include historical vegetation changes. Although proxy-based records are not able to fully quantify vegetation structure and function, they can provide benchmarks, which can be used for validating process-based simulations. Furthermore, comparisons between proxy data and model simulations are useful tools for exploiting the advantages of both proxies and vegetation models. For example, LPJ-GUESS has been utilized to simulate the European Arctic treeline during the Holocene and compared with proxy-based treeline reconstructions. Utilizing an Arctic treeline threshold biomass value of $2 \mathrm{~kg} \mathrm{C} \mathrm{m}^{-2}$ leads to an agreement of the simulated and proxy-based treeline, with mismatches seen in mountainous areas (Fang et al., 2013).

\subsubsection{Methods to study long-term records of BC}

Environmental archives, such as ice cores, peats, and lake and marine sediments, chronologically encapsulate material, including material deposited from the atmosphere (e.g. Rose and Ruppel, 2015). These archives can preserve long-term records for up to millennia (e.g. Petit et al., 1999; Zachos et al., 2001) and are essential when assessing past, present, and future Arctic climate change, both for setting modern variations into a broader context and for model validation. 
Despite the importance of such data in climate change evaluations, very few records of some important Arctic variables are available (e.g. BC; McConnell et al., 2007). Before CRAICC commenced Arctic BC deposition records were available only from high-altitude Greenland (McConnell, 2010), which do not represent BC deposition in the rest of the Arctic located closer to sea level (e.g. McConnell et al., 2007). BC records are more readily available from Antarctica (e.g. Bisiaux et al., 2012a, b), the Himalayas (e.g. Xu et al., 2009; Kaspari et al., 2011), and the European Alps (e.g. Lavanchy et al., 1999; Painter et al., 2013).

Black carbon originates from the incomplete natural and anthropogenic combustion of biomass and fossil fuels, and due to myriad emission sources and formation conditions, the term "black carbon" covers a wide spectrum of carbonaceous particles ranging from charred biomass to soot formed by gas condensation in high-temperature flames. Currently, no single accepted definition for BC exists, particularly between disciplines (Rose and Ruppel, 2015). Moreover, BC is an operational term, which means that its precise definition depends on the method used for its quantification. Coincidingly, no standard BC quantification method exists, and analyses of identical samples have shown that measurement methods differ by up to a factor of 7 in concentration (Watson et al., 2005). Schmidt et al. (2001) even reported concentration differences of a factor of 500 between measured $\mathrm{BC}$ in a soil sample inter-comparison study. Thus, comparing results between different methods remains challenging, particularly between disciplines, as, for instance, atmospheric measurements may quantify BC particles based on light absorption properties, while snow or soil measurements may extract and quantify BC based on chemical and/or thermal properties (e.g. Hammes et al., 2007).

Within CRAICC, two well-established and widely used methods were employed for BC analysis from a Svalbard ice core and four northern Finnish lake sediments. The Svalbard ice core is a $125 \mathrm{~m}$ ice core collected from the Holtedahlfonna glacier, which dates from ca. 1700 to 2004. It was analysed using a conventional thermal-optical method for elemental carbon (EC), which is a proxy for BC (Birch and Cary, 1996). After subsampling, ice samples were melted and filtered through quartz fibre filters and EC was quantified with a Sunset Instrument (Sunset Laboratory Inc., Forest Grove, USA) using the EUSAAR_2 temperature protocol (Cavalli et al., 2010) for determining the carbonaceous aerosol fraction on the filters (Ruppel et al., 2014). Finnish lake sediments were radiometrically $\left({ }^{137} \mathrm{Cs},{ }^{210} \mathrm{~Pb}\right)$ dated covering ca. $150 \mathrm{yr} \mathrm{BP}$, and were analysed for soot BC (SBC) with a chemothermal oxidation method (CTO375) developed specifically for BC quantification from sediments (Gustafsson et al., 1997, 2001). After thermal removal of organic material and chemical removal of carbonates from the samples, SBC concentrations were determined with an elemental analyser (Ruppel et al., 2015). This method detects condensed SBC formed at high temperatures in gas- phase combustion, irrespective of the combusted material (Elmquist et al., 2006). Soot BC particles represent the smallest size fraction of $\mathrm{BC}$, whereas the filter-based thermaloptical method used for the ice core samples may most effectively determine bigger char-type $\mathrm{BC}$ and agglomerated soot particles.

\subsection{Data from in situ measurements}

\subsubsection{Methods for offline characterization of particles}

During the last decade, there have been considerable developments with respect to new online and offline techniques, typically based on mass spectrometry, for investigating the chemical composition of atmospheric gases and particles (Nozière et al., 2015; Glasius and Goldstein, 2016; Laj et al., 2009). In this section some of the methods utilized within CRAICC to study atmospheric particles in cryospheric environments and relevant laboratory studies are presented. Further detail of the Soot on Snow project, the sea spray aerosol simulation tanks, and the SMEAR (Stations Measuring the Ecosystem-Atmosphere Relations) stations is also given.

Molecular tracers - levoglucosan. The chemical speciation of particles provides information on the composition and processes involved in the formation and growth of those particles. Atmospheric particles are composed of a multitude of organic compounds (Goldstein and Galbally, 2007), and thus it is not feasible to completely elucidate their chemical composition. Instead, molecular tracers for specific sources or processes can be identified and investigated. An example of this is the use of levoglucosan as a tracer for biomass burning emissions in aerosol particles collected on Svalbard in the European high Arctic (Yttri et al., 2014).

Molecular tracers - secondary organic aerosols. Few studies have explored the formation and distribution of SOA in the Arctic. Hansen et al. (2014) investigated molecular tracers of biogenic and anthropogenic SOA in both North Greenland and Svalbard using the filter collection of particles followed by extraction and analysis by high-performance liquid chromatography coupled with quadrupole time-of-flight mass spectrometry (HPLC-qTOF-MS) using an electrospray ionization inlet. This methodology is well suited for analysis of the polar organic compounds often found in oxidized SOA, while less polar constituents, such as the alkanes characteristic of emissions from fossil fuels and their combustion products, are not observed.

Within the last decade organosulfates and nitrooxy organosulfates have been identified as an important, novel class of SOA constituents (Surratt et al., 2007; Iinuma et al., 2007). Organosulfates and nitrooxy organosulfates are analysed using HPLC-qTOF-MS and are identified from the presence of $\mathrm{HSO}_{4}^{-}(\mathrm{m} / z=97)$, the neutral loss of $\mathrm{SO}_{3}$ $(80 \mathrm{Da})$, and in the case of nitrooxy organosulfates an additional neutral loss of $\mathrm{HNO}_{3}$ (63 Da; Surratt et al., 2007). The influence of temperature on the gas-particle distribution 
of semi-volatile compounds is a major challenge to building a holistic understanding of aerosols in cold climates. Temperatures may change tens of degrees from the ambient air to collection or detection, leading volatile species to evaporate within sampling inlets. This issue requires careful consideration, and potential artefacts should be investigated and avoided using separate gas and particle sampling for offline analysis (Kristensen et al., 2016).

Inorganic ions and BC in aerosols. Particle size distributions of inorganic anions during Arctic haze were determined using size-selective collection (by MOUDI) followed by ion chromatography (Fenger et al., 2013). Furthermore, long-term monitoring data were used for the source apportionment of particles over 2 years (Nguyen et al., 2013), as well as BC and sulfate (Massling et al., 2015) at the Villum research station, Station Nord $\left(81^{\circ} 36^{\prime} \mathrm{N}, 16^{\circ} 40^{\prime} \mathrm{W}\right)$, Greenland.

INPs. Cloud processes can also be influenced by icenucleating particles, which assist in the heterogeneous nucleation and growth of atmospheric ice (Vali et al., 2015). Within CRAICC a combination of particle and surface measurements has been utilized to compare and contrast how quantifiable material and thermo-kinetic properties affect ice nucleation efficiency in relation to the thermodynamic driving force. For studies of the ice nucleation proclivity of particles the CRAICC partners participated in the development of the Frankfurt isothermal static diffusion chamber for ice nucleation (FRIDGE) and the complementary electrostatic deposition unit (PEAC7) used to collect particle samples for FRIDGE analysis (Schrod et al., 2016; Thomson et al., 2018). The PEAC7 is a sampling unit for the electrostatic deposition of aerosol particles onto silicon wafer substrates and subsequent characterization in the FRIDGE temperature- and humidity-controlled chamber (Schrod et al., 2016). Using high-resolution photography of the substrate surface, INPs are directly counted as a function of temperature and water vapour saturation. Multiple benefits of the PEAC7 sampling unit include (i) enabling sampling in clean environments with very low ambient concentrations and (ii) enabling the identification of single INPs with further characterization using scanning electron microscopy. In CRAICC this powerful tool was deployed to two locations to characterize ambient INP concentrations. Those locations included the Villum research station and Nyålesund (Svalbard). Each of these locations is characterized by low ambient aerosol particle concentrations and thus suited to the PEAC7 sampling technique.

\subsubsection{Methods for online characterization of particles}

Within CRAICC a wide range of instrumentation was used to determine aerosol physical properties in laboratory studies and during field measurements. Some are well-established techniques only briefly described below, while others are more recently developed and thus described in somewhat more detail.
Mass spectrometry. Online quantitative measurements of particle chemical composition for non-refractory submicron aerosol particles were performed using an Aerodyne aerosol chemical speciation monitor (ACSM; Aerodyne Research Inc.; $\mathrm{Ng}$ et al., 2011). Gas-phase precursors participating in new aerosol particle formation were measured with several mass spectrometers including an atmospheric pressure interface time-of-flight mass spectrometer (APi-TOF; Aerodyne Research Inc. and Tofwerk AG) for the molecular composition of naturally charged ions and clusters (Junninen et al., 2010), a nitrate chemical ionization atmospheric pressure interface time-of-flight mass spectrometer (CI-APiTOF; Aerodyne Research Inc. and Tofwerk AG) for neutral clusters like sulfuric acid and organic vapour (Jokinen et al., 2012; Kürten et al., 2014), and a proton-transfer-reaction time-of-flight mass spectrometer (PTR-TOF; Ionicon Analytik $\mathrm{GmbH}$ ) for organic vapours (Graus et al., 2010). Each technique allows chemical species to be identified by their mass signatures and isotopic fractions (Junninen et al., 2010; Ehn et al., 2010; Schobesberger et al., 2013).

$D M P S$ and SMPS. Aerosol particle size distributions were measured in the field and the laboratory using standard electrical-mobility- and optical-based techniques. Electricalmobility-based instruments rely on the size separation of charged particles in a differential mobility analyser (DMA) column. This is followed by condensation of a low-volatility liquid on the size-selected particles and optical counting in a condensation particle counter (CPC; see, for example, Wiedensohler et al. (2012) for a detailed description). The combination of a DMA and CPC is referred to as a scanning mobility particle sizer (SMPS) or differential mobility particle sizer (DMPS) system. These systems are used for the size classification of submicron-sized particles. For size measurements of larger particles, optical particle sizers (OPSs) are used.

V-TDMA and H-TDMA. Particle volatility was probed using thermodenuders in a tandem DMA set-up (V-TDMA), whereby particles are passed through an oven heated to a known temperature. The heating is followed by a cooling section in which gases volatilized from the particles are trapped. Particle size is measured before and after the thermodenuder to assess the contribution of volatile compounds to the aerosol condensed phase. Measurements are performed at a series of oven temperatures to extract information about the volatility distribution of the aerosol constituents. Similarly, particle hygroscopicity can be ascertained at subsaturated conditions using a hygroscopicity tandem differential mobility analyser (H-TDMA), wherein particle size is measured before and after exposure to well-defined relative humidity (Liu et al., 1978). Within CRAICC particles in the boreal forest environment were also characterized using a combination of the two instruments (i.e. the VH-TDMA; Hong et al., 2014).

Cloud condensation nucleus counter (CCNC). The ability of particles to form cloud droplets was measured using 
established CCNC techniques. For example, the continuousflow thermal-gradient diffusion-type CCNC manufactured by Droplet Measurement Technologies. Such a CCNC operates by exposing particles to well-known supersaturations of water, generated by applying a temperature gradient over a wetted column, and using optical detection to monitor droplet formation (Roberts and Nenes, 2005).

PINCii. Instrumentation for the online analysis of INP was developed as a result of a formalized technology sharing agreement and collaboration by six institutional partners (Ulrike Lohmann group, ETH Zurich; Frank Stratmann group, TROPOS Leipzig; Markku Kulmala group, University of Helsinki; Merete Bilde group, Aarhus University; Erik Swietlicki group, Lund University; and the University of Gothenburg) that was initiated by the CRAICC partners. The six-partner group has worked to develop and build a nextgeneration portable ice nucleation chamber (PINCii; Fig. 2), which is a continuous-flow diffusion chamber (CFDC) designed to update earlier parallel-plate CFDCs (e.g. ZINC, PINC, SPIN; Stetzer et al., 2008; Garimella et al., 2016). The PINCii instrument is an ice-coated flow tube reactor system designed to stimulate and measure ice nucleation within a test aerosol flow. Dry particles sampled from ambient or laboratory-generated flows are injected into a chamber, which contains a controlled water vapour supersaturated environment with respect to ice. Thus, by monitoring both the input and output flow the fraction of INP can be directly determined. Papers describing the PINCii instrument and the initial results of its first field deployment and ambient measurements are currently in preparation (see also Sect. 4.1.4; Castarède et al., 2019; Brasseur et al., 2018; Wu et al., 2018).

\subsubsection{SoS project and sea spray aerosol simulation tanks}

Soot on Snow (SoS) project. As part of CRAICC, the SoS project was conducted to study the effect of light-absorbing particles on snow surfaces. It consisted of a series of field experiments for which $\mathrm{BC}$ and other light-absorbing impurities, including Icelandic dust, were dry-deposited onto the surface of natural snowpacks and the consequent effects on albedo, snow density, other physical properties, including melting, were measured during the spring season. The broadband albedo was measured with pyranometers, in addition to the directional reflectance of snow. Concentrations of EC in the snowpack were analysed using a thermal-optical method (as described for the Svalbard ice core; Sect. 3.1.2) and compared with the measured albedo and that modelled with the SNow, ICe, and Aerosol Radiative (SNICAR) model (Flanner et al., 2007, 2009). Details of the experiments were presented by Meinander et al. (2014), Peltoniemi et al. (2015), and Svensson et al. (2016).

Sea spray aerosol simulation tanks. During CRAICC significant effort was devoted to improving the understanding of sea spray aerosol. One important development was the de-

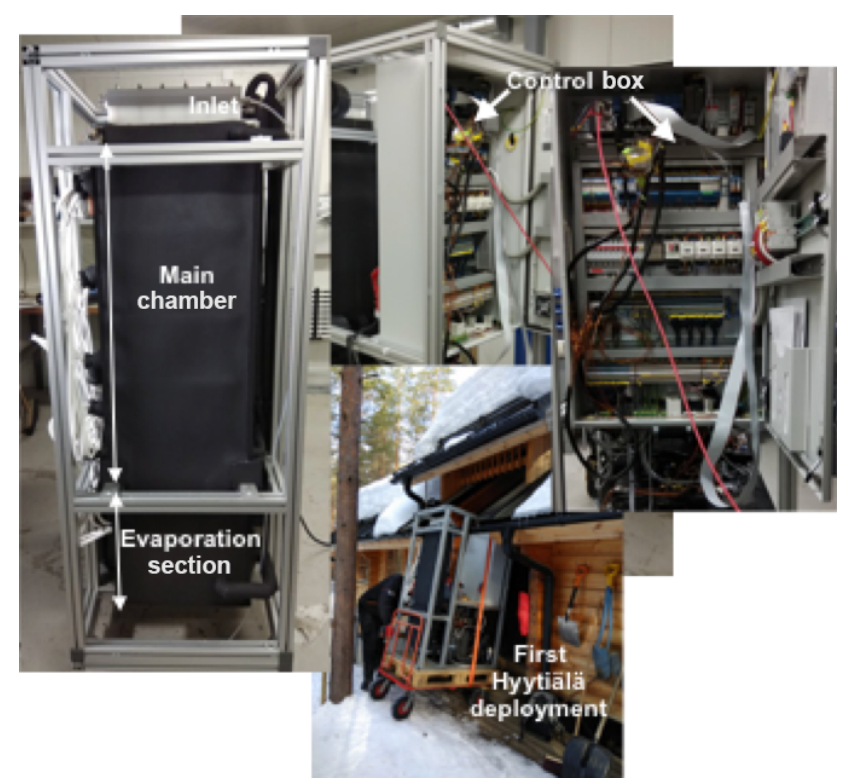

Figure 2. Images of the PINCii instrument with the main ice-coated flow reactor chamber, evaporation sections, and electronic control box indicated. The instrument was first deployed for field testing during the 2018 Hyytiälä HyICE measurement campaign.

sign, construction, and use of new temperature-controlled sea spray aerosol simulation tanks (King et al., 2012; Salter et al., 2014). In these tanks air is entrained in real or artificial seawater via frits, diffusers, or plunging jets. The entrained air breaks up into bubbles, which rise to the surface where aerosols are generated by bubble-bursting processes. These tanks can be coupled with other aerosol characterization instrumentation, for example particle size and number concentrations (see above), and can thus be used to probe a variety of physical and chemical properties of sea spray aerosol, including cloud-forming ability, hygroscopicity, and volatility.

\subsubsection{Long-term measurement stations involved in CRAICC}

The CRAICC core permanent research infrastructure included 18 well-established field research stations, covering ecosystems from Arctic to boreal locations (Fig. 3). These stations provided the time-resolved datasets used by the CRAICC community and are reflected in many publications from the Nordic Centre of Excellence.

\subsection{Multiscale modelling}

Different modelling systems have been utilized by CRAICC to simulate myriad levels of Earth systems. Here we describe the main tools used within the consortium. 


\subsubsection{Process-based modelling of the formation and growth of SOA in the Arctic region}

The CRAICC consortium contributed to the continuing development of a model for two-dimensional Lagrangian aerosol dynamics, gas- and particle-phase chemistry, and radiative transfer (ADCHEM; Roldin et al., 2011) with improved representations of biogenic secondary organic aerosol formation (Hermansson et al., 2014, Öström et al., 2017). New process-based schemes for aerosol dynamics, particlephase molecular diffusion mass transfer limitations, organic and inorganic particle-phase chemistry, and gas-phase chemistry schemes were implemented and constrained based on laboratory smog chamber experiments (Roldin et al., 2014, 2015). The latest version of ADCHEM includes a detailed gas-phase chemistry scheme that is based on the Master Chemical Mechanism (MCMv3.3.1; Jenkin et al., 1997; Saunders et al., 2003). This scheme also includes a novel scheme for the formation of highly oxygenated organic molecules (HOMs) formed from the ozonolysis and $\mathrm{OH}$ oxidation of monoterpenes. The HOM formation scheme is based on experimental work by Ehn et al. (2014) that was recently used to evaluate the contribution of HOMs to the activation and growth of new particles during observed new particle formation events in subarctic forests (Öström et al., 2017). The non-equilibrium SOA formation scheme simulates size-resolved particle growth using concentrations of around 700 different organic molecules provided by the gasphase chemistry scheme. The SOA scheme can also account for heterogeneous oligomerization and nonideal organic and inorganic particle-phase interactions as well as the impact of particle-phase mass transfer limitations on the formation and evaporation of SOA particles (Roldin et al., 2014, 2015; Öström et al., 2017).

\subsubsection{Mesoscale modelling of Arctic BC and Icelandic dust deposition}

To assess long-term BC concentrations and deposition in the Arctic an offline Eulerian chemical transport model was run for the period between 1980 and 2015. The System for Integrated modeLling of Atmospheric composition (SILAM) is documented in detail by Sofiev et al. $(2006,2014)$. The SILAM model has several chemical transformation modules, including gas-phase chemistry and secondary inorganic aerosol formation, linearized sulfur oxide chemistry, radioactive nuclide decay, and aerosol dynamics (condensation and coagulation) computed either from thermodynamic equilibrium or dynamically. The aerosol size spectrum is described with a sectional approach and a user-defined bin distribution. Mechanisms of dry deposition vary from primarily turbulent diffusion-driven removal of fine aerosols to primarily gravitational settling of coarse particles, depending on the particle size (Kouznetsov and Sofiev, 2012). Wet deposition distinguishes between below- and in-cloud scavenging by both

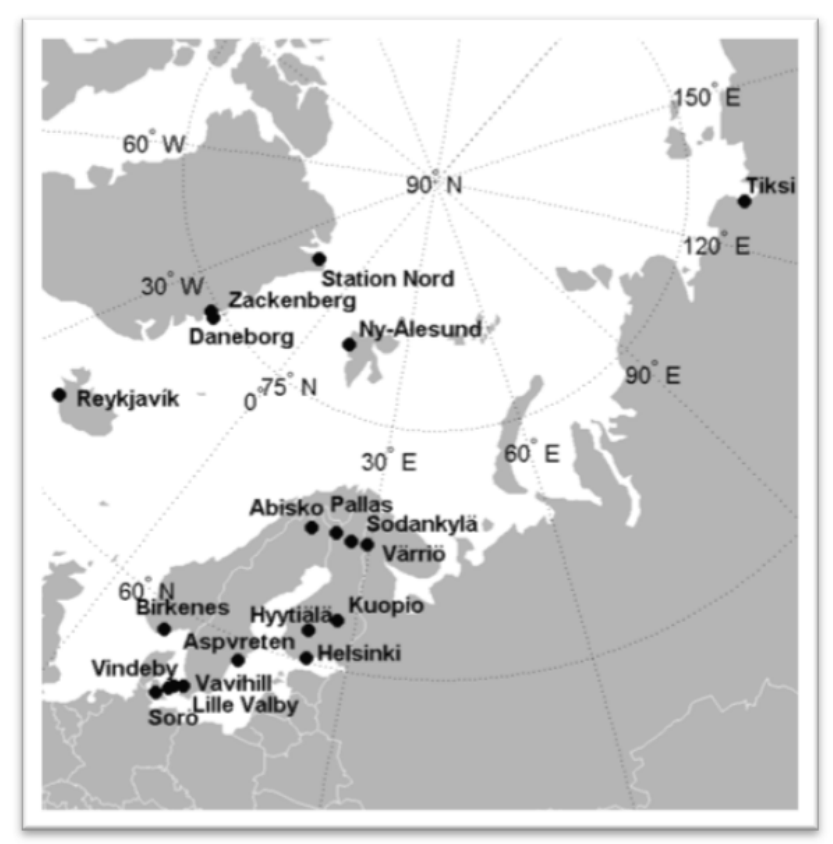

Figure 3. Map of the core field stations in CRAICC: Troll station, Antarctica; Vavihill, Sweden; Birkenes, Norway; Lille Valby, Denmark; Vindeby, Denmark; Sorø, Denmark; Aspvreten, central Sweden; SMEAR III, Finland; SMEAR II, central Finland; SMEAR IV, Kuopio, central Finland; Sodankylä, Finland; SMEAR I, Värriö, Finland; Abisko, Sweden; Pallas GAW station, Finland; Tiksi, Siberia; Daneborg and Zackenberg, Greenland; NyÅlesund, Spitzbergen (Svalbard, Norway); Villum research station, Greenland.

rain and snow (Horn et al., 1987; Smith and Clark, 1989; Jylhä, 1991; Sofiev et al., 2006). BC and other fine anthropogenic particulate matter (PM) components are modelled as inert aerosol with $0.5 \mu \mathrm{m}$ dry diameters. Emissions from natural sources (fires, sea salt, and desert dust) are parameterized in terms of continuous distributions and split into species-specific size bins. Deposition and settling of each bin are related to the mass-mean wet diameter of the bin. The SILAM model has been extensively evaluated against European and global air quality observations (Solazzo et al., 2012; Huijnen et al., 2010; Ruppel et al., 2017) and is driven by ERA-Interim (Dee et al., 2011) meteorological data with $3 \mathrm{~h}$ temporal and $0.72^{\circ}$ horizontal resolutions. SILAM uses the MACCity emission dataset (Granier et al., 2011) for anthropogenic emissions, except for flaring emissions, which were taken from the ECLIPSE dataset (Stohl et al., 2013). Emissions are available every 5 years, beginning in 1980 for MACCity and in 1990 for ECLIPSE, with the remaining years estimated by linear interpolation. Global simulations utilized a horizontal resolution of $0.72^{\circ} \times 0.72^{\circ}$ and a vertical grid consisting of nine unevenly spaced atmospheric layers. The lowest, thinnest layer was $25 \mathrm{~m}$ thick, with the top layer reaching into the stratosphere. The source contribu- 
tion to BC deposited at Holtedahlfonna was investigated by tagging the different emission sectors while computing the atmospheric dispersion of BC.

To support the interpretation of dust storm observations in Iceland, simulations with the numerical weather prediction model HIRLAM (Unden et al., 2003) were used. The simulations were run on a $5 \mathrm{~km}$ horizontal grid at 65 vertical levels, with forcing at the boundaries from the operational suite of the ECMWF. The turbulence calculations were based on the CBR scheme (Cuxart et al., 2000) and the Interaction Soil Biosphere Atmosphere (ISBA) employed at the surface (Noilhan and Mahfouf, 1996).

\subsubsection{Earth system models (ESMs) applied for feedback simulations}

NorESM1-M is the Norwegian Earth System Model version 1 (Bentsen et al., 2013; Iversen et al., 2013). This particular set-up of NorESM1, used in both CRAICC and in the Coupled Model Intercomparison Project Phase 5 (CMIP5), has an intermediate horizontal atmospheric resolution of $1.9^{\circ} \times 2.5^{\circ}$ and 26 vertical levels. The ocean module is an updated version of the isopycnic ocean model MICOM, while the sea-ice (CICE4) and land (CLM4) models and the coupler (CPL7) are similar to CCSM4 (Gent et al., 2011), differing only in the tuning of snow grain size for fresh snow on sea ice within CICE4. The atmosphere module, CAM4-Oslo (Kirkevåg et al., 2013), is a version of CAM4 extended with advanced representation of aerosols, aerosol-radiation, and aerosol-cloud interactions.

The land model has its own carbon cycle model and includes the SNICAR model (Flanner et al., 2007, 2009). The latter facilitates calculations of the effects on radiative transfer from snow darkening by deposited light-absorbing aerosols, i.e. BC and mineral dust. The albedo effect of lightabsorbing aerosols deposited on snow-covered and bare sea ice is also accounted for in the sea-ice model.

CAM4-Oslo calculates mass concentrations of aerosol species that are tagged according to production mechanisms in clear and cloudy air for four size classes (nucleation, Aitken, accumulation, and coarse mode). Furthermore, it includes primary emission, gaseous and aqueous chemistry (cloud processing), gas-to-particle production (nucleation), condensation, and coagulation of small particles onto larger pre-existing particles. Loss terms are dry deposition and incloud and below-cloud scavenging. Aerosol components included are sulfate, BC, organic matter, sea salt, and mineral dust distributed over 11 modes for externally and internally mixed particles that are emitted or produced in air, 9 of which are tagged to production mechanisms in air or in cloud droplets. In addition to these 20 transported tracers for aerosols, there are two additional tracers for the gaseous aerosol precursors $\mathrm{SO}_{2}$ and DMS. Optical properties are estimated from Mie theory, while supersaturation and hygro- scopic growth for CCN activation are calculated from Köhler theory.

Internally mixed water from water vapour condensation is treated separately using look-up tables for the aerosol optical parameters. Other look-up tables are used to obtain dry size parameters (dry radii and standard deviations) of the aerosol population, which are used as input in the calculation of $\mathrm{CCN}$ activation, following Abdul-Razzak and Ghan (2000).

A separate post-CMIP5 NorESM1 version with explicit parameterizations of nucleation and secondary organic aerosols (Makkonen et al., 2014) has also been used in CRAICC. In this model version, hereafter referred to as NorESM1-CRAICC, the land model uses the MEGAN parameterization for interactive biogenic volatile organic compound (BVOC) emissions instead of the prescribed sources applied in the CMIP5 version of the model.

The atmosphere model CAM4-Oslo has also been extensively validated and compared with other models through the AeroCom initiative (Aerosol Comparisons between Observations and Models) by Jiao et al. (2014), Tsigaridis et al. (2014), Kipling et al. (2016), and Koffi et al. (2016). A separate evaluation of NorESM1-M and other CMIP5 models through the remote sensing of aerosols in the Arctic has been made by Glantz et al. (2013). NorESM1-M is also taking part in the ongoing Precipitation Driver Response Model Intercomparison Project (PDRMIP; see e.g. Samset et al., 2016; Myhre et al., 2017).

\subsection{Data collected through remote sensing techniques}

\subsubsection{Aerosol lidar (CL51 ceilometer)}

The atmospheric boundary layer in the Arctic is of key importance because it connects the atmosphere, cryosphere, and marine components of the climate system. Nevertheless, observational data from the Arctic boundary layer are sparse. This is partly due to the hostile climatic conditions with low and even extreme temperatures that are beyond the operational range of many meteorological instruments. Long-term climatological measurements are traditionally performed with rugged instruments such as sturdy cup anemometers and wind vanes located near the groundtypically at heights between 2 and $10 \mathrm{~m}$. Except for the few sites with regular radio soundings, limited information on the vertical structure of the Arctic atmospheric boundary layer is available.

A preponderance of information on the structure of the Arctic atmospheric boundary layer has been obtained during intensive observations carried out over limited time periods, primarily during summer months (Gryning et al., 1985; Lampert et al., 2011; Burgemeister et al., 2013; Di Liberto et al., 2012; Batchvarova et al., 2014; Achert et al., 2015). However, recent technological improvements to ground-based lidar remote sensing may significantly benefit future Arctic meteorological research. Utilizing components developed for 
use in fibre optics communication, lidars have become more compact, reliable, and easier to use. The development of eye-safe fibre-based lidars started in the mid-1990s and the first commercial products became available around 2005. One such instrument, an aerosol lidar (CL51 ceilometer from Vaisala), was installed at Villum research station in spring 2011. The CL51 measures the backscatter profile of the aerosols in the atmosphere and has survived to measure in the harsh Arctic conditions for several years. The aerosol backscatter is measured as a function of height with a vertical resolution of $10 \mathrm{~m}$ up to $7 \mathrm{~km}$ of height. The backscattered signal depends on the number concentration, size, and optical properties of the particles in the air.

\subsubsection{Satellite}

Satellites provide a plethora of environmental data, including information on atmospheric composition and surface properties over wide spatial areas. Their instruments provide coverage that is spatially and temporally delineated based on orbiting patterns and swath width. Satellite observations are highly complementary to ground-based in situ and remote sensing measurements, and they make observations possible over remote and difficult-to-access areas where in situ measurements are not available. However, satellites are typically confined to optical (UV-Vis), infrared (NIR-TIR), and microwave (radar) observations that do not necessarily contain the same detail as ground-based measurements. For atmospheric composition, different instrument platforms are used to detect trace gases, greenhouse gases, and aerosols and clouds. These include sensors such as TROPOMI, the Moderate Resolution Imaging Spectroradiometer (MODIS), VIIRS, and GOME-2 with daily global coverage at spatial resolutions varying from $250 \mathrm{~m}$ for aerosols and clouds (MODIS and VIIRS) to $3.5 \mathrm{~km} \times 7 \mathrm{~km}$ for methane, $\mathrm{NO}_{2}$, and $\mathrm{SO}_{2}$ from TROPOMI. Other sensors such as SLSTR provide smaller but still useful coverage, especially at high latitudes. Together with information on forest fires and aerosol absorption such data provide information on the emission and transport of aerosols and trace gases and their effects on air quality, climate, and pathways to the Arctic. $\mathrm{CO}_{2}$ and SIF (solar-induced chlorophyll fluorescence) are retrieved from OCO-2 data with a revisit time of 16 days because of the rather narrow swath $(10 \mathrm{~km})$; the OCO-2 pixel size is $1.3 \mathrm{~km} \times 2.2 \mathrm{~km}$. Thus, the spatial resolution of OCO-2 allows an anthropogenic $\mathrm{CO}_{2}$ signature to be distinguished (Hakkarainen et al., 2016; Eldering et al., 2017). As for other GHG satellites, TanSat is comparable to OCO-2 in resolution, and GOSAT has a revisit time of only 3 days but a pixel diameter of $10 \mathrm{~km}$. For many optical techniques satellite data are only collected when solar radiation is available and solar zenith angles are large enough, which is a serious limitation over polar regions.

The detection of gases requires high spectral resolution (spectrometers, interferometers) with specific wave- lengths for the gases of interest. The design of such instruments implies a relatively low spatial resolution of tens of kilometres. Examples are SCIAMACHY, GOME2, OMI, and TROPOMI, with in incremental improvement of the spatial resolution, which for the recently launched (2017) TROPOMI instrument on the Sentinel-5P satellite is $7 \mathrm{~km} \times 7 \mathrm{~km}$ sub-nadir compared to the OMI footprint of $13 \mathrm{~km} \times 24 \mathrm{~km}$. TROPOMI extends the capabilities of OMI and measures column concentrations of ozone, formaldehyde, carbon monoxide, $\mathrm{NO}_{2}, \mathrm{SO}_{2}$, and methane, as well as aerosol layer height using the $\mathrm{O}-\mathrm{A}$ band and the absorbing aerosol index, a qualitative parameter indicating the presence of absorbing aerosol particles, and UV radiation. Information on trace gases, such as $\mathrm{NO}_{2}, \mathrm{SO}_{2}$, and formaldehyde (a proxy for less volatile organic compounds), and nearsurface UV radiation is also important for the formation of aerosol particles through gas-to-particle conversion.

Dedicated instruments for quantitative measurements of aerosol and cloud properties are radiometers with moderate spatial resolution, which do not require high spectral resolution but need a wide range of spectral bands (e.g. MODIS, VIIRS) and preferably also several viewing angles (MISR) and polarization (POLDER). Other instruments used for the retrieval of aerosol properties are e.g. SeaWiFS, MERIS, the AVHRR instruments, which together provide a long time series that started around 1981, and the dual-view ATSR series (ATSR-2, AATSR; 1995-2012) followed up by SLSTR launched in 2016 on Sentinel-3.

Some of the instruments mentioned above are also used, or even designed, to retrieve information on land and ocean surface properties. The AVHRR, ATSR, and SLSTR instruments were designed to measure land and ocean surface temperature. MODIS also provides land surface temperature, land surface albedo, and bidirectional reflectance distribution function (BRDF); several of the sensors mentioned provide information on forest fires by virtue of their TIR channels. SeaWiFS, MERIS, and OLCI (on Sentinel-3) were designed to measure ocean parameters and in particular ocean colour.

Satellite information has been used in the CRAICC feedback analysis, as described in more detail in Sect. 4. The use of satellites to study spatial changes in glaciers, sea-ice extent, dust storm occurrence, and deposition is discussed in Sect. 4.1. High-spatial-resolution sensors such as Landsat and Sentinel-2 provide detailed information on land surface properties and were used to detect high-latitude dust sources and the spatial extent of glaciers. MODIS was used to detect dust storms over Iceland.

Two MODIS instruments onboard the Terra and Aqua satellites have been routinely collecting information on multiple environmental parameters since the year 2000. CRAICC studies on large-scale snow-covered surface albedo changes were based on MODIS products of snow cover fraction and surface albedo (MCD34C3). The MODIS snowmapping algorithm is based on the normalized difference snow index (NDSI), which utilizes the fact that snow has 
a high reflectance in the visible part of the solar spectrum and low reflectance in the infrared (Hall et al., 2002). The MODIS BRDF and albedo algorithm utilize multiple spectral bands to retrieve broadband albedo information (for detail see Lucht et al., 2000; Schaaf et al., 2002). MODIS data products are consistently validated, readily available, and widely used by the research community, including CRAICC.

MODIS data have been used by Atlaskina et al. (2015) to study the temperature dependence of the albedo of snowcovered land surfaces in the Northern Hemisphere as described in Sect. 4.2.3. MODIS and AATSR have been used to explore the retrieval of aerosol parameters in Arctic regions (Istomina et al., 2010; Mei et al., 2013). For an overview of aerosol remote sensing in polar regions using ground-based and satellite instruments, see Tomasi et al. (2015). The use of satellite data to study Arctic amplification has also led to a controversy in the literature as described in Sect. 4.2.2.

\section{Process, interaction, and feedback analysis}

The CRAICC research package focused on the identification and quantification of high-latitude Earth system feedbacks. This required a holistic understanding of essential Arctic systems and their interactions and included long-term observations and detailed measurement campaigns as well as complementary multiscale modelling platforms. This multipronged research strategy allowed the centre to assess myriad pathways outlined within the diagram of Arctic feedbacks (Fig. 1). Individual studies have focused on particular components (A-E in Fig. 1) or interactions between two or more components, including attempts to integrate and quantify fully connected feedback loops. That said, given the large natural variability of Arctic systems and significant coupling interactions with lower latitudes, the quantification of single feedback loops and parameters remains challenging.

In general, quantifying a feedback loop requires the observation of the dampening (negative) or strengthening (positive) of a system displacement.

For the Arctic, human activities are one trigger for environmental change, although CRAICC has also considered Arctic feedbacks in the absence of anthropogenic forcing. In this chapter, we present the main outcomes of CRAICC research related to changes in natural emissions and processes (Sect. 4.1 to 4.4) and changes in the Arctic based on anthropogenic impacts (Sect. 4.5). However, the reader should remember that in total CRAICC published more than 150 papers in international journals and here only a number of selected results are highlighted with reference to the original publications for more detail. A list of all CRAICC publications is available on the project website: https://www.atm. helsinki.fi/craicc (last access: 4 February 2019).

\subsection{Atmosphere}

\subsubsection{Icelandic deserts and dust (component $E$ in Fig. 1)}

Iceland straddles the Arctic circle in the north Atlantic Ocean and is thus significant as a source and monitoring point for Arctic climate change. That said in situ aerosol observations from Iceland are minimal. The city of Reykjavik and the Environmental Agency of Iceland have maintained PM $_{10}$ (particulate matter with diameter less than $10 \mu \mathrm{m}$ ) observations at a couple of fixed locations for 15 years in Reykjavik, far from the local dust sources (Thorsteinsson et al., 2011), while shorter-term monitoring installations have been established during volcanic eruption events (Thorsteinsson et al., 2012; Dagsson-Waldhauserova et al., 2014a). There is also a unique dataset of dust and volcanic ash observations that have been collected by the Icelandic Meteorological Office for nearly a century. Frequent volcanic eruptions increase the annual dust frequency, and the consequent dust-volcanic ash resuspension events prolong the impacts of eruptions (Thorsteinsson et al., 2012; Thordarson and Höskuldsson, 2008). For example, after the Eyjafjallajökull eruption in 2010, the erosion flux exceeded $11000 \mathrm{~kg} \mathrm{~m}^{-1}$ during one dust event (Arnalds et al., 2013), which is one of the most severe wind erosion events ever recorded on Earth.

Given its location and ecosystem, much of the aerosol particulate in Iceland originates from wind-surface interactions. Icelandic surfaces are classified by the "AUI Nytjaland" land cover database into vegetation classes (Gisladottir et al., 2014), which shows that Iceland's total desert area is about $43400 \mathrm{~km}^{2}$ (Arnalds et al., 2016). About $15000 \mathrm{~km}^{2}$ of the total desert area is active aeolian surface, which includes super-active dust hot spots. Over the long term Iceland has been observed to have 34-135 dust days per year without strong seasonality (Dagsson-Waldhauserova et al., 2013, 2014a). Dust is produced at a rate of about $31-40 \mathrm{Tg} \mathrm{yr}^{-1}$ (Fig. 4) and that dust is redeposited onto the land, into the ocean, and onto glaciers (total area of $>500000 \mathrm{~km}^{2}$ ), with some dust plumes capable of travelling over $1000 \mathrm{~km}$ (Fig. 4, MODIS data; Arnalds et al., 2016). Iceland is the largest Arctic and European desert with a dust event frequency comparable to major lower-latitude desert areas like the Gobi or Iranian deserts (Arnalds et al., 2016).

The lack of established observations led CRAICC to support several field dust-aerosol measurement campaigns between 2013 and 2016 (Dagsson-Waldhauserova et al., 2014b, 2015, 2016). During severe dust storms $\mathrm{PM}_{10}$ concentrations exceeding $6500 \mathrm{\mu g} \mathrm{m}^{-3}$ were measured (1 min averaging time) with median $\mathrm{PM}_{10}$ values $>1000 \mu \mathrm{g} \mathrm{m}^{-3}$ during $24 \mathrm{~h}$ intervals. During a moderate storm a $\mathrm{PM}_{1}$ maximum of $261 \mu \mathrm{g} \mathrm{m}^{-3}$ was measured. High values of submicron particles are typical of Icelandic volcanic dust, with resulting $\mathrm{PM}_{1} / \mathrm{PM}_{2.5}$ ratios of $>0.9$, while $\mathrm{PM}_{1} / \mathrm{PM}_{10}$ ratios range from 0.34 to 0.63 . These values are comparable to urban air pollution rather than natural dust storm events observed 


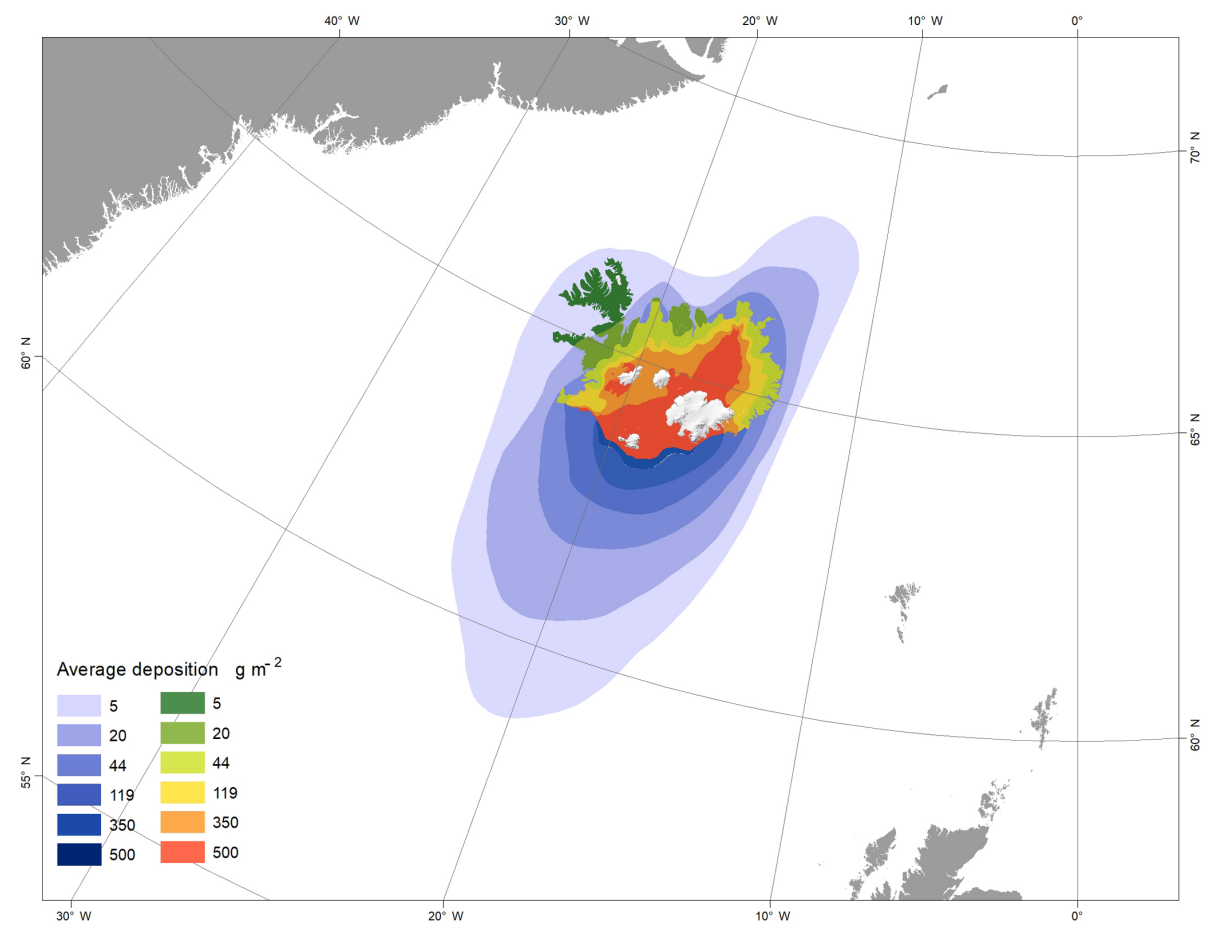

Figure 4. Annual dust deposition rates of Icelandic dust (Arnalds et al., 2014).

in other regions. Particle number concentrations $(\mathrm{PM} \approx 0.3-$ $10 \mu \mathrm{m}, \mathrm{OPS})$ are also high, with maximum concentrations of $\approx 150000$ particles $\mathrm{cm}^{-3}$ recorded with a primary peak in the size distribution between 300 and $337 \mathrm{~nm}$ and a smaller peak for particles with diameters between 1.5 and $5 \mu \mathrm{m}$. Such extreme concentrations are reflective of ongoing volcanic eruptions. The dust in Iceland is primarily volcanic in origin and dark in colour, with many particles that include sharptipped shards and large bubbles. About $80 \%$ of PM is volcanic glass that is rich in heavy metals, such as iron and titanium.

Satellite data collected since the 1970s yield detailed information on spatial changes in glaciers, sea-ice extent, dust storm occurrence, and dust deposition in Iceland. Highresolution imagery from the Landsat-8 (NASA) and Sentinel2 (ESA) satellites allows for improved analysis of dust source areas, although at latitudes above $65^{\circ}$ temporal resolution is limited to approximately twice weekly. Despite having a relatively mild and humid climate dust storms are visible in Iceland about 40 days a year on average (MODIS $250 \mathrm{~m}$ resolution images), which is a conservative estimate given that low light and clouds likely obscure events. About twice as many events were observed to occur annually between 2002 and 2012 (Georgsdóttir, 2012), and preliminary results for 2010 to 2016 show a similar frequency, especially with increases in 2010 after the Eyjafjallajökull eruption due to subsequent volcanic ash resuspensions. The prolonged melting season on Icelandic glaciers is captured by Sentinel2 images, which show suspended dust as well as older ash layers in the glaciers, both of which affect the surface albedo (Fig. 5). Although MODIS observations correspond to the lowest dust frequencies relative to meteorological observations, daily images from MODIS captured high-frequency dust events during warm autumns in north-eastern Iceland in 2015 and 2016. Annual dust deposition of $17 \mathrm{~g} \mathrm{~m}^{-2}$ clearly affects albedo, which, for example, was observed to be reduced by 0.36 (albedo dropped from 0.86 to 0.5 ) after a Vatnajökull glacier dust event, leading to increasing snowmelt of $\approx 0.6 \mathrm{~m}$ annually (loop $\mathrm{E} \rightarrow \mathrm{C}$ in Fig. 1; Wittmann et al., 2017).

In addition to increasing frequency, Icelandic dust storms exhibit spatial and temporal variability. Storms are most frequent in the north in summer, while in the south the dust storms are more frequent in late winter. Additionally, there is significant inter-annual and decadal dust storm variability (Dagsson-Waldhauserova et al., 2013, 2014a). With a combination of in situ observations, numerical modelling (HIRLAM model with $5 \mathrm{~km}$ horizontal resolution), and meteorological time series analysis, Arnalds et al. (2014) have assessed individual dust storms to estimate the quantity of annual Icelandic dust emissions. They estimate that an average $31-40 \mathrm{Tg}$ of dust is suspended annually, with $12 \%-$ $35 \%$ of that reaching the ocean before being redeposited (Arnalds et al., 2014; see Fig. 4). Further numerical simulations of wind during dust storms has revealed the local nature of the windstorms, underlining the need for high atmospheric and topographic spatial resolutions for accurate simulations (Dagsson-Waldhauserova et al., 2016; Baddock 


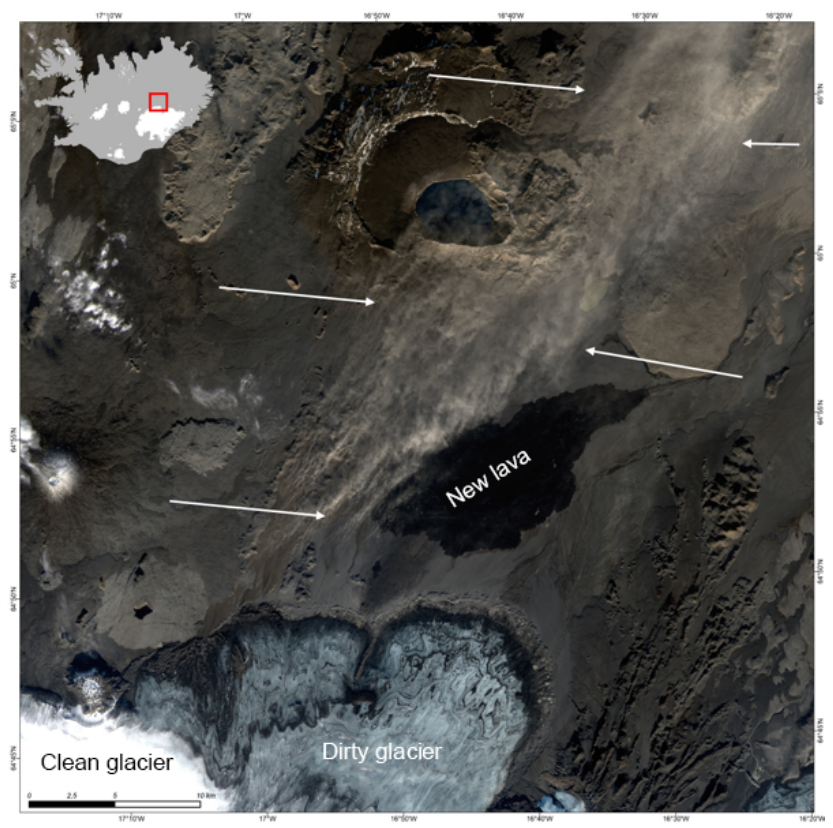

Figure 5. Landsat image of the Vatnajökull glacier (lower left corner, clean and dirty) polluted with dust (lower middle, dirty glacier) with a dust storm (brown dust plume indicated with white arrows) originating from the glacial flood plain Dyngjusandur over the new lava (dark surface in the centre of the image) from the Holuhraun eruption 2014-2015. Data are from https://landsat.usgs. gov/landsat-data-access (last access: 4 February 2019).

et al., 2017). In another study using FLEXDUST and FLEXPART simulations, and meteorological reanalysis data from Groot Zwaaftink et al. (2017), annual Icelandic dust emissions were estimated to be an order of magnitude lower at $4.3 \pm 0.8 \mathrm{Tg}$ with about $7 \%$ of that reaching the high Arctic $\left(>80^{\circ} \mathrm{N}\right)$. However, Groot Zwaaftink et al. (2017) likely underestimate dust activity from the hyperactive dust hot spots which produce high dust outputs, for example the redistribution of material after volcanic events and glacial outbursts. Dust uptake processes are also poorly understood, and Arnalds et al. (2016) calculated deposition rates which also included large particles with short travel distances $<100 \mathrm{~km}$. That said, both estimates illustrate the importance of highlatitude dust production in the Arctic and the global context.

\subsubsection{Biogenic SOA formation and its role for the growth of new particles into $\mathrm{CCN}$ over the sub-Arctic regions (loop $B \rightarrow E \rightarrow C$ in Fig. 1)}

The Arctic Ocean is surrounded by vast regions of tundra and boreal forest, which during the summer period emit large quantities of BVOCs. In order to fully understand how warming-enhanced BVOC emissions will influence the BVOC-aerosol-cloud-climate feedback loop in the Arctic climate system in the future, a detailed understanding of the processes governing the formation and growth of new parti-
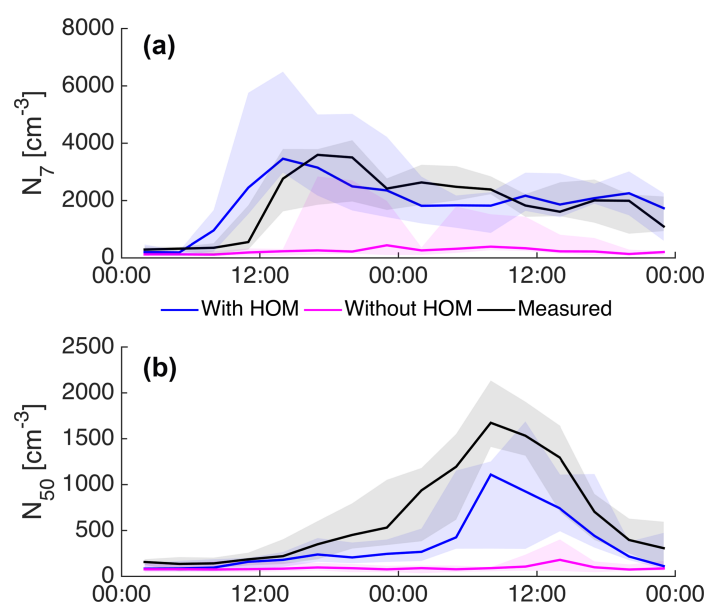

Figure 6. Modelled and measured (a) $N_{7}$ and (b) $N_{50}$. The model results are shown for simulations with and without HOM formation via the autoxidation of monoterpenes (blue and pink lines, respectively). The solid lines show the median values from 10 NPF events at Pallas. The shaded areas give the $25 \%$ to $75 \%$ interval.

cles is crucial. Within CRAICC the Lagrangian model ADCHEM was used to simulate the formation and growth of new particles along air mass trajectories originating from the Arctic Ocean and travelling over tundra and boreal forests before arriving at the Pallas Atmosphere-Ecosystem Supersite $\left(67.97^{\circ} \mathrm{N}, 24.12^{\circ} \mathrm{E} ; 565 \mathrm{~m}\right.$ a.s.l.) in Northern Finland. A main focus was to constrain the processes governing the growth of new particles into the climatically important cloud condensation nuclei size range. Model simulations together with measured particle number size distributions reveal that during observed new particle formation (NPF) event days in Pallas, new particle formation begins when the air masses move from the Arctic Ocean inland over the boreal forest. The analysed event days are characterized by lower concentrations of particles larger than $50 \mathrm{~nm}$ in diameter $\left(N_{50 \mathrm{~nm}}\right)$, with median $N_{50 \mathrm{~nm}}$ of $140 \mathrm{~cm}^{-3}$.

According to the model simulations, particle growth can largely be attributed to condensation of low-volatility and highly oxygenated organic compounds (Fig. 6; Öström et al., 2017). With the HOM condensation mechanism included, ADCHEM can capture the initial growth between 1.5 and $20 \mathrm{~nm}$ in diameter during the observed new particle formation events. However, the model still underestimates particle growth between 20 and $80 \mathrm{~nm}$ in diameter and therefore underestimates the concentrations of particles in the CCN size range (diameter $>50 \mathrm{~nm}$ ) the day following a nucleation event. Both in the model and observations the $N_{50} \mathrm{~nm}$ peaks at around 06:00 UTC the day after new particle formation events with median $N_{50 \mathrm{~nm}}$ of 1109 and $1674 \mathrm{~cm}^{-3}$, respectively (Öström et al., 2017). The more than 1 order of magnitude increase in the $N_{50 \mathrm{~nm}}$ concentration during the morning after NPF event days, in the model and observations, indicates that growth from biogenic secondary material is an 
important process for maintaining $\mathrm{CCN}$ concentrations over subarctic forests, as long as primary particle emissions are low.

Kyrö et al. (2014) studied the effect of reduced sulfur emissions from the Kola Peninsula on aerosol growth, concentrations, and long-term NPF trends at SMEAR I in eastern Lapland, Finland. The frequency of NPF days (clear, class I events) was found to decrease by about $10 \%$ per year concurrently with decreasing $\mathrm{SO}_{2}$ (also $\approx 10 \%$ per year). High concentrations of $\mathrm{SO}_{2}$ and $\mathrm{H}_{2} \mathrm{SO}_{4}$ were found to promote the onset of nucleation by several hours and even catalyse some events without sunlight. In general, air masses coming over the Kola Peninsula were found to favour NPF, with sulfuric acid explaining up to $50 \%$ of the observed growth of new particles. Decreasing sulfur emissions decreased the condensation sink by about $8 \%$ per year and thus increased the event time $J_{3}$ (particle formation rate at $3 \mathrm{~nm}$ particle diameter) by almost $30 \%$ per year. The biggest decrease in NPF frequency was during spring and autumn, when the importance of $\mathrm{H}_{2} \mathrm{SO}_{4}$ for growth was maximum and $\mathrm{H}_{2} \mathrm{SO}_{4}$ concentrations were too low to grow the particles to potential CCN sizes. Simultaneously, during these seasons surface temperatures are on average too low to compensate for and enhance SOA formation. Collectively these effects have resulted in a $3 \%-4 \%$ per year decrease in potential $\mathrm{CCN}$ concentrations.

\subsubsection{SOA in Arctic regions (loops $\mathrm{D} \rightarrow \mathrm{A}$ and $\mathrm{E} \rightarrow \mathrm{A}$ in Fig. 1)}

Secondary organic aerosol precursor sources and processes can be tracked using molecular tracers such as carboxylic acids and organosulfates. Carboxylic acids are typically of either biogenic or anthropogenic origin, while organosulfates are formed from the reactive uptake of organics on acidic sulfate aerosols (Surratt et al., 2007; Iinuma et al., 2007). The formation of organosulfates thus represents a mechanism for anthropogenic enhancement of biogenic SOA (Hoyle et al., 2011). Within CRAICC organosulfates were discovered in the Nordic and Arctic environment (Kristensen and Glasius, 2011; Hansen et al., 2014; Nguyen et al., 2014a; Kristensen et al., 2016). Hansen et al. (2014) measured the first yearround time series of Arctic organosulfates and identified elevated levels during the late winter haze period at both the Villum research station and in Svalbard, probably due to the influence of anthropogenic sulfate aerosols. Another recent study in Northern Europe during winter points to coal combustion (i.e. high-sulfur fuel) as an important precursor of organosulfates in aerosols (Glasius et al., 2018).

The first annual time series measurements of humic-like substances (HULIS) in Arctic aerosols were also obtained within CRAICC (Nguyen et al., 2014b). HULIS consists of complex, relatively high-molecular-weight polyacidic organic molecules (e.g. Decesari et al., 2000) and influences the light-absorbing properties of aerosols. The average concentration of HULIS was measured to be higher during months with less sunlight (November-April, $11 \mathrm{ng} \mathrm{C} \mathrm{m}^{-3}$ ) than during the remainder of the year $\left(4 \mathrm{ng} \mathrm{C} \mathrm{m}^{-3}\right)$ (Nguyen et al., 2014b).

A prominent feature of organic aerosols is their aqueous surface activity. Already 2 decades ago, Facchini et al. (1999) recognized the potential impact of surface tension on aerosol-cloud interactions, but the subject has remained a source of recurring debate in the aerosol chemistry and cloud microphysics communities (e.g. Ruehl et al., 2016; Ovadnevaite et al., 2017). Building on the work of Sorjamaa et al. (2004) and Prisle et al. (2008, 2010), researchers in CRAICC studied hygroscopic growth and the cloud-forming potential of laboratory-synthesized organosulfates (Hansen et al., 2015) and commercial modelled HULIS samples (Kristensen et al., 2014) using H-TDMA and CCNC chambers. These studies demonstrated the presence of complex surface tension effects, surface partitioning, and salting out, which significantly broadened the understanding of surface activity for water uptake and the cloud activation of atmospheric organics with very different origins and chemical characters.

\subsubsection{Ice nucleation}

Field measurement campaigns have been initiated in an effort to quantify the ice-nucleating capacity of Arctic and Nordic air masses. Simultaneously, idealized laboratory experiments have been conducted to examine the underlying physicochemistry and molecular-scale processes from water adsorption to heterogeneous nucleation. Results from such studies complement cloud-resolved modelling studies whereby CRAICC efforts have tried to connect the availability of ice nuclei to the production of ice crystals in clouds, advances which contribute to understanding how, for example, mixedphase clouds form and evolve (Savre and Ekman, 2015a, b).

\section{Laboratory studies}

Idealized molecular beam and light-scattering experiments have focused on building a fundamental understanding of how critical-scale ice clusters initially form and grow vis à vis vapour deposition on well-characterized surfaces (Kong et al., 2012; Thomson et al., 2015). Observations demonstrate that surfactants play an important role due to their ability to enhance and/or suppress the adsorption and desorption kinetics of atmospheric particles (Kong et al., 2014a; Papagiannakopoulos et al., 2014; Lejonthun et al., 2014; Thomson et al., 2013; Johansson et al., 2017). In particular, organic hydrocarbon surfactant layers - that for experimental purposes are used to model atmospherically relevant organic layers - have size- and temperature-dependent effects on ice nucleation, growth morphology, and molecular water uptake (Kong et al., 2014b; Papagiannakopoulos et al., 2013). An important implication of such findings is that common atmospheric surfactants, such as VOCs, can promote and/or 
hinder water uptake, changing the hydrophilicity of atmospheric nanoparticles. Additional, laboratory investigations focused on how soluble salts may nucleate ice and whether or not at below-eutectic temperatures sea salts might act as ice-nucleating particles rather than deliquesce as CCN (Kong et al., 2018; Wagner et al., 2018; Castarède and Thomson, 2018). All of these processes may affect cloud evolution and lifetime and thereby impact fundamental environmental processes like the water cycle and radiative balance. Arctic clouds are known to be unique and often those that are most important to the regional radiative balance are mixed-phase clouds (Morrison et al., 2012), which include both liquid and solid cloud particles and therefore become inherently more unstable as temperatures diverge from the triple point (Savre and Ekman, 2015a, b). Thus, small effects, like those enumerated above, that influence the sensitive balance between liquid and solid cloud particle coexistence may have amplified environmental feedbacks in Arctic air.

\section{Field studies}

The INP counting and characterization instrumentation (Sect. 3.2) introduced to the Nordic region through the CRAICC collaboration was used in various field studies. The PEAC7 electrostatic deposition collectors and subsequent FRIDGE analysis (Schrod et al., 2016) were used to initiate the acquisition of building time series data for INP concentration in the Arctic environment, where very few observational data currently exist. A 2-year time series of measurements was established in Svalbard in conjunction with a global data series initiated through the EU FP7 BACCHUS project (data currently being analysed). In an additional study the PEAC7 was used to sample seafaring ship emission plumes transiting the Port of Gothenburg, Sweden. In those measurements, an amplification of ice-nucleating capacity was observed from ship emissions (Thomson et al., 2018). Absolute INP activities observed from the ship plumes agreed with previous measurements of soot particles that suggest they are weak ice nucleators (Dymarska et al., 2006; Friedman et al., 2011; Schill et al., 2016). However, because these emissions are strongly concentrated, with INP emission factors of $10^{5}-10^{7}$ per kilogram fuel, they still result in strongly increasing INP compared to ambient values. As such, the observed amplification may be important to consider as shipping routes open in Arctic waters and sea-ice loss increases (Peters et al., 2011; Fuglestvedt et al., 2014). The magnitude of cloud- and climate-scale effects will be a product of many additional factors, including how such INP observations may change with particle ageing and how microphysical feedbacks and cloud response manifest in nonobvious ways (for example, see Possner et al., 2015).

In a very recent field campaign (HyICE2018) aimed at investigations of ice nucleation within the boreal environment, the PINCii instrument developed within CRAICC was first field deployed. In tests leading up to the campaign, and dur- ing preliminary campaign data analysis, the observed PINCii operational parameters and observed INP measurements are in good agreement with other instruments (Fig. 7). In Fig. 7a the stability of the PINCii chamber background is illustrated, and in Fig. 7b initial tests of the conditions for water droplet breakthrough are shown to be in line with other existing CFDCs (Stetzer et al., 2008; Garimella et al., 2016; Kong et al., 2018). During HyICE2018 data for instrument intercomparison were also collected using multiple existing INP measurement platforms (PINC, FRIDGE, SPIN, etc.). Campaign data analysis by all involved research groups is currently ongoing (Castarède et al., 2019; Brasseur et al., 2018; Wu et al., 2018).

\subsubsection{Boundary layer stability in the Arctic (loop $B \rightarrow$ E in Fig. 1)}

The boundary layer in the Arctic differs in a number of ways from its counterpart in the mid-latitudes. Away from the Arctic (and Antarctic) the diurnal variation in surface heating controls the dynamics of the boundary layer. During daytime, atmospheric mixing is driven by the sun heating the surface and wind shear throughout the boundary layer (Batchvarova and Gryning, 1991). After sunset, turbulence decays and a new neutral and stable layer with little turbulence forms over the ground. In the Arctic, the diurnal variability is absent throughout most of the year. During the long dark winter period, a long-lived shallow stable boundary layer is expected to form. The layer is shallow, partly due to surface cooling during the Arctic night and partly due to the large Coriolis force at high latitudes. If resilient enough, the stable layer may even extend through the Arctic spring-summer after the sun is continuously above the horizon. Such conditions are favourable for the creation of atmospheric waves and lowlevel jets, both of which influence the atmospheric boundary layer and atmospheric exchange processes. However, very little is known about these processes and their importance for the climate system.

Convective boundary layers driven by upward heat flux due to ground warming are also expected in the Arctic. Even in inner Antarctica at the Dome $\mathrm{C}$ research station, which is characterized by very low temperatures, Argentini et al. (2005) observed convective boundary layers. The formation of the Dome C convective boundary layers is likely connected to the very low ambient temperatures - typically $-30^{\circ} \mathrm{C}$. King et al. (2006) argue that at such low temperatures boundary layer formation is due to the partitioning of available energy into sensible heat flux.

Figure 8 shows an example of the boundary layer height evolution with time over 2 weeks during a period of continuous Arctic sun at the Villum research station in the high Arctic. The land surface is fully covered by snow during the observations and the sun is visible throughout the entire day with a $13^{\circ}$ elevation angle that only varies diurnally by about $1^{\circ}$. The diurnal cycle that is characteristic for the behaviour 

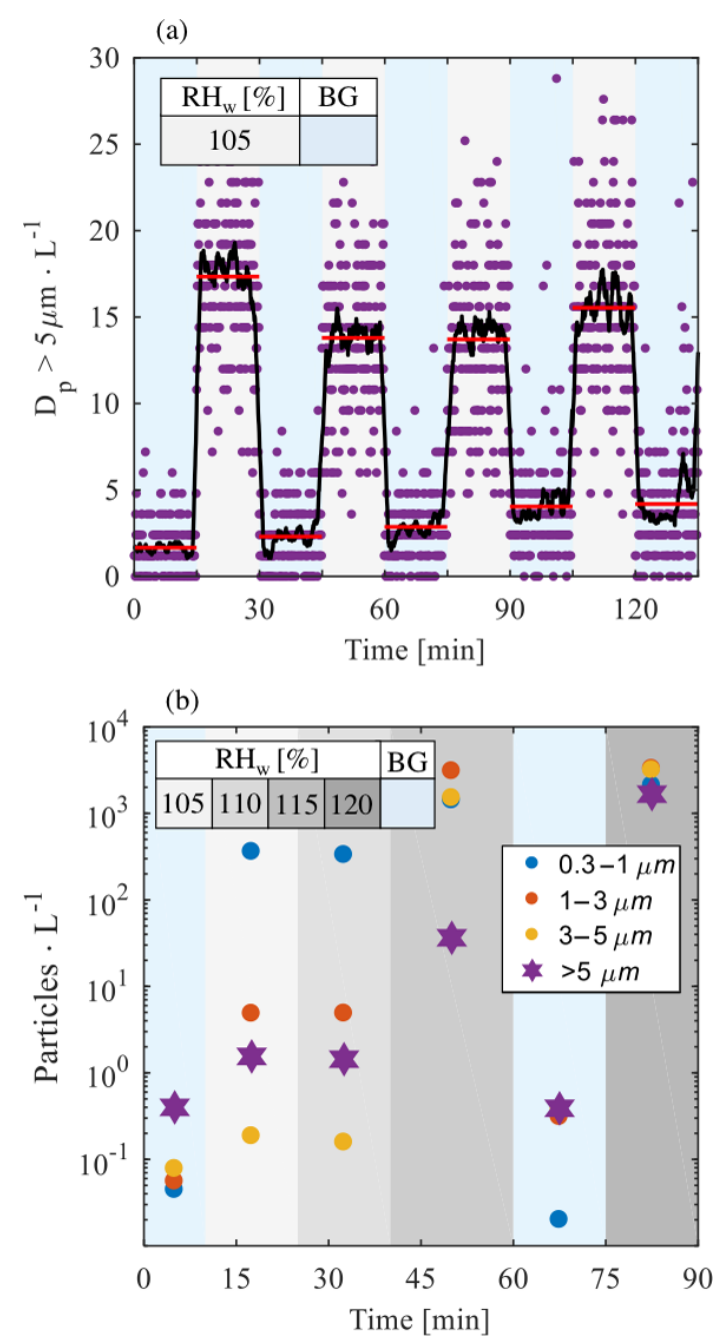

Figure 7. Initial data collected using the PINCii chamber. A fourchannel optical particle counter (OPC) placed at the exit of the ice growth chamber is used to count particles exposed to various thermodynamic forcing illustrated using the chamber relative humidity with respect to water $\mathrm{RH}_{\mathrm{W}}$; in all cases presented here the experimental temperature was $-32{ }^{\circ} \mathrm{C}$. The sample flow is initially directed through a $2.5 \mu \mathrm{m}$ impactor to eliminate large particles, and after the ice growth chamber the flow is exposed to an evaporation section where ice particles continue to grow while liquid droplets shrink. (a) An example of 15 min incremented measurements of clean, background (BG) air and ambient air containing counted INPs $\left(D_{\mathrm{p}}>5 \mu \mathrm{m}\right)$ at $\mathrm{RH}_{\mathrm{W}}=105 \%$. The data points show the raw OPC data acquired as $5 \mathrm{~s}$ time averages of $1 \mathrm{~s}$ data; the black line depicts a 2 min centred moving average, and the red lines are the $15 \mathrm{~min}$ increment averages. The data are also illustrative of the slow increase in the chamber's background contribution over 2 to $3 \mathrm{~h}$, in line with existing CFDC systems. (b) Increment averages illustrative of the chamber's so-called "droplet breakthrough" when at the highest $\mathrm{RH}_{\mathrm{w}} \gtrsim 115 \%$ particle numbers in all size bins are amplified because liquid droplets no longer fully disappear within the evaporation section. of the boundary layer at mid-latitudes is absent. Instead, the boundary layer depth remains $\approx 250 \mathrm{~m}$ over the entire 5day period with occasional outbreaks of wave-like motions. Thus, it is clearly not representative of an idealized boundary layer but is rather influenced by effects that are not yet fully understood. Figure 9 illustrates the conditions at the same location in mid-July. For the selected days the boundary layer is about $100 \mathrm{~m}$ and again considerable wave-like motions are observed.

\subsection{Cryosphere}

\subsubsection{BC in snow - field measurements (component $\mathrm{C}$ in Fig. 1)}

In Sodankylä, Finland $\left(67^{\circ} 22^{\prime} \mathrm{N}, 26^{\circ} 39^{\prime} \mathrm{E}\right), \mathrm{BC}$ and $\mathrm{OC}$ in snow were measured in connection with broadband and spectral snow albedo, as well as other ancillary parameters of seasonal European Arctic snow. Measured low UV albedo values were partly explained by the properties of melting snow and also UV absorption caused by impurities in the snow (Meinander et al., 2013). The results revealed that the OC in the snow could have a significant contribution to light absorption. Light absorption by OC may also partly explain the high mass absorption cross section (MAC) value needed for $\mathrm{BC}$ to match the measured low albedo values with the SNICAR (Flanner et al., 2007) simulated albedo. To derive optical properties for OC that is considered representative of the $\mathrm{OC}$ in the snow, spectrally resolved MAC estimates for the target are needed.

The SoS field experiment showed that soot has a negative effect on snow albedo (Svensson et al., 2016); however, the measured effect was not as pronounced in outdoor conditions as in a previous laboratory study (Hadley and Kirchstetter, 2012). In Fig. 10, the albedo of the snow from the first 3 days of the SoS experiments and the corresponding EC concentration are presented; the figure also contains a fit to the experimental data. In the experiments, it was observed that the absorbing contaminants on snow enhanced the metamorphism of snow under strong sunlight conditions (Peltoniemi et al., 2015). Immediately after deposition, the surface of the contaminated snowpack appeared darker than the natural snow in all viewing directions, but the absorbing particles sank deep into the snow within minutes. The nadir measurement remained the darkest, but at larger zenith angles the surface of the contaminated snow was almost as white as clean snow. Thus, for a ground observer the darkening caused by impurities can be completely invisible, causing overestimations of the albedo, while a nadir-observing satellite sees a more absorbing surface, thus underestimating the albedo (Peltoniemi et al., 2015).

Atmospheric deposition not only influences albedo but also other physical properties of snow and ice (e.g. Meinander et al., 2014). Experiments focused on physical characteristics of snowpack utilized artificially added light-absorbing 


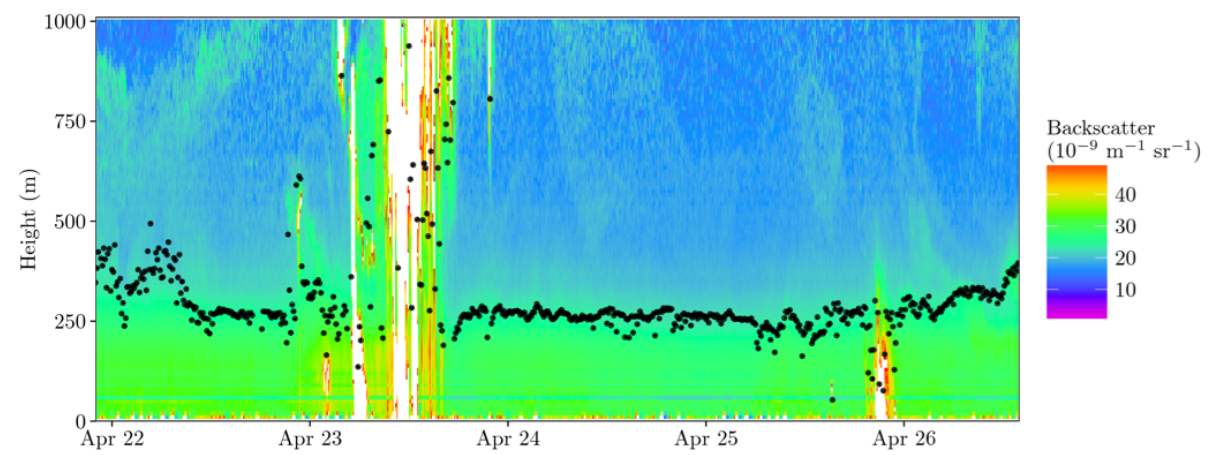

Figure 8. Backscatter profiles measured by a ceilometer from 22 to 27 April 2012 at the Villum research station, high Arctic. The bar to the right shows the backscatter density. The circles show the height of the boundary layer.

(a)

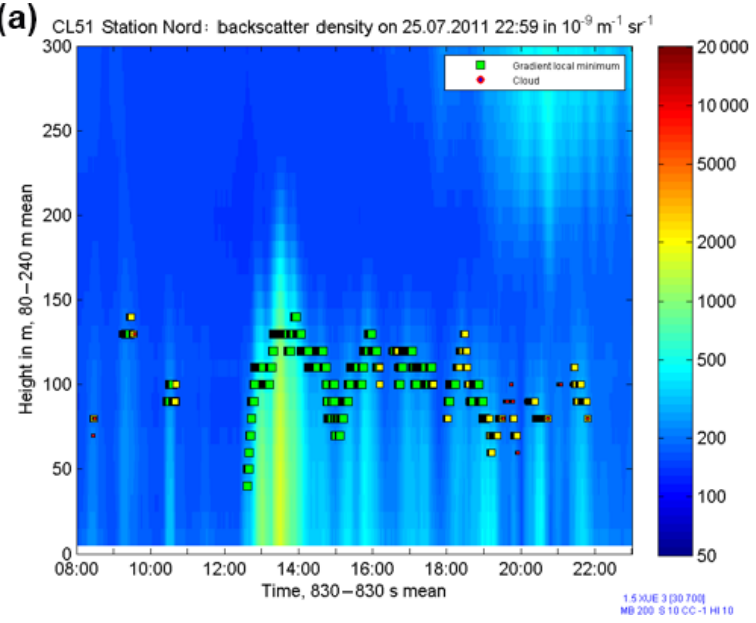

(b)

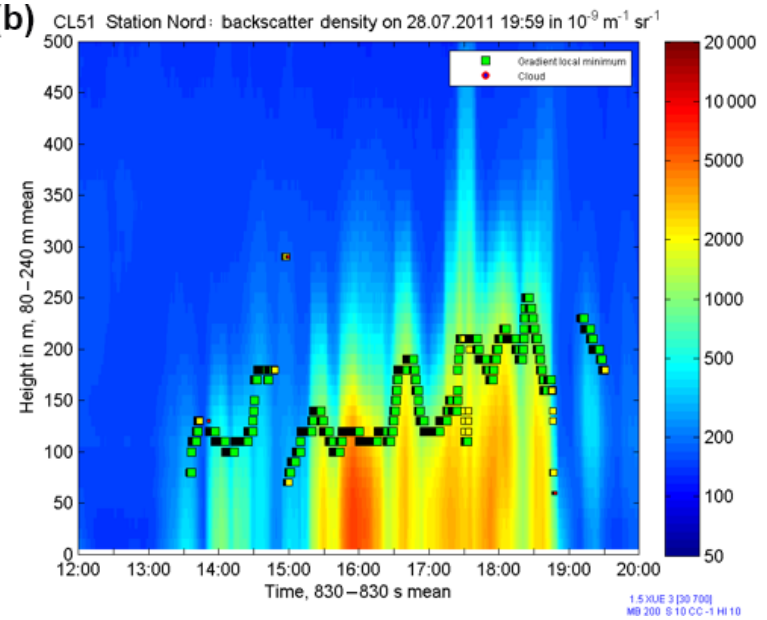

Figure 9. Backscatter profiles from Villum research station measured by a ceilometer on 25 July (a) and 28 July (b) in 2011 . The bar to the right shows the backscatter density in $10^{-9} \mathrm{~m}^{-1} \mathrm{sr}^{-1}$. The squares show the height of the boundary layer.

impurities, which decreased the density of seasonally melting natural snow (Meinander et al., 2014). The data suggests that $\mathrm{BC}$ can decrease the liquid water retention capacity of melting snow. No relationship was found in the case of natural non-melting snow. The significance of these results comes via the fact that snow density multiplied by snow depth equals the important climate model parameter of snow water equivalent (SWE).

\subsubsection{Dust, BC, OC, and volcanic ash-snow field campaigns (loop $\mathrm{C} \rightarrow \mathrm{A} \rightarrow \mathrm{B}$ in Fig. 1)}

Dust aerosols interact with rain, snow, and ice during dust storms. Suspended dust was observed during moist and low wind conditions (Dagsson-Waldhauserova et al., 2014b) and the phenomenon of snow-dust storms has been documented (Dagsson-Waldhauserova et al., 2015). Icelandic dust is therefore likely to affect the cryosphere in Iceland and elsewhere (Meinander et al., 2016). We hypothesize that Icelandic dust on snow can be one of the causes for Arctic amplification. This effect is explained as a positive feed- back loop in which Icelandic dust deposited on snow decreases surface albedo and increases solar radiation absorption, snowmelt, and ice melt (Fig. 11). Such effects are normally linked to soot but volcanic ash and dust from Iceland may actually have a larger influence in the Arctic region. This is in contrast to what is generally concluded on crustal dust climate effects in the latest IPCC report (IPCC, 2013).

About $50 \%$ of the annual dust events in the southern part of Iceland take place at subzero temperatures or in winter (November-April), when dust can be mixed with snow. This implies that the impacts and significance of Icelandic eruptions and dust events may be seriously underestimated. In studies related to aerosol effects on Arctic climate the effect of mineral dust is often not explicitly considered (e.g. Yang et al., 2014; Najafi et al., 2015), although paleoclimate data archives indicate a substantial contribution of dust to radiative cooling in the Arctic (Lambert et al., 2013). Climate change can also increase extreme wind events and dust storms. Human-initiated deforestation has also enhanced the desert area in Iceland, which coupled with changing climate 

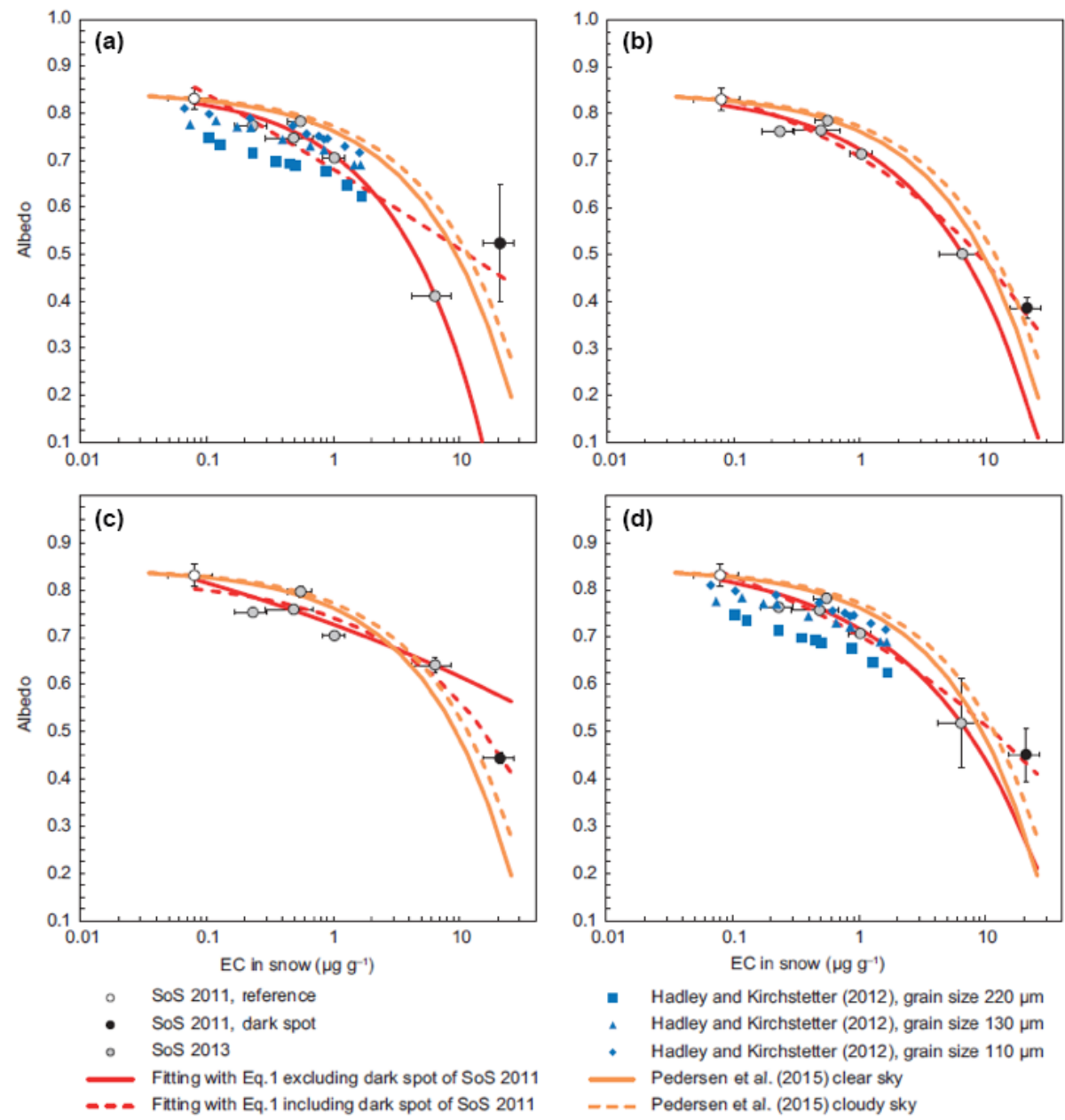

Figure 10. Broadband albedos at noon on SoS days 1-3 as a function of the EC concentration in the surface layer: (a) day 1, (b) day 2, (b) day 3, and (d) days 1-3. In all plots, the SoS 2011 reference albedo is the average over solar noon albedo during the first week of the experiment. In (a)-(c), the gray and black circles are $60 \mathrm{~min}$ albedo averages at solar noon, and the vertical and horizontal bars are standard deviations for albedo and EC, respectively. In (d), the circles are the albedo averages at solar noon on days $1-3$, and the vertical and horizontal bars are standard deviations for albedo and EC, respectively (Svensson et al., 2016).

can increase the probability for increasing dust event occurrences (Sect. 12 in Arnalds, 2015).

Such positive feedbacks between snow and impurities were investigated during several outdoor and indoor experiments with applications of Icelandic dust, volcanic ash, and BC on snow surfaces in Lapland and Finland (Meinander et al., 2014; Dragosics et al., 2016; Peltoniemi et al., 2015; Svensson et al., 2016). The outdoor SoS 2013 experiment showed that volcanic dust on snow causes reductions in albedo and increases snow melting similarly to that of BC. The spectral reflectance of Icelandic dust was observed to be as black as soot and, measured at $400-2500 \mathrm{~nm}$, remained $<0.04$, which is typical for highly absorbing particles (Peltoniemi et al., 2015). In fact, the snow albedo effect of lightabsorbing aerosols and the use of satellites to measure the darkening of the Greenland ice sheet (GrIS) has been the subject of a recent controversy in the scientific literature (Po-

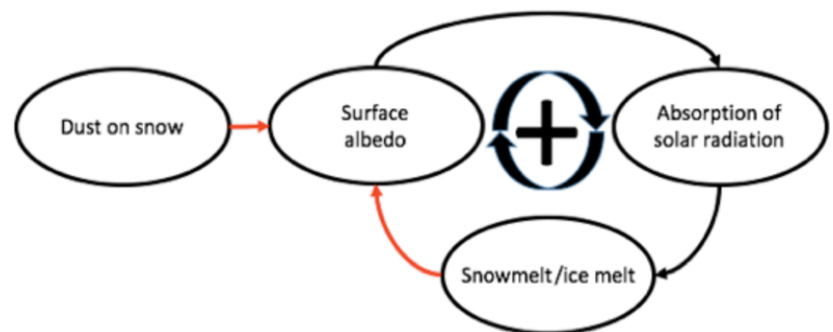

Figure 11. The feedback loop of the "dust-albedo effect" for Icelandic dust events (perturbation), a new hypothesis that Icelandic dust deposited on snow can be a cause for Arctic amplification via such a positive feedback. Measurements show that black Icelandic dust particles are highly light absorbing, similar to soot particles (Peltoniemi et al., 2015). 
lashenski et al., 2015; Tedesco et al., 2016). Polashenski et al. (2015) studied satellite-observed trends in the Greenland ice sheet albedo and found no evidence supporting a hypothesis that these are caused by the deposition of $\mathrm{BC}$ or dust. Instead, they attribute the albedo trend observed by MODIS Terra (but not by MODIS Aqua) to uncorrected sensor degradation. Tedesco et al. (2016) in turn explain that Polashenski et al. (2015) use a daily product, which has been shown to deteriorate with latitude. Instead, Tedesco et al. (2016) use the GLASS surface albedo product, a 16-day integrated product which is a combination of data from MODIS and AVHRR and accounts for directional (BRDF) effects at high solar zenith angles, and observed a statistically significant decrease in the surface albedo over the GrIS. They compare their observations with model results and conclude that discrepancies are due to the absence of light-absorbing impurities in the model. Furthermore, the observed albedo trend is confined to regions of the GrIS that undergo melting in the summer with the dry-snow zone showing no trend. Both papers point at the absence of trends in the concentrations and deposition of either $\mathrm{BC}$ or dust, which leads to the conclusion that the observed albedo trends are not caused by changes in the deposition of these species. However, rather than ascribing the trend to sensor degradation, as in Polashenki et al. (2015), Tedesco et al. (2016) suggest that the albedo trend is caused by the exposure of a "dark band" of dirty ice and to increased consolidation of light-absorbing material at the surface from melting. Within CRAICC, Meinander et al. (2016), addressing these concerns, concluded that an assessment of the effect of Icelandic dust on snow-ice surface darkening and melt is currently unavailable and therefore scientific research is critically needed. These authors hypothesize that, in the Arctic, Icelandic dust may have a comparable or even larger effect on the cryosphere than soot (Bond et al., 2013). Observations and modelling results on Icelandic dust and cryosphere interactions for the past, present, and future are urgently needed.

Ash from the 2010 eruption of Eyjafjallajökull was used to find an insulating threshold for snow and/or ice. If the layer thickness of ash on snow or ice is very thin, it has the potential to increase snowmelt, but for thicker layers the snowmelt can be decreased compared to clean ice due to thermal isolation. In experiments by Dragosics et al. (2016) and Wittmann et al. (2017), a 9-15 mm thick ash layer on top of snow had an insulating effect, whereas a thin layer of only $1 \mathrm{~mm}$ increased melting to a maximum.

\subsubsection{Changes of springtime snow-covered surface albedo (component $\mathrm{C}$ in Fig. 1)}

Atlaskina et al. (2015), using 13 years (2000-2012) of MODIS observations, have conducted a study on snowcovered land surface albedo during spring in different geographical areas of the Northern Hemisphere. The study showed that in the territories where the snow cover fraction did not change and remained $100 \%$ throughout the study period, albedo has changed by \pm 0.2 over the 12 -year period. The effects of air temperature, summertime enhanced vegetation index, and precipitation amount and frequency on the surface albedo were investigated in an attempt to explain the observed changes. A clear effect of the air temperature was found where and when the monthly average air temperature exceeded -15 to $-10^{\circ} \mathrm{C}$, which is colder than what is observed in the laboratory experiments. In laboratory experiments snow albedo is stable at temperatures colder than $-10^{\circ} \mathrm{C}$ (e.g. Aoki et al., 2003). When temperatures reach $-5^{\circ} \mathrm{C}$ and higher, snow albedo decreases. Laboratory experiments are widely used to describe snow properties in models, but CRAICC research showed that they might represent atmosphere-cryosphere interactions unrealistically. This finding indicates that positive snow-albedo feedback takes place even at relatively low temperatures and when snow cover is complete. The results indicate that some Arctic areas are more sensitive to warming and therefore can exhibit climate change at a faster rate. In the study, the relation between surface albedo and the other parameters was less clear in comparison to the temperature effect or even absent in most regions.

\subsection{Vegetation and land use}

\subsubsection{Vegetation-climate interactions in the past (loop $A \rightarrow B \rightarrow C$ in Fig. 1)}

When European Arctic treeline LPJ-GUESS model simulations are compared with the locations of modern treeline detected from satellite imagery and past treeline determined using proxy-based reconstructions, the simulated treeline agrees with the spatial distribution of the actual treeline when a threshold biomass value of $2 \mathrm{C} \mathrm{kg} \mathrm{m}^{-2}$ is used (Fang et al., 2013). Mismatches are primarily observed over mountainous regions, such as in northernmost Fennoscandia and in regions near the Ural Mountains. The likely cause is that the spatially distributed climate data used to drive the climate model are limited in terms of representing the varying climate conditions between valleys and mountain peaks. Inaccuracies and simplifications in species-specific simulations are also caused by the parameterization of coniferous species. For example, one significant factor contributing to low simulated biomass of pine in Fennoscandia modern treeline vegetation is that in the LPG-GUESS simulation pine is classified as a shade-intolerant species and is therefore suppressed by shade-tolerant spruce when the ranges of these two species overlap. Such comparisons suggest that needed improvements include the spatial resolution of climate data within regions with complex terrain, such as steep slope gradients, and vegetation models need to simulate mixed forests composed of species with close bioclimatic thresholds.

Due to the inherent difficulties of species-specific simulations the CRAICC focus was on simulating the dynamics 


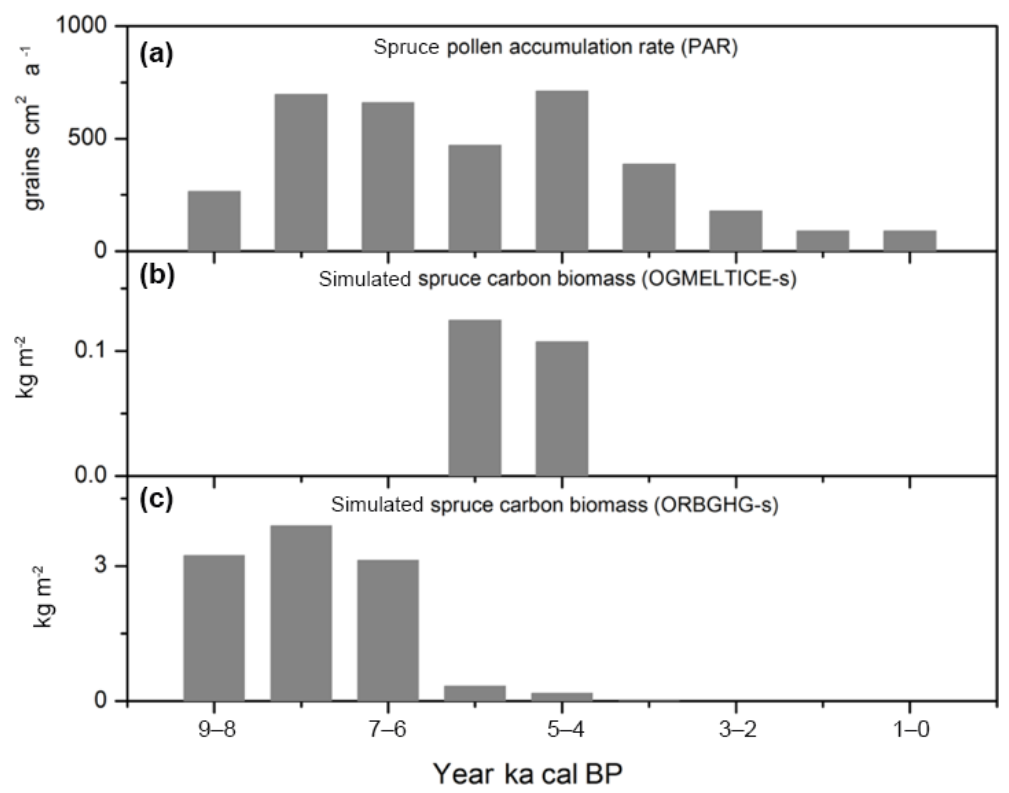

Figure 12. Time series comparisons between the pollen data from Kharinei Lake in the modern tundra $\left(62.75^{\circ} \mathrm{N}, 67.37^{\circ} \mathrm{E}\right)$ and the simulated spruce biomass from the nearest grid cell $\left(62.50^{\circ} \mathrm{N}, 67.00^{\circ} \mathrm{E}\right)$. (a) Pollen accumulation rate (PAR) data for spruce, (b) the simulated spruce biomass based on paleoclimate scenario OGMELTICE-s, and (c) the simulated spruce biomass based on paleoclimate scenario ORBGHG-s. The simulated biomass and PAR values are shown as mean values of 1000-year intervals.

of coniferous treeline instead of species-level treeline shifts. The simulations and proxy data both indicate a northward expansion of treeline in the middle Holocene and a retreat during the late Holocene. In Fig. 12 northward expansion towards the current tundra is indicated by the rise of spruce pollen values $9000 \mathrm{yr} \mathrm{BP}$ and the late Holocene retreat by the decline of spruce pollen values after $5000 \mathrm{yr}$ BP. When the simulated treeline dynamics are compared with these data, it can be seen that the model correctly captures the northward expansion of the boreal forest during the mid-Holocene and realistically simulates a treeline retreat in response to climate cooling during the last 3000 years. However, there are data-simulation disagreements, particularly during the early Holocene, which mainly result from the differences between the two paleoclimate model scenarios used to drive the simulations. Thus, the results show that the LPJ-GUESS dynamic vegetation model does not perform particularly well for species-specific biomass simulations. However, the general advances and retreats of the Arctic treeline can be realistically simulated with the dynamic vegetation model. In the model, the northward advances of the treeline are positively related to temperature variations, leading to a positive feedback loop between temperature and treeline.

\subsubsection{Warming-enhanced biogenic emissions from boreal forest (loop $A \rightarrow B \rightarrow E$ in Fig. 1)}

Boreal forest landscapes, including boreal soils, waters, and vegetation, are well-known sources of biogenic emissions (Penuelas et al., 2014). A CRAICC modelling platform was applied to assess the potential Earth system feedback linking BVOC emissions from boreal forests, and the resulting SOA formation, to direct and indirect aerosol and climate effects. Two experiments were performed with NorESM1CRAICC to quantify the effects of BVOC feedbacks using a slab-ocean model and the Community Land Model (CLM) with interactive BVOC emissions calculated according to the MEGAN module. While including the BVOC feedback mechanism, the model was run for a pre-industrial $\mathrm{CO}_{2}$ level of $357 \mathrm{ppm}\left(1 \times \mathrm{CO}_{2}-\mathrm{FB}\right)$ and a $\mathrm{CO}_{2}$ doubling $\left(2 \times \mathrm{CO}_{2}\right.$ FB) scenario. To achieve equilibrium the model was integrated for 70 years. In the boreal forest region, monoterpene emissions increased from 18 to $28 \mathrm{Tg} \mathrm{yr}^{-1}$ due to climate change from doubled $\mathrm{CO}_{2}$. The increase in monoterpenes led to nearly doubling the simulated SOA formation and a $10 \%$ increase in total particulate organic matter (POM). NorESM1-CRAICC simulates the effect of SOA formation on (1) nucleation, (2) nuclei growth, and (3) bulk SOA mass formation (Makkonen et al., 2014). The effect of the $10 \%$ increase in POM can be attributed to the changes in aerosol size distributions resulting from several competing pathways. Increased POM contributes to increased coagulation and is a condensation sink, possibly decreasing nucleation and subsequent growth. Furthermore, the aerosol size distribution is modified by simulated changes in cloudiness and precipitation. Indeed, cloud cover over boreal forest increases from $54.1 \%$ to $56.9 \%$ ( $0.5 \%$ standard deviation) and mean precipitation intensity increases slightly from 0.09 to $0.10 \mathrm{~mm} \mathrm{~h}^{-1}$ (standard deviation 0.0017 ). 
Table 1. Simulations of aerosol-climate effects of anthropogenic land use. MOZART refers to a version of NorESM1-CRAICC coupled with a tropospheric chemistry model.

\begin{tabular}{llcllll}
\hline $\begin{array}{l}\text { Model } \\
\text { simulation }\end{array}$ & Version & $\begin{array}{c}\text { Land } \\
\text { use }\end{array}$ & Oxidants & Boundary conditions (year) & Length \\
\hline 1 & MOZART & 1850 & Online & Present-day climatology (2000) & 12 years \\
2 & MOZART & 2000 & Online & Present-day climatology (2000) & 12 years \\
\hline 3 & SOA & 1850 & Present-day climatology (2000) & Present-day climatology (2000) & 7 years \\
4 & SOA & 2000 & Present-day climatology (2000) & Present-day climatology (2000) & 7 years \\
\hline
\end{tabular}

NorESM1-CRAICC was also used to simulate an alternative climate warming scenario, in which biogenic VOC emissions were not allowed to change ("no feedback" experiment, $2 \times \mathrm{CO}_{2}$-NOFB). Thus, the two simulations, one with and one without BVOC-aerosol-climate feedback, allow us to quantify the BVOC effect on aerosols and climate. In a control $\left(1 \times \mathrm{CO}_{2}\right)$ simulation, total particle concentrations over boreal forest regions averaged 820 particles $\mathrm{cm}^{-3}$, while in the climate change simulation without BVOC-aerosol feedback particle concentrations decreased to 790 particles $\mathrm{cm}^{-3}$, but the increased SOA formation in the $2 \times \mathrm{CO}_{2}$-FB simulation resulted in increased concentrations of 880 particles $\mathrm{cm}^{-3}$. Similarly, the vertically integrated cloud droplet number concentrations increased from $1.9 \times 10^{6}$ to $2.6 \times 10^{6} \mathrm{~cm}^{-2}$ with BVOC-aerosol feedback and only to $2.3 \times 10^{6} \mathrm{~cm}^{-2}$ without feedback when simulating a doubled $\mathrm{CO}_{2}$ scenario.

The strength of the simulated BVOC-aerosol-climate feedback is clearly weaker over tropical regions compared to boreal forest. In the tropics, monoterpene emissions are shown to increase $20 \%$, resulting in a POM increase of only $2 \%$ due to simulated climate change. However, even at the global scale, the BVOC-aerosol-climate feedback can increase SOA formation by $45 \%$ in a doubled $\mathrm{CO}_{2}$ experiment, showing the potential for a strong feedback mechanism during the 21 st century.

\subsubsection{Aerosol-climate effects of land-use change (loop $\mathrm{D} \rightarrow \mathrm{E} \rightarrow \mathrm{A}$ in Fig. 1)}

The CRAICC modelling platform was also applied to assess the importance of land-use perturbations for atmospheric chemistry and aerosols. While the albedo and GHG effects of land use are widely recognized, accounting for the changing spectra of primary aerosol and BVOC emissions is largely missing. Anthropogenic land-use change at high latitudes could play a role in modifying aerosol-climate feedbacks through direct and indirect aerosol effects. A total of four simulations (Table 1) were performed using NorESM1CRAICC to study the effects of land-use change on BVOC emissions, atmospheric chemistry, and SOA formation.

Since 1850 there has been significant tropical deforestation in South America, South Asia, and Africa and consider- able extratropical deforestation of mixed and boreal forests in Eurasia and North America. NorESM1-CRAICC shows large reductions of BVOC fluxes over these regions as a result of deforestation. Globally, when isoprene and monoterpene emissions are modelled and all other factors controlling BVOC emissions are kept fixed, the emissions are modelled to be about $10 \%$ lower in 2000 than in 1850 due to land-use change (comparing simulations 1 and 2 in Table 1). The global reduction of BVOC emissions leads to an increase in $\mathrm{OH}$ concentrations in the boundary layer of up to $40 \%$ over regions marked by strong deforestation because BVOCs are important compounds controlling $\mathrm{OH}$ reactivity and abundance through direct reactions. Simulations 1 and 2 also show that boundary layer ozone concentrations are reduced (up to $10 \%$ ) because BVOCs serve as ozone precursors when $\mathrm{NO}_{x}$ concentrations are high.

Simulations 3 and 4 indicate that lower BVOC emissions lead to a reduction in SOA formation, lower loadings of organic aerosol (Fig. 13a), and lower cloud droplet concentrations (Fig. 13b) if oxidants are fixed at present-day levels. The effects of deforestation are seen as decreased organic aerosol burden and cloud droplet number concentration. The changes in organic aerosol are particularly marked in the Northern Hemisphere, including large portions of boreal forests in Eurasia and North America.

\subsection{Ocean and lakes}

\subsubsection{Arctic sea ice}

The thin veneer of sea ice which covers much of the Arctic Ocean is an important variable for the energy and ecosystem balances of northern latitudes. A historical minimum in sea-ice extent occurred in 2012, during which time CRAICC joined the CHINARE Arctic expedition to carry out various observations on sea ice and other atmospheric and oceanographic conditions (Lei et al., 2014, 2015). Additional satellite imagery analysis using data from 1979 to 2012 to analyse inter-annual, seasonal, and spatial changes in the sea ice shows that general thinning of the ice cover and delayed freeze-up result in high variability during the month of October (Lei et al., 2015). Changes to the freezing and melting cycles of that ice are also important for the survival of multi- 

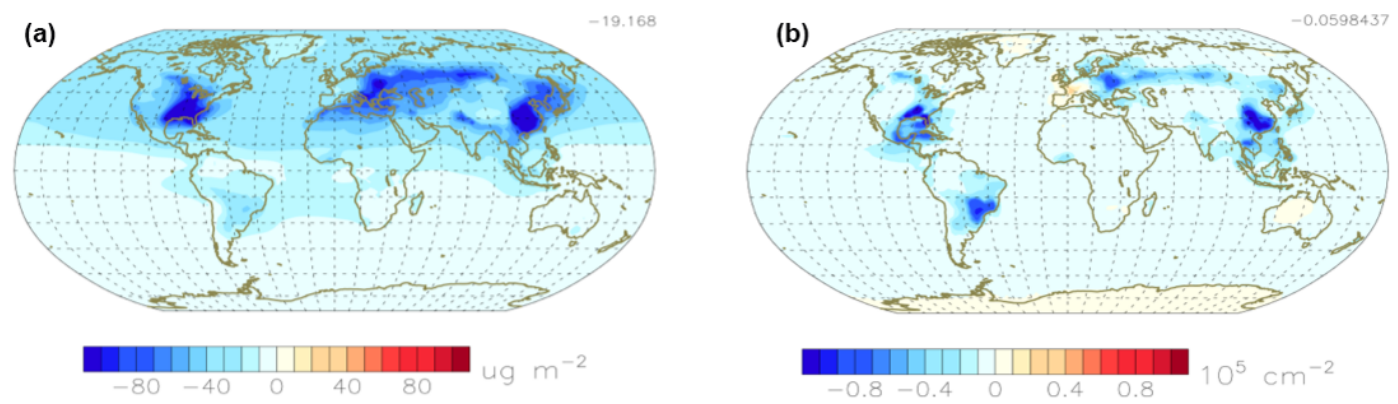

Figure 13. Simulated (a) organic aerosol column burden change and (b) cloud droplet concentration changes between 1850 and 2000 ; attributed to anthropogenic land-use change (CMIP5).

year sea ice (e.g. Rothrock and Maykut, 1999; Wadhams, 2016; Johannessen et al., 2019). Seasonal ice forms annually due to sub-freezing winter temperatures, while multi-year sea ice is connected to summer warming because the equilibrium thickness is highly sensitive to summer melt. Land-fast ice around the Arctic Ocean's coasts and islands is seasonal and its mechanics are sensitive to the ice thickness and forcing by winds and tides (Yang et al., 2015). Sea-ice transport out of the central Arctic Ocean is a significant sink for ice that is sensitive to large-scale atmospheric circulation, for example the Arctic Oscillation. Even just a few decades ago most of the central Arctic was covered by multi-year ice 3-4 m thick. Now a larger and larger fraction of the central Arctic has experienced ice-free periods, and the thickness of multiyear ice has decreased by $1 \mathrm{~m}$ (Wadhams, 2016). In a future warmer Arctic, sea-ice extent and thickness may also experience qualitative changes, for example more snow ice and frazil ice may form as a result of different freezing pathways. Present Arctic sea-ice models do not represent the physics and uncertainties of such future sea-ice cover scenarios well.

\section{Sea-ice cover modulating marine emissions $(\operatorname{loop} \mathrm{C} \rightarrow \mathrm{A}$ in Fig. 1)}

Changes in sea-ice cover and sea temperatures also affect marine emissions to the atmosphere, including sea salt aerosols, organic sea spray, and DMS (Struthers et al., 2011; Nilsson et al., 2001; Browse et al., 2014). There are a number of secondary processes that are also likely to effect marine emissions under large-scale melting. For example, bubbles are generated on melting sea ice (Norris et al., 2011), leading to enhanced sea spray formation because they protrude from the ocean surface (de Leeuw et al., 2011). The melting of sea ice also, at least temporarily, causes a brackish surface layer of water that has been observed to produce fewer but bigger bubbles and therefore fewer sea spray particles (Mårtensson et al., 2003). The issue of how the surface melts is also important. Sea spray particle flux measured over open leads was found to be an order of magnitude smaller than measured over the open sea (Nilsson et al., 2001). Thus, while an overall trend of increasing marine emissions is expected with decreasing sea ice, the spatial geometry of the melting will be important in addition to the effects of changes in salinity, fetch, and biological activity. Taken together, these changes will alter the character of the Arctic atmospheric aerosol and thus likely play a role in Arctic cloud formation and cloud processes.

Struthers et al. (2013) combined global climate model output with an emission parameterization to estimate the change in regional and global sea salt aerosol number emissions from 1870 to 2100 . Globally averaged, a general increase in sea salt aerosol number emissions was found due to increasing surface wind speed. However, emission changes were not uniform over the aerosol size spectrum due to an increase in sea surface temperature. From 1870 to 2100 the modelled emissions of coarse-mode particles increased by approximately $10 \%$ (global average), whereas no significant change in the emissions of ultrafine-mode aerosols was found over the same period. Significant regional differences in the number emission trends were also found. Based on global climate model output from CAM-Oslo (Seland et al., 2008; Kirkevåg et al., 2008), the predecessor of CAM4-Oslo in NorESM1, no straightforward relationship was found between the change in the number emissions and changes in the sea salt aerosol burden or optical thickness. This was attributed to a change in the simulated residence time of sea salt aerosol. For the $21 \mathrm{st}$ century, a decrease in residence time leads to a weaker sea salt aerosol-climate feedback than what would be inferred based on changes in number emissions alone. It should be noted that the above-cited simulations of sea spray in CAM4Oslo and NorESM1, including Struthers et al. (2013), did not apply an improved temperature-dependent sea spray source parameterization (Salter et al., 2015) built on data from a new Stockholm sea spray simulation tank (Salter et al., 2014). The Salter et al. (2015) parameterization is likely to result in more temperature-sensitive emissions compared to the previously used parameterization by Mårtensson et al. (2003).

Sea spray simulation chambers like the Stockholm simulation tank developed and/or deployed within CRAICC (Sect. 3.2.3) have enabled investigations of the physical and chemical properties of sea spray aerosol. The cloud-forming ability of sea spray aerosol has been targeted in a series of 
studies coupling CCN counters to sea spray tanks containing real and artificial seawater samples. King et al. (2012) established a baseline for artificial sea salt CCN activity and found that the particle generation method (diffuser vs. plunging jet) can affect particle size distributions and particle properties. During two spring campaigns Rasmussen et al. (2017) investigated the $\mathrm{CCN}$ activity of particles generated from seawater samples collected in the bay of Aarhus, DK. The measured CCN activity was similar to particles generated using artificial sea salt and did not vary significantly over the sampling period. Another laboratory study dedicated to the effect of saturated (solid) and unsaturated (liquid) fatty acids on sea spray aerosol properties showed that a significant organic volume fraction of saturated fatty acid ( $>60 \%)$ was needed to decrease $\mathrm{CCN}$ activity compared to that of a purely inorganic sea salt particle of the same size (Nguyen et al., 2017). Salter et al. (2016) presented observations of the size-dependent enrichment of calcium in sea spray aerosol generated from both artificial seawater and natural seawater collected in the North Atlantic. A significant result from CRAICC has been to clarify the possible role of hydrates in dried sea salt particles on climate-relevant properties. Rasmussen et al. (2017) used a sea spray simulation tank coupled with a thermodenuder to show that sea spray volatility can to a large extent be ascribed to the presence of hydrates, while Zieger et al. (2017) used the Stockholm apparatus and found it likely that the presence of hydrates reduces the hygroscopic growth of inorganic sea spray aerosol by $8 \%-15 \%$ compared with pure sodium chloride.

Connecting the fundamentals of sea spray from bubble formation and bursting to atmospheric aerosol processes is key to understanding the complex feedbacks associated with changing Arctic surface conditions, as enumerated in Fig. 1, loop $\mathrm{C} \rightarrow \mathrm{A}$.

\section{Long Icelandic record of sea-ice extent (component $\mathrm{C}$ in Fig. 1)}

Iceland represents an underutilized source for Arctic sea-ice recording. Meteorological observations have been carried out in Iceland since the early 1800s although the Icelandic Meteorological Office was not established until 1921. In place of scientific observations, regional historical sources indicate the extent of glaciers and the presence of sea ice centuries back in time (Björnsson, 2016; Ogilvie and Jónsdóttir, 1997). For example, information on monthly sea-ice extent goes back to 1850 based on farmer diaries and ship captain logbooks (Jónsdóttir, 1995). Systematic observations begin in the early 1900s (DMI, 2018) and are more recently complemented by higher-temporal- and spatial-resolution data obtained from the 1970s onward during the satellite era. Geologic indicators such as sediment records also provide insight into environmental change over the last millennia (Knudsen et al., 2009; Larsen et al., 2011).
Sea-ice extent off the Icelandic coast shows considerable variation with time. Conditions were severe throughout the second half of the 19th century and into the 1920s, with sea ice blocking the north coast for weeks or months in most years, often with serious implications for fishing, farming, and transport (Jónsdóttir, 1995). Much milder conditions followed and were observed up to 1965 , when harsh conditions returned for more than a decade. The 21 st century has seen dramatic changes in Northern Hemisphere sea-ice cover with decreased ice extent, thickness, and proportion of multi-year ice within the ice pack (NSIDC, 2018; Wadhams, 2016; Lei et al., 2014; Jónsdóttir and Sveinbjörnsson, 2007).

\subsubsection{High-latitude lakes and lake-atmosphere interactions (loop $\mathrm{B} \rightarrow \mathrm{C}$ and $\mathrm{E} \rightarrow \mathrm{A}$ in Fig. 1)}

Most lakes on Earth are located at high latitudes in the Arctic and boreal regions where they are covered by ice during winter (Verpoorter et al., 2014). Changing cryospheric conditions are critical to how these lakes evolve and influence the global climate system. High-latitude lake-atmosphere interactions are largely governed by surface temperature, waves, and the presence and character of ice cover. Lake processes can act on timescales of days to months, depending on lake size, while longer memory effects can extend over the length of the ice season. Lakes are active players in weather phenomena and budgets of gases, and large lakes and lake districts show up in regional climatology (Yang et al., 2013; Leppäranta, 2015). Numerous publications have shown that recent climate warming has affected lake icing, resulting in later freezing dates and earlier ice break-up dates, both on the order of 5-7 days, over the last century (Kirillin et al., 2012). In addition to higher air temperatures, break-up is forced by solar radiation, which causes melting throughout the ice column, where internal melting also contributes to mechanical weakening and ice cover breakage. Overall ice thickness may decrease due to milder autumn-winter conditions or less cloudy spring conditions that directly affect the radiation balance at lake surfaces. Trends in winter precipitation that affect snow amount can also affect ice thickness and quality.

In contrast to land surfaces, turbulent heat transfer in lakes provides a strong smoothing mechanism for temperature variations. Surface roughness is less over lakes than over land and the water surfaces are continuously striving to achieve water vapour equilibrium vis à vis ongoing evaporation and sublimation, resulting in locally humid conditions. Ice cover has a major impact: turbulence decays, circulation becomes thermohaline, and lake water becomes decoupled from the atmosphere. Cold, freshwater ice is largely non-permeable to gases but becomes permeable as it deteriorates during melting. Compounds deposited from the atmosphere are stored within the ice cover during the ice season and released during the short melting period. 
The annual cycle of boreal and tundra lakes can be divided into stratified summer conditions, the ice season, and mixing periods between them (Fig. 14). The formation of the summer stratification necessitates that air temperatures rise to more than $4^{\circ} \mathrm{C}$, while freezing takes place only with sustained below-freezing air temperatures and is delayed depending on lake depth. Lake ice response to climate warming is expected to manifest as reduced ice cover periods but also a change in the quality of ice seasons. Early and late winter are characterized by periods when ice is weak and may be broken by wind. During the stable phase, ice cover is safe and thick enough to support on-ice traffic. In a warming climate, the stable period is expected to shorten due to the decreasing ice thickness, and eventually the entire ice season may become unstable.

Although lakes only comprise about $3.7 \%$ of the Earth's non-glaciated land area (Verpoorter et al., 2014) they are very efficient in emitting greenhouse gases. Recently, it has been shown that on a global scale as much as $2.1 \mathrm{PgC}$ is annually emitted from $\mathrm{CO}_{2}$ reservoirs in lakes, ponds, and running waters (Raymond et al., 2013). This amount is comparable to the annual $\mathrm{CO}_{2}$ uptake by oceans $\left(\approx 2.0 \mathrm{Pg} \mathrm{Cyr}^{-1}\right.$; Wanninkhof et al., 2013). Thus, fresh water must also be considered as an important regulator within the global carbon cycle and thereby also influences climate.

A large fraction of the $\mathrm{CO}_{2}$ emitted from inland waters has its origin in surrounding terrestrial ecosystems. However, a substantial amount is also produced by microbial and photochemical mineralization within the water column (Cole et al., 1994; Humborg et al., 2010; Weyhenmeyer et al., 2015). The production of $\mathrm{CO}_{2}$ within the water column depends upon the availability of dissolved organic carbon (DOC), which enters inland waters from the surrounding watersheds. Kasurinen et al. (2016) developed models to quantify the DOC export from soils in northern watersheds. The modelling approach showed that DOC concentrations depend on watershed water storage as well as on soil temperature. Consequently, changes in land use will have a major impact on DOC export and therefore $\mathrm{CO}_{2}$ production in lakes.

Each year during the cold winter months substantial amounts of $\mathrm{CO}_{2}$ are produced and accumulated below lake ice cover (Denfeld et al., 2015, 2016a). Similarly, $\mathrm{CH}_{4}$ is produced below ice cover, in particular when nutrients do not limit its production (Ricão Canelhas et al., 2016; Denfeld et al., 2016b). At ice break-up (melting stage) these gases can be emitted into the atmosphere. However, gas production in water below ice is still less than production during the open water season (Denfeld et al., 2016a). Thus, given sustained nutrient conditions, similar groundwater hydrological connectivity, and sustained biological $\mathrm{CO}_{2}$ in the water column, it is also likely that gas production and emissions from inland waters will increase with longer and stronger cryosphere melt seasons (Denfeld et al., 2016a). It has been further suggested that these and other physical manifestations of global warm-

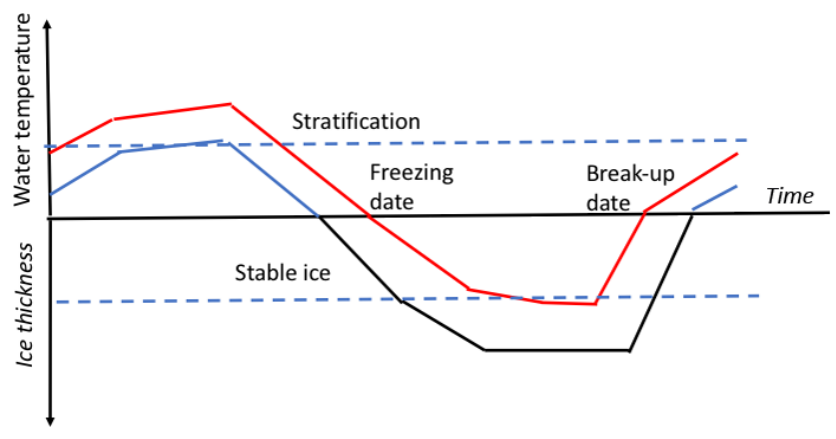

Figure 14. The annual cycle of boreal and tundra lake surface temperatures and ice thicknesses. The blue-black lines show a reference state with the red line illustrating climate warming impact. Ice and open water seasons change their length, including the presence of winter stable ice cover and/or summer stratification.

ing will impact ice phenology including time-delayed effects and feedbacks, which inspires continued research.

\subsection{Anthropogenic aerosols influence in the Arctic}

\subsubsection{Past $\mathrm{BC}$ deposition (loop $\mathrm{D} \rightarrow \mathrm{A}$ in Fig. 1)}

CRAICC has greatly increased the available BC deposition data from the Arctic. Previous observations of BC deposition were mainly from North American emission-influenced and high-elevation Greenland sites (McConnell et al., 2007; McConnell and Edwards, 2008; McConnell, 2010; Keegan et al., 2014), which are not necessarily representative of overall $\mathrm{BC}$ deposition trends at lower-elevation Arctic locations. Many of those receive the majority of their BC loading from Eurasia (McConnell et al., 2007; Hirdman et al., 2010). The Greenland records show increasing BC deposition from 1850, peaking around 1910, followed by a decline to almost pre-industrial levels after 1950 (McConnell et al., 2007; McConnell and Edwards, 2008; McConnell, 2010; Keegan et al., 2014). The CRAICC work includes a pioneering determination of depositional BC fluxes from the atmosphere to a Svalbard ice core (Ruppel et al., 2014) and four northern Finnish lakes sediments (Ruppel et al., 2015), questioning the prevailing conception of declining or stable Arctic $\mathrm{BC}$ values during the last decades.

The Svalbard and Greenland ice cores show similar temporal BC trends between 1750 and 1950, after which the Svalbard ice core indicates an increase in EC (a thermaloptical proxy for BC) deposition post-1970 (Fig. 15a), deviating strongly from the Greenland records. This increase is hypothesized to be partly caused by increased flaring emissions from gas and oil extraction in northern Russia (Ruppel et al., 2014). Flaring has been a previously underestimated Arctic BC emission source but is suggested to account for $42 \%$ of mean annual atmospheric surface BC concentrations in the Arctic (Stohl et al., 2013). These withinArctic BC emissions do not reach the high-elevation Green- 
land ice core sites due to restricted isentropic uplift in the atmosphere between the emission sources and Greenland summit (Stohl, 2006; Stohl et al., 2013), which helps to explain the differences between Greenland and Svalbard BC deposition trends.

Four northern Finland lake sediment records also show a similar standardized average SBC deposition trend in agreement with the Svalbard ice core with increasing deposition since 1970 (Fig. 15b; Ruppel et al., 2015). Lake sediment BC records are more sensitive to external factors (e.g. delayed $\mathrm{BC}$ import from catchment areas) than ice cores, and thus only general trends observed in multiple records can be considered significant (Rose and Ruppel, 2015). The observed SBC deposition increase is likely caused by regional BC emissions from the Kola Peninsula, as BC deposition from long-distance sources would have been expected to clearly affect all the studied sediment records (Ruppel et al., 2015). Thus, although the observed results cannot be extrapolated to wider regions, the fact that increasing BC deposition trends were observed in different environmental archives analysed with different methods suggests a robust result. Furthermore, the implication of the findings is that $\mathrm{BC}$ sources are considerable and that similar BC deposition trends may be observed in other parts of the Arctic.

Consequently, the CRAICC data suggest that BC deposition has increased since 1970 in some parts of the Arctic, coinciding with an increasing climatic impact of BC. This highlights substantial gaps in the previous (AMAP, 2011, 2015; Bond et al., 2013) understanding of Arctic BC trends. Conclusions that Arctic warming has occurred during the last 20 years despite decreasing BC concentrations (AMAP, 2011) may have been premature. More observational BC deposition data are urgently needed to confirm the $\mathrm{BC}$ trends across other parts of the Arctic.

The Svalbard ice core and Finnish lake sediment BC records both underline the potential existence of strong $\mathrm{BC}$ emission sources within the Arctic (Ruppel et al., 2014, 2015). The presence of high-latitude BC sources is important because within-Arctic BC emissions have a higher probability to remain in the region and are known to result in an amplified Arctic surface warming $(5 x)$ compared to the same emissions originating at mid-latitudes (Sand et al., 2013a). If the BC deposition trend has increased since the 1970s over wider Arctic areas, $\mathrm{BC}$ may have hastened the retreat of the Arctic sea ice, contrary to what has been previously thought (e.g. Doherty et al., 2010) based on temporal snapshots derived from $\mathrm{BC}$ in snow measurements, which show lower values between 2005 and 2009 than during the 1980s.

SILAM chemical transport modelling results developed within CRAICC to investigate the Svalbard ice core data have the potential of increasing the general understanding of meteorological processes driving $\mathrm{BC}$ deposition trends. Modelled BC deposition trends at the Svalbard glacier show variations that appear independent from $\mathrm{BC}$ emissions or trends in atmospheric BC concentration between 1980
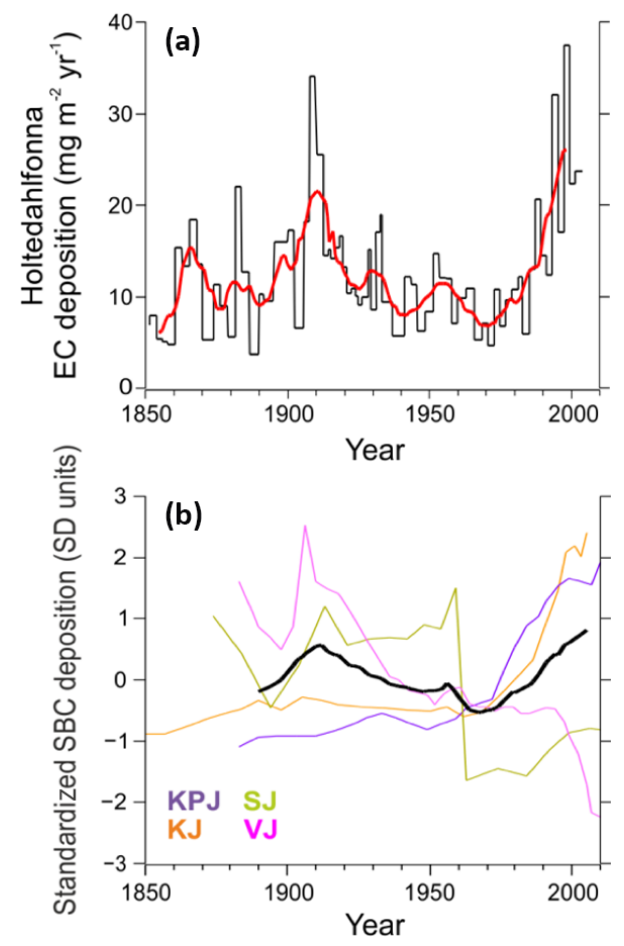

Figure 15. BC deposition at a Svalbard glacier and four northern Finland lakes between 1850 and 2010. (a) EC deposition at Holtedahlfonna and a 10-year running average (red line). (b) Stacked SBC deposition at four northern Finland lakes (KPJ, $\mathrm{KJ}$, SJ, and $\mathrm{VJ}$ ) expressed as standard deviations from the mean. The black curve indicates a LOESS smoother (span of 0.15) of time intervals from which data are available from all the lakes. Adapted with permission from Ruppel et al. (2015). (C2015, American Chemical Society.

and 2015. According to the model, about $99 \%$ of BC mass is wet-deposited on the glacier, indicating that meteorological processes such as precipitation and scavenging efficiency have a stronger influence on $\mathrm{BC}$ deposition than the emissions or trends in atmospheric concentration (Ruppel et al., 2017). Additionally, the model results indicate that, contrary to expectations, dry deposition does not follow a similar trend to atmospheric concentrations across the Arctic, in particular at sites located closer to anthropogenic sources (Soares et al., 2019). Thus, the model results do not point to a specific within-Arctic BC emission source being responsible for the observed post-1970s increase in European Arctic $\mathrm{BC}$ deposition, but highlight the fact that temporal trends in atmospheric $\mathrm{BC}$ concentrations and deposition may diverge due to meteorological processes. Consequently, Arctic BC deposition trends should not directly be inferred based on atmospheric $\mathrm{BC}$ measurements, and more observational BC deposition data are required to comprehensively assess the climate impact of BC in Arctic snow (Ruppel et al., 2017). 


\subsubsection{European emission reductions enhancing Arctic changes (loop $\mathrm{D} \rightarrow \mathrm{A} \rightarrow \mathrm{B}$ in Fig. 1)}

With the reduction of atmospheric sulfate concentrations since the 1980s in Europe and North America, the aerosol cooling effect has likely decreased. Using the CMIP5 version of the climate model NorESM1-M, Acosta Navarro et al. (2016) found that the reduction of sulfate in Europe between 1980 and 2005 can explain as much as half of the warming observed in the Arctic during the same period. Air quality emission(s) regulations have succeeded in reducing soil and water acidification and have therefore also removed a large portion of the aerosol dampening effect, and thus the Arctic is experiencing warming more in line with increased global greenhouse gas levels. However, over continental Europe itself the modelled warming due to the same European emission regulations is only one-fifth of the observed warming (Kirkevåg et al., 2016). Acosta Navarro et al. (2016) found that a redistribution of the energy input to the Arctic over the year appears to be a critical factor in explaining the stronger temperature response in the Arctic. In short, the reduction of European anthropogenic sulfate emissions leads to increased summertime atmospheric heat transport $\left(+0.25 \mathrm{~W} \mathrm{~m}^{-2}\right)$ and increased yearly oceanic heat transport into the Arctic region $\left(+0.48 \mathrm{~W} \mathrm{~m}^{-2}\right)$. Together with the increased ocean heat transport, the summertime energy surplus is mainly used to melt sea ice, thus increasing the amount of available energy in the Arctic and delaying the onset of autumn freezing. Delayed freezing is reflected in a larger heat transfer from the ocean to the atmosphere during fall and winter, causing strong lower tropospheric warming.

\subsubsection{Contrasting mid- and high-latitude anthropogenic emissions (loop $\mathrm{D} \rightarrow \mathrm{A} \rightarrow \mathrm{B}$ in Fig. 1)}

Most aerosol particulate reaches the Arctic through longrange transport. Arctic sites have measured surface concentrations of EBC ("equivalent" $\mathrm{BC}$ determined using light absorption methods) and sulfate for over 3 decades. At these monitoring sites, northern Eurasia has been identified as the largest EBC source region (Sharma et al., 2004: Eleftheriadis et al., 2009; Hirdman et al., 2010), with contributions peaking in winter and spring. During summer, BC emissions from agricultural and boreal fires have a primary influence on Arctic concentrations (Stohl et al., 2006, 2007). Within CRAICC, Sand et al. (2015a) studied feedback effects of increasing $\mathrm{BC}$ in the atmosphere. The modelling experiment increased $\mathrm{BC}$ to unrealistically high levels to show that increased $\mathrm{BC}$ concentrations may change cloudiness and precipitation in ways that will feed back onto the spatial distribution and atmospheric residence times of BC. In extreme cases, increased $\mathrm{BC}$ in the upper parts of the troposphere may contribute to stabilizing the atmospheric column below and destabilizing the column above, thus causing a positive feedback which mixes BC to higher altitudes and further from emission sources, e.g. to polar latitudes. These feedback effects are not accounted for in many model experiments wherein $\mathrm{BC}$ concentrations are directly controlled.

Using NorESM1 with an emission inventory that includes flaring and seasonal variations from domestic sources, Sand et al. (2013a) investigated how mid-latitude BC emissions impact the Arctic in comparison with local $\mathrm{BC}$ emissions. They find that $\mathrm{BC}$ emitted within the Arctic has a $5 \times$ surface temperature response in the Arctic compared to the same amount of $\mathrm{BC}$ emitted at mid-latitudes. A large fraction of this warming is due to increased absorption from $\mathrm{BC}$ deposited on snow-sea ice. BC emitted at mid-latitudes, on the other hand, enters the Arctic at higher altitudes and is therefore less likely to be deposited on the surface. BC at higher altitudes may warm surrounding atmospheric layers, but the high static stability of the Arctic atmosphere suppresses any heat exchange between the upper and lower atmosphere (Sand et al., 2013b). Motivated by the BC mitigation potential, Sand et al. (2015b) split the emissions into different sectors and regions and provided detailed numbers for the surface temperature sensitivity in the Arctic per $\mathrm{kg}$ emission of BC, taking co-emitted species into account. They found that domestic emissions from Asia have the largest warming effect in the Arctic due to the large absolute amount of these emissions and the relative high $\mathrm{BC}$-to- $\mathrm{SO}_{2}$ fraction. However, the Arctic is most sensitive, per unit mass emitted, to Russian flaring emissions, followed by forest fires and flaring emissions in the Nordic countries.

\section{Legacy of CRAICC}

The results presented throughout this review were only achieved by combining established and newly developed scientific methods and tools and by combining these in new and innovative ways. While these individual scientific results are indeed a major outcome of CRAICC, perhaps an even more important legacy is the way in which the new methods and tools were implemented in a synchronized manner in order to elucidate the feedback loops of interest (Fig. 1). In doing so, they will further influence the polar science community and enhance our understanding of the complex Arctic climate system even beyond the CRAICC initiative.

The driving concept behind all research activities within CRAICC was to closely link and coordinate all efforts needed to address our research questions related to the identified Arctic feedback loops. This was based on necessity, since no single research group had the capacity to undertake all the needed research. The combined expertise of the Nordic Earth system and Arctic climate science communities proved to be able to muster sufficient capacity to adopt the required holistic perspective on Arctic climate change.

As in all fields of natural science, we strived to integrate our combined knowledge into models - operating at different 
scales and levels of detail - in a condensed and operational fashion such that these models could be used to tackle important research questions. All models needed to be based on, and evaluated against, observations in order for them to gain credibility and acceptance. Such observations were made both in the laboratory - where conditions can be manipulated - as well as in field experiments and long-term monitoring efforts, which were typically subject to larger variability and less control.

CRAICC modelling platform. Modelling within CRAICC spanned a wide range of temporal and spatial scales from molecular cluster dynamics models ( $\AA$ and fs scales), to aerosol dynamics and atmospheric chemistry models (scales of nanometres to kilometres and seconds to hours), to regional chemical transport models (kilometres and hours to days), to dynamic vegetation models, and finally to global climate and Earth system models (global and decadal scales). A major challenge - although not unique to CRAICC - had been to link models across scales. Rather than focusing on directly nesting models, by passing model domain boundary conditions between models while computing or offline, the approach has been focused on passing scientific information and process understanding between model scales.

CRAICC experimental platform. The experimental platform in CRAICC also spanned scales and complexity and involved laboratory process studies, campaign process and characterization studies, and long-term field observations across a geographically distributed network of stations. Designed laboratory and field experiments were used to derive and test parameterizations, specifically in an effort to distil descriptions of the complex web of interlinked processes down to their dependence on controlling parameters. The level of detail allowed in the models, typically set by computing capacity, determined the complexity of the incorporated process parameterizations. All parameterizations needed to be justified and verified, which is what CRAICC was able to provide owing to the wide-ranging expertise gathered within the research programme.

Long-term field observation network. An extensive longterm field observation network extended from Sorø, Denmark, to the Villum research station in North Greenland at $81^{\circ} 36^{\prime} \mathrm{N}$. It built heavily on the existing environmental research infrastructure for aerosols, trace gases, and clouds (ACTRIS; https://www.actris.eu/default.aspx, last access: 4 February 2019), which has an ESFRI status as a strategically important research infrastructure in Europe. CRAICC also utilized observational data from the INTERACT Arctic station network and gained access to some of the 79 INTERACT sites (http://www.eu-interact.org/, last access: 4 February 2019). Despite the existing extensive infrastructure at northern latitudes, there was an additional need for long-term observations in the pan-European Arctic, which led CRAICC partners to initiate the Pan-Eurasian Experiment (PEEX) programme (see PEEX section below).
Example(s) of CRAICC research "loop" to investigate feedbacks. Here we present two examples of how new methods, process studies, and models were developed in a coordinated way within CRAICC and how they were used to elucidate the feedback loops under scrutiny. Following the identification of important feedback loops involved in Arctic climate change, the proper combination of new scientific experiments, methods, tools, and observations needed to examine the feedbacks was designed and carried out within CRAICC. Whatever the feedback being studied, this followed a similar circular pattern or "research loop" as outlined below.

Laboratory and field experiments $\rightarrow$ parameterizations for process and global climate models $\rightarrow$ model runs at various temporal and spatial scales $\rightarrow$ verification against field observations $\rightarrow$ feedback loops evaluated with the objective of rigorous quantification $\rightarrow$ identification of knowledge gaps and requirements for improved process understanding, parameterizations, finer model resolution, better coupling between Earth system compartments, etc. $\rightarrow$ new iteration.

The following are two examples of how this was carried out in practice within CRAICC.

Example 1: Warming-enhanced biogenic emissions from boreal forest (involved in loop $D \rightarrow A \rightarrow B \rightarrow E \rightarrow A$ in Fig. 1).

The feedback loops could only be evaluated using models (alternative long-term datasets from SMEAR II, Hyytiälä, Finland: Temp-BVOC-BSOA-AOD-CCN with higher albedo cooling), given that this was the only way in which we could "experiment" with different scenarios.

Laboratory and field experiments (smog chamber studies, SMEAR II, etc.) $\rightarrow$ parameterizations for process and global climate models (ADCHEM, NorESM1, etc.) $\rightarrow$ model runs at various temporal and spatial scales (giving number concentration fields) $\rightarrow$ verification against field observations of $\mathrm{CCN}$ concentrations, $\mathrm{OA}$, and their ageing timescales and resulting atmospheric residence time $\rightarrow$ feedback loops evaluated.

Example 2: Sea spray number production (involved in loop $D \rightarrow A \rightarrow B \rightarrow C \rightarrow D$ in Fig. 1).

Another key aspect of the work on sea spray aerosol conducted during CRAICC was the tight links between the laboratory experiments described previously and global modelling. The effects of temperature on sea spray aerosol production described by Salter et al. (2014) were implemented in NorESM1 as a sea spray source function (Salter et al., 2015), while Zieger et al. (2017) highlighted the implications of their measurements of inorganic sea spray aerosol hygroscopicity using ECHAM6-HAM2.

Laboratory and field experiments (bubble chambers: dependence on wind speed, bubble concentration and size spectrum, seawater salinity and temperature, surface microlayer properties) $\rightarrow$ parameterizations for process and global climate models (ADCHEM, MATCH, CAM-Oslo) $\rightarrow$ model runs at various temporal and spatial scales (giving number concentrations fields) $\rightarrow$ evaluation against field ob- 
servations of sea spray number concentrations and their ageing timescales and resulting atmospheric residence time $\rightarrow$ feedback loops evaluated (led to identification of knowledge gaps and requirements, for instance for improved process understanding, parameterizations, finer model resolution, better coupling between Earth system compartments).

Continuing the legacy through eSTICC. The eSTICC (eScience Tools for Investigating Climate Change) is a Nordic Centre of Excellence that aims for a more accurate description of the high-latitude feedback processes in the climate system by improving e-science tools (e.g. computational models, data platforms) for the climate research community. The eSTICC originated mainly from modelling activities in the three Nordic centres CRAICC, DEFROST (impact of a changing cryosphere: depicting ecosystem-climate feedbacks from permafrost, snow, and ice), and SVALI (stability and variations of Arctic sea ice). Nearly all of the escience groups active in CRAICC have continued their cooperation in this new centre. The eSTICC has pooled together researchers from 13 top institutes in the Nordic countries working in the fields of climate and/or e-science to improve e-science tools for climate research. Specifically, eSTICC develops tools needed for more efficient use of experimental and model data and to improve the computational efficiency and coding standards of ESMs and tools for inverse modelling of emission fluxes.

PEEX was initiated in 2012 as a bottom-up initiative by several European and Russian research communities (Lappalainen et al., 2014; Kulmala et al., 2015, 2016). It was an extension not only of the research approach carried out by a Finnish Centre of Excellence (Centre of Excellence in Atmospheric Science - from Molecular and Biological processes to the Global Climate) but also of the CRAICC initiative. In 2017 PEEX carried out the implementation of the PEEX Science Plan, which in many aspects shares research interests regarding Arctic environments with the CRAICC initiative, but further expands the region of interest to cover the boreal environments of northern Eurasian (Lappalainen et al., 2015). PEEX also actively involves socio-economic and social science in its research approach by linking socioeconomic factors to systems analysis, scenarios, and narratives of the northern future (Kulmala et al., 2016; Lappalainen et al., 2016). The understanding and controlling of GHG and SLCF emission(s) and concentration dynamics over the Russian Arctic-boreal regions and the stability of Russian permafrost, currently occupying $65 \%$ of the Russian national territory (Melnikov et al., 2018), is a significant scientific and social challenge for the northern Eurasian region. Thus, the environmental changes and energy policy choices taking place in and being made by Russia are especially relevant not only regionally, but also globally, for the global climate-biosphere system.

Similar to one of CRAICC's main interests, PEEX aims at increasing the amount of available data from Arctic-boreal regions. This will be done by establishing a long-term, co- ordinated comprehensive in situ observation network across the Arctic-boreal regions of northern Eurasia (Hari et al., 2016). The concept of the hierarchical PEEX in situ station network is based on know-how of the measurement theory and techniques developed at the SMEAR II flagship station in Hyytiälä, Finland (Hari et al., 2016). The backbone of the PEEX station network is built on the existing biosphere (ecological) and atmospheric observation networks in collaboration with European, Russian, and Chinese partners. Starting in 2012 PEEX began preparatory work with Russian station networks and collected preliminary information on in situ station measurements from over 170 stations (Alekseychik et al., 2016). The overview of the measurement capacity of the existing stations and analysis of future needs will be the first step connecting Russian data more strongly to international research infrastructure frameworks, especially to $\mathrm{Eu}-$ ropean research infrastructure like ACTRIS, ICOS, ANAEE, and LTER. As a part of the PEEX infrastructure the "PEEX Modelling Platform" (MP) has also been established. The MP combines multidisciplinary datasets of varying temporal and spatial scales and provides a seamless modelling interface for regional models and global ESMs. The MP also provides different types of visualization tools for comparing measured datasets with modelled data and trajectory information. For model validation the MP also enables connections between satellite observations and ground-based observations, which additionally promotes a clear understanding of the current state of the atmosphere.

Knowledge transfer. In the CRAICC community, we have recognized the importance of discipline-tied fundamental education for tackling multidisciplinary research problems. However, in climate and global change science a shift towards multidisciplinarity is also needed in education (Nordic Climate Change Research, 2009). In CRAICC, we developed a model for improving learning outcomes in multidisciplinary atmospheric science. The model includes pedagogical experiments, utilization of modern technologies (e.g. Junninen et al., 2009), workshops for teachers and supervisors, and most importantly organizing a series of interdisciplinary research-intensive short courses. CRAICC had dedicated education programmes including master- and doctorallevel studies. At the master's level, a new Arctic study module was introduced in the existing Joint Nordic Master's Programme in Atmosphere-Biosphere Studies (ABS). On the doctoral level, emphasis was placed on joint intensive courses, doctoral student mobility, and cross-supervision between CRAICC partners.

A total of 21 jointly organized intensive CRAICC research courses were given for more than 484 participating students. The courses were interdisciplinary and emphasized 
- measurement techniques and field experiments (six courses);

- advanced data analysis of atmospheric and ecosystem observations (seven courses);

- theoretical approaches and basic understanding (four courses);

- Arctic environment (three courses); and

- modelling (one course).

A total of 18 doctoral students were recruited to carry out research related to the topics studied in CRAICC, and all of them graduated within 1 year of the project's completion.

\section{Summary and outlook}

The major CRAICC project aim was to quantitatively evaluate the identified feedback loops within the Arctic climate system with respect to changing climate and anthropogenic influences. While the most well-quantified feedback loop in the Arctic climate system is the amplification of warming caused by albedo changes with decreasing sea-ice extent, there remain significant areas of scientific uncertainty with regard to other Arctic system feedbacks and aerosol-cloudclimate interactions. For example, the changes in emissions of particulate and gaseous compounds due to rapidly decreasing Arctic sea-ice coverage will also have feedback effects on albedo (Stendel et al., 2008). Earth system modelling efforts carried out within CRAICC have contributed to both the identification and quantification of Arctic feedbacks. However, the quantification of single feedback mechanisms remains difficult and the impact of further warming on ecosystems demands continued investigation.

The loss of Arctic sea ice was a major area of emphasis within CRAICC. Decreasing sea-ice extent will result in changes in natural emissions (e.g. sea spray) from open water; it will also increase humidity levels and influence the formation of clouds and the chemistry of the atmosphere. All of these will have consequential climate feedbacks. In particular, DMS-, amine-, bromine-, and iodine-containing organic and inorganic species will be fundamentally impacted. The increase in sea spray emissions from more open ocean and fetch will change their potential CCN contribution (potentially a negative feedback). Experiments with interactive DMS in NorESM1 have been done (Schwinger et al., 2017) indicating potentially strong regional Earth system feedbacks via DMS, and the mechanisms will be studied further in new model versions. However, in the long term the disappearance of sea ice ends the surface water temperature buffering near the melting point, which will allow the sea surface water temperature to gradually increase. For sea spray, that might reverse the emission trend. With increasing sea surface temperature, Mårtensson et al. (2003), Zábori et al. (2012), and
Salter et al. $(2014,2015)$ have shown that sea spray emissions will decrease, resulting in a positive feedback on climate change.

The opening of Arctic seas during summer will also make commercial shipping possible, but emissions from Arctic shipping have to be evaluated with respect to cloud and climate impacts in addition to the fuel and technological changes that might also evolve in future scenarios. Activity will be highly dependent on the Arctic sea-ice extent, which has been rapidly changing in the last decades. The emissions from ship transport, depending on the fuel, season, and cloud type may lead to warming and/or cooling effects. That said, shorter shipping routes will potentially lead to less global emissions.

Exchange processes between the atmosphere and the cryosphere are another area for which CRAICC has contributed to narrowing the existing knowledge gaps. Although similar processes govern the deposition of particles in the Arctic and mid-latitudes, particle emissions are different and can respond differently to climate change. Future emission projections of primary particles and secondary aerosol precursors in a changing Arctic climate are handicapped because even present emissions are not well quantified. Furthermore, chemistry in the snowpack is not well understood and BVOCs from thawing permafrost are expected to comprise a large and increasing fraction of Arctic and sub-Arctic secondary aerosol precursor emissions. The oxidation and conversion of BVOCs to condensable organic compounds requires more scientific investigation because the impact of secondary organic aerosols on e.g. cloud formation is still too uncertain to make reliable forecasts of Arctic climate, especially in a warmer Arctic. Further warming of the Arctic will enhance BVOC emissions, which in turn will have a significant impact on the organic aerosol mass load. Thus, the role of organic aerosol in the Arctic, including the role of organosulfates, remains a key area for knowledge advancement (Hansen et al., 2014; Kristensen and Glasius, 2011; Öström et al., 2017).

A reduction in the uncertainty of projections on BVOC emissions arising from both terrestrial and marine sources is needed in order to predict future Arctic climate scenarios and to determine one of the most important feedback loops in the Arctic climate system. In addition, natural (including vegetation changes due to climate change) and human-induced (management, urban development) land-use changes will impact BVOC emissions. Within CRAICC Earth system modelling included detailed aerosol effects and basic physical aerosol processes as well as updated parameterizations for BVOC emissions. Model experiments were carried out to investigate the BVOC-aerosol-cloud-climate feedback loop. Idealized climate change simulations indicated significant increases in global monoterpene emissions, emphasizing a potentially strong negative climate feedback mechanism, especially over boreal forest. Nevertheless, future work needs to be done to better quantify BVOC emissions in a future 
climate. To build a deeper understanding of aerosol ageing processes, including long-range transport from Eurasia and North America to the Arctic, it will be necessary to obtain size-segregated chemical composition information for submicrometre Arctic aerosol particles and VOCs. This information is also highly relevant for determining the $\mathrm{CCN}$ potential of aerosols.

A Lagrangian chemistry transport model was also implemented within CRAICC in order to evaluate how BVOC emissions from subarctic forests impact the formation of new particles and their growth into the $\mathrm{CCN}$ size range (Öström et al., 2017). New particles over the subarctic forest were found to be dominated by low-volatility HOMs formed from the ozonolysis and $\mathrm{OH}$ oxidation of monoterpenes. Given the relatively low present-day emissions of anthropogenic secondary aerosol precursors and primary particles in the subarctic forest region, new particle formation and subsequent growth by HOMs most likely has an important role in maintaining $\mathrm{CCN}$ concentrations. However, because precursors involved in new particle formation are still not well described, the anthropogenic impact on new particle formation is not well constrained. This causes large uncertainties in the estimates for both pre-industrial and future $\mathrm{CCN}$ concentrations in the Arctic and sub-Arctic. Thus, without more fundamental knowledge about the formation and initial growth of new particles and their role in maintaining $\mathrm{CCN}$ concentrations, the strength and importance of the BVOC-aerosolcloud-climate feedback loop remain poorly quantified.

The forecasted significant warming, consequent vegetation shifts, and ice-free Arctic waters all suggest that natural aerosol precursor emissions from the biosphere will increase substantially, although currently the magnitude of these effects is unknown (Bäck et al., 2012; Aalto et al., 2015; Schollert et al., 2016). In particular, if an increase in the height and cover of shrubs and graminoids occurs as a response to warming in the Arctic (Elmendorf et al., 2012), there will be a major impact on emission rates and consequently SOA formation (Tiiva et al., 2008; Faubert et al., 2010; Valolahti et al., 2015; Kramshøj et al., 2016). Conversely to temperature, increasing $\mathrm{CO}_{2}$ decreases BVOC (at least isoprenoid) emissions. However, using Earth system simulations, the combined impact of increasing (doubled) $\mathrm{CO}_{2}$ and temperature was shown to increase both BVOC emissions and aerosol number concentration by $>30 \%$ (Makkonen et al., 2014). Furthermore, changes in aquatic ecosystems are known to affect biogenic emissions, but insufficient understanding prevents the processes from being quantified (Faust et al., 2016).

Atmospheric pollutants are often reactive species that undergo continuous transformations in the gas, particle, and aqueous phases, implying that new compounds are formed and secondary aerosol mass is produced by gas-to-particle conversion or cloud processing. Anthropogenic pollution in the Arctic remains sourced primarily from long-range transport, and its chemical and physical atmospheric transforma- tion varies seasonally due to the position of the polar dome and due to the alternating absence and presence of solar radiation in the high Arctic. Thus, the endpoint of products also varies, with significant uncertainty due to the relatively long ageing times and myriad exposure conditions. Furthermore, although many reaction schemes are well known, few are studied under extreme conditions at temperatures far below $0^{\circ} \mathrm{C}$. In general, this leads to a lack of knowledge concerning the partitioning of species between the gas and particle phases at extreme conditions.

In most cases spatially resolved concentrations of atmospheric species are restricted to surface-level measurements. In the Arctic, information in the vertical dimension is largely missing due to the region's remoteness and harsh environmental conditions. A number of modern techniques could promote Arctic data collection with vertical resolution, including unmanned aerial vehicles (UAVs), tethered balloons, and ground- and satellite-based remote sensing technologies. Aircraft measurements also remain an option, but are expensive and only cover small time spans. Currently, such observations are not contributing to existing monitoring networks and are limited in time and space, but the use of such technologies needs to be extended and promoted throughout the Arctic.

Although the state of scientific understanding regarding the direct forcing of greenhouse gases and atmospheric particles has developed, the level of understanding of aerosol indirect forcing remains limited. In the high Arctic, even aerosol direct forcing leaves open questions because the mixing state of long-range-transported pollution is not sufficiently well described. The role of clouds, especially the impact of anthropogenically emitted particles on clouds, is still uncertain although it has been the focus of intense research for decades. Indirect forcing of Arctic clouds is also unique because the polar night excludes cloud interactions with solar radiation, but does allow cloud interactions with terrestrial radiation. The Arctic haze season is also a unique anthropogenically influenced phenomenon and requires deeper insight into its cloud impacts. More experimental work on the seasonal behaviour of cloud radiation is needed and must be implemented into climate models. Such ESM work in CRAICC has been carried out to analyse its influence on the number of available $\mathrm{CCN}$ in a future climate. However, further quantification of indirect aerosol effects requires more fundamental understanding of the role of Arctic clouds and the anthropogenic influences on Arctic cloud formation and evolution.

A substantial part of Arctic warming has been attributed to BC deposition on snow- and ice-covered surfaces (Quinn et al., 2008). CRAICC has contributed to illuminating this scientific area of interest using measurements of atmospheric $\mathrm{BC}$ concentrations and deposition and comparing the observed values to modelled results (e.g. Massling et al., 2015; Ruppel et al., 2017). In addition, BC records retrieved from paleoclimate archives (lake sediments and ice cores) within CRAICC have contributed to understanding the scale and 
significance of modern variations in $\mathrm{BC}$ with respect to historical values (Ruppel et al., 2014, 2015). However, estimates of how the spatial distribution of albedo will change due to future $\mathrm{BC}$ deposition remains highly uncertain due to limited knowledge and the fact that Arctic response to BC may be unique. Furthermore, the growth of Arctic shipping and extraction of minerals and oil from Arctic reservoirs may significantly affect local sources. By comparing local BC emissions to mid-latitude emissions, Sand et al. (2013a) found that local emissions have a much stronger surface temperature response than mid-latitude emissions. In addition to the direct albedo response to $\mathrm{BC}, \mathrm{BC}$ particles also affect snowpack albedo by changing the snow and ice crystal grain sizes, an effect that is not well described and is not included in climate models. The bottom line is that $\mathrm{BC}$ projections need to be improved for further model implementation.

Snow albedo varies spatially, temporally, and spectrally and is determined by snow properties and the surrounding environment. From these, the effective snow grain size, i.e. grain size and shape distributions or specific surface area (Domine et al., 2006), is the most important parameter determining snow albedo. Surface darkening due to BC, dust, or other impurity deposition causes spectrally dependent albedo declines. Natural snow metamorphism processes constantly modify albedo, and when snow ages, with or without melting, snow grain sizes increase and as a consequence albedo decreases (Wiscombe and Warren, 1980). Future changes in temperature, rainfall, wind, humidity, cloudiness, and/or depositing aerosols will therefore affect snow albedo. Extreme winds, in turn, can break snow grains into smaller entities and create snow dunes or induce snow-dust storms (Dagsson-Waldhauserova et al., 2015), all of which significantly contribute to changes in snow albedo. Within CRAICC strong efforts were made to characterize the Icelandic dust reaching the high Arctic. The influence of dust on climate in the cryosphere has not been sufficiently studied, although it may be of the same order of magnitude as the effect of BC on cryospheric surfaces. Experiments quantifying the melting and insulation effects of dust layers on snow- and ice-covered surfaces were carried out within the CRAICC project (Dragosics et al., 2016; Wittmann et al., 2017). The frequency, variability, and intensity of Icelandic dust events were investigated (Dagsson-Waldhauserova et al., 2013, 2014a) and the physical properties of Icelandic dust were determined (Dagsson-Waldhauserova et al., 2014b, 2015, 2016). Dust influence may also be amplified by the melting of Icelandic (Arctic) glaciers, which may amplify the effect of dust resuspension.

With the rapid development of computing power, paleoclimate models are becoming increasingly useful tools to investigate past climate changes on various spatial scales. Climate models are mathematical representations of our ability to model the climate system, including movements of heat and mass within components of the climate system and also interactions between different components. Testing of differ- ent scenarios, termed sensitivity testing, allows us to explore plausible mechanisms behind climate changes and to analyse temporal-spatial variability. All paleoclimate models include uncertainties, and the magnitude of the uncertainty in the model output depends not only on the forcings used in the simulations, but also on model-specific features, such as the physical principles, complexity, and resolution. Multimodel comparisons and proxy-model comparisons provide the means to test the reliability of model performance. The reliability of the models and simulations increase if independent models consistently indicate the same or similar results and if the model results agree with the proxy-based climate reconstructions. Such recent model tests have shown that paleoclimate models generally indicate consistent results for the Holocene in northern Europe, including the Arctic, but differ substantially in other Arctic regions, such as eastern Siberia and Alaska (Zhang et al., 2017).

The influence of short-lived climate forcers in the high Arctic is still a highly uncertain quantity as it depends on natural and anthropogenic emissions and their complex interactions. Both types of emissions may change in the future, but those changes may also be for different reasons. Anthropogenic emissions will change as a result of changed activity patterns and burdens at mid-latitudes and in industrialized areas, the regions from which most anthropogenic emissions observed in the high Arctic presently originate. Changes may involve e.g. the introduction of new cleaner technology and changes in emission regulations. In general, better emission protections are needed as they strongly determine the level of pollution in the Arctic. Within CRAICC, a large number of data from multiple research platforms were utilized in order to qualitatively and, more importantly, quantitatively assess the state of the knowledge of natural emissions and their changes.

Field scientists and climate modellers have worked closely together to advance the knowledge of many complex Arctic topics. The lack of extensive ground-based monitoring in the Arctic promotes this kind of large international collaboration between scientists that operate or use existing Arctic monitoring networks. In the Arctic, in addition to the direct effects of increasing global $\mathrm{CO}_{2}$, there is a risk that an acceleration of climatic changes will occur due to feedback processes that are unique to the Arctic. Continued Arctic research is needed to provide better parameterizations in global models, which can be used to identify risks and climate thresholds, thereby informing politics and policymaking, and help to weigh climate adaptation versus climate mitigation.

Data availability. The data for simulations performed under Sect. 4.1.2 are available at https://doi.org/10.1594/PANGAEA. 877695 (Öström et al., 2016). Video created by NordForsk about the aims and outcomes of CRAICC: https://trotv.solidtango.com/ video/nordforsk-craicc?locale=en (Prisme Media, 2019). 
Author contributions. MB and ET served as the chief authors and editors for the paper, with MB coordinating contributions from all co-authors. The scientific contributions were provided by all coauthors.

Competing interests. The authors declare that they have no conflict of interest.

Special issue statement. This article is part of the special issue "Pan-Eurasian Experiment (PEEX)". It is not associated with a conference.

Acknowledgements. The CRAICC team acknowledges the following institutions for financial support: the Finnish Cultural Foundation grant, Markku Kulmala "International Working Groups"; Russian mega-grant no. 11.G34.31.0048 (University of Nizhny Novgorod); Academy of Finland contracts 259537, 257411, and 254195; Beautiful Beijing (Finland-China collaboration project) funded by TEKES; Nordforsk CRAICC-PEEX (amendment to contract 26060); CRAICC-CRUCIAL (project no. 81257); Icelandic Research Fund (Rannis) grant no. 152248051; Danish Environmental Protection Agency with means from the Dancea fund for environmental support to the Arctic region (M 112 002700); the Villum Foundation; the Carlsberg Foundation (project 009_1_0515); COST1303 (TOPROF); COST ES1404 (HarmoSnow); and the Pan-Eurasian Experiment (PEEX). The development and use of NorESM1 was supported by the Norwegian Research Council through the projects EarthClim (207711/E10), EVA (grant no. 229771), NOTUR (nn2345k), and NorStore (ns2345k) and through the Nordic Centre of Excellence eSTICC (57001) and the EU H2020 project CRESCENDO (grant no. 641816). The CRAICC team also thanks Rogier Floors for providing Fig. 8 and Christoph Münkel for Fig. 9. The authors and entire CRAICC community would like to thank and acknowledge the work and inspiration of Jon Egill Kristjansson, whose life was cut short during these collaborations. Jon Egill Kristjansson is deeply missed, but his scientific legacy continues.

Edited by: Imre Salma

Reviewed by: two anonymous referees

\section{References}

Aalto J, Porcar-Castell, A., Atherton, J., Kolari, P., Pohja, T., Hari, P., Nikinmaa, E., Petäjä, T., and Bäck, J.: Onset of photosynthesis in spring speeds up monoterpene synthesis and leads to emission bursts, Plant Cell Environ., 38, 2299-2312, https://doi.org/10.1111/pce.12550, 2015.

Abdul-Razzak, H. and Ghan, S. J.: A parameterization of aerosol activation, Part 2: Multiple aerosol types, J. Geophys. Res., 105, 6837-6844, 2000.

Achtert, P., Brooks, I. M., Brooks, B. J., Moat, B. I., Prytherch, J., Persson, P. O. G., and Tjernström, M.: Measurement of wind profiles by motion-stabilised ship-borne Doppler lidar, Atmos.
Meas. Tech., 8, 4993-5007, https://doi.org/10.5194/amt-8-49932015, 2015.

Acosta Navarro, J. C., Varma, V., Riipinen, I., Seland, Ø., Kirkevåg, A., Struthers, H., Iversen, T., Hansson, H.-C., and Ekman, A. M. L.: Amplification of Arctic warming by past air pollution reductions in Europe, Nat. Geosci., 9, 277-281, 2016.

Acosta Navarro, J. C., Ekman, A. M. L., Pausata, F., Lewinschal, A., Varma, V., Seland, Ø., Gauss, M., Iversen, T, Kirkevåg, A., Riipinen, I., and Hansson, H.-C.: Future response of temperature and precipitation to reduced aerosol emissions as compared with increased greenhouse gas concentrations, J. Climate, 30, 939954, https://doi.org/10.1175/JCLI-D-16-0466.1, 2017.

Alekseychik, P., Lappalainen, H. K., Petäjä, T., Zaitseva, N., Heimann, H., Laurila, T., Lihavainen, H., Asmi, E., Arshinov, M., Shevchenko, V., Makshtas, A., Dubtsov, S., Mikhailov, E., Lapshina, E., Kirpotin, S., Kurbatova, Y., Ding, A., Guo, H., Park, S., Lavric, J. V., Reum, F., Panov, A., Prokushkin, A., and Kulmala, M.: Ground-based station network in Arctic and Subarctic Eurasia: an overview, J. Geogr. Environ. Sustain., 2, 75-88, 2016.

AMAP: The Impact of Black Carbon on Arctic Climate, Arctic Monitoring and Assessment Programme (AMAP), Oslo, Norway, 72 pp., 2011.

AMAP: AMAP Assessment 2015: Black carbon and ozone as Arctic climate forcers, Arctic Monitoring and Assessment Programme (AMAP), Oslo, Norway, vii + 116 pp., 2015.

AMAP: Snow, Water, Ice and Permafrost in the Arctic (SWIPA), Arctic Monitoring and Assessment Programme (AMAP), Oslo, Norway, xiv + 269 pp., 2017.

Andreae, M. O. and Gelencsér, A.: Black carbon or brown carbon? The nature of light-absorbing carbonaceous aerosols, Atmos. Chem. Phys., 6, 3131-3148, https://doi.org/10.5194/acp-63131-2006, 2006.

Aoki, T., Hachikubo, A., and Hori, M.: Effects of snow physical parameters on shortwave broadband albedos, J. Geophys. Res.-Atmos., 108, 4616, https://doi.org/10.1029/2003JD003506, 2003.

Argentini, S., Viola, A., Sempreviva A. M., and Petenko, I.: Summer Boundary-Layer Height at the Plateau Site of Dome C, Antarctica, Bound.-Lay. Meteorol., 115, 409-422, 2005.

Arnalds, O.: The Soils of Iceland, World Soils Book Series, Springer, Dordrecht, the Netherlands, 2015.

Arnalds, O., Thorarinsdottir, E. F., Thorsson, J., DagssonWaldhauserova, P., and Agustsdottir, A. M.: An extreme wind erosion event of the fresh Eyjafjallajokull 2010 volcanic ash, Nat. Scient. Rep., 3, 1257, https://doi.org/10.1038/srep01257, 2013.

Arnalds, O., Olafsson, H., and Dagsson-Waldhauserova, P.: Quantification of iron rich volcanogenic dust emissions and ocean deposition from Icelandic dust sources, Biogeosciences, 11, 66236632, https://doi.org/10.5194/bg-11-6623-2014, 2014.

Arnalds, O., Dagsson-Waldhauserova, P., and Olafsson, H.: The Icelandic volcanic aeolian environment: Processes and impacts - A review, Aeolian Res., 20, 176-195, 2016.

Arrhenius, S.: On the influence of carbonic acid in the air upon the temperature of the ground, Philos. Mag. J. Sci., 5, 237-276, 1896.

Atlaskina, K., Berninger, F., and de Leeuw, G.: Satellite observations of changes in snow-covered land surface albedo during spring in the Northern Hemisphere, The Cryosphere, 9, 18791893, https://doi.org/10.5194/tc-9-1879-2015, 2015. 
Bäck, J., Aalto, J., Henriksson, M., Hakola, H., He, Q., and Boy, M.: Chemodiversity of a Scots pine stand and implications for terpene air concentrations, Biogeosciences, 9, 689-702, https://doi.org/10.5194/bg-9-689-2012, 2012.

Baddock, M. C., Mockford, T., Bullard, J. E., and Thorsteinsson, T.: Pathways of high-latitude dust in the North Atlantic, Earth Planet. Sc. Lett., 459, 170-182, https://doi.org/10.1016/j.epsl.2016.11.034, 2017.

Batchvarova, E. and Gryning, S. E.: Applied model for the growth of the daytime mixed layer, Bound.-Lay. Meteorol., 56, 261-274, 1991.

Batchvarova, E., Gryning, S. E., Skov, H., Sørensen L. L., Kirova, H., and Münkel, C.: Boundary-Layer and Air Quality Study at "Station Nord" in Greenland, Air Pollution Modeling and its Application XXIII, edited by: Steyn, D. and Mathur, R., Springer Proceedings in Complexity, Springer International Publishing, Switzerland, 525-529, 2014.

Bekryaev, R., Polyakov, I., and Alexeev, V.: Role of Polar Amplification in Long-Term Surface Air Temperature Variations and Modern Arctic Warming, J. Climate, 23, 3888-3906, 2010.

Bentsen, M., Bethke, I., Debernard, J. B., Iversen, T., Kirkevåg, A., Seland, Ø., Drange, H., Roelandt, C., Seierstad, I. A., Hoose, C., and Kristjánsson, J. E.: The Norwegian Earth System Model, NorESM1-M - Part 1: Description and basic evaluation of the physical climate, Geosci. Model Dev., 6, 687-720, https://doi.org/10.5194/gmd-6-687-2013, 2013.

Birch, M. E. and Cary, R. A.: Elemental carbon-based method for monitoring occupational exposures, to particulate diesel exhaust, Aerosol. Sci. Tech., 25, 221-241, 1996.

Bisiaux, M. M., Edwards, R., McConnell, J. R., Albert, M. R., Anschütz, H., Neumann, T. A., Isaksson, E., and Penner, J. E.: Variability of black carbon deposition to the East Antarctic Plateau, 1800-2000 AD, Atmos. Chem. Phys., 12, 3799-3808, https://doi.org/10.5194/acp-12-3799-2012, 2012a.

Bisiaux, M. M., Edwards, R., McConnell, J. R., Curran, M. A. J., Van Ommen, T. D., Smith, A. M., Neumann, T. A., Pasteris, D. R., Penner, J. E., and Taylor, K.: Changes in black carbon deposition to Antarctica from two high-resolution ice core records, 1850-2000 AD, Atmos. Chem. Phys., 12, 4107-4115, https://doi.org/10.5194/acp-12-4107-2012, 2012b.

Björnsson, H.: The Glaciers of Iceland. A historical, cultural and scientific overview, in: Atlantis Advances in Quaternary Science, Springer, 613 pp., 2016.

Bond, T. C., Doherty, S. J., Fahey, D. W., Forster, P. M., Berntsen, T., DeAngelo, B. J., Flanner, M. G., Ghan, S., Kärcher, B., Koch, D., Kinne, S., Kondo, Y., Quinn, P. K., Sarofim, M. F., Schultz, M. G., Schulz, M., Venkataraman, C., Zhang, H., Zhang, S., Bellouin, N., Guttikunda, S. K., Hopke, P. K., Jacobson, M. Z., Kaiser, J. W., Klimont, Z., Lohmann, U., Schwarz, J. P., Shindell, D., Storelvmo, T., Warren, S. G., and Zender, C. S.: Bounding the role of black carbon in the climate system: A scientific assessment, J. Geophys. Res.-Atmos., 188, 5380-5552, 2013.

Brasseur, Z., Wu, Y., Castarède, D., Ahonen, L., Thomson, E. S., Kulmala, M., Petäjä, T., and Duplissy, J.: Development and operation of the ice nucleation chamber PINCII during the ice nucleation campaign held in Hyytiälä, Finland, in: The Centre of Excellence in Atmospheric Science - From Molecular and Biological processes to The Global Climate Annual Seminar, 2729 November 2018, Kuopio, Finland, 2018.
Browse, J., Carslaw, K. S., Mann, G. W., Birch, C. E., Arnold, S. R., and Leck, C.: The complex response of Arctic aerosol to sea-ice retreat, Atmos. Chem. Phys., 14, 7543-7557, https://doi.org/10.5194/acp-14-7543-2014, 2014.

Bullard, J. E., Baddock, M., Bradwell, T., Crusius, J., Darlington, E., Gaiero, D., Gassó, S., Gisladottir, G., Hodgkins, R., McCulloch, R., Neuman, C. M., Mockford, T., Stewart, H., and Thorsteinsson, T.: High latitude dust in the earth system, Rev. Geophys., 54, 447-485, https://doi.org/10.1002/2016RG000518, 2016.

Burgemeister, S., Ritter, C., Maturilli, M., Neuber, R., and Schulz, A.: WindLIDAR measurements in the Arctic boundar layer, in: Ny-Ålesund Science managers Committee 11th Seminar, 911 October 2013, National Research Council, Rome, Italy, p. 34, available at: http://issuu.com/cnr-dta/docs/nysmac_11abstracts (last access: 4 February 2019), 2013.

Castarède, D. and Thomson, E. S.: A thermodynamic description for the hygroscopic growth of atmospheric aerosol particles, Atmos. Chem. Phys., 18, 14939-14948, https://doi.org/10.5194/acp-18-14939-2018, 2018.

Castarède, D., Brasseur, Z., Wu, Y., Duplissy, J., and Thomson, E. T.: Updating the Zurich Portable Ice Nucleation Chamber, in preparation, 2019.

Cavalli, F., Viana, M., Yttri, K. E., Genberg, J., and Putaud, J.-P.: Toward a standardised thermal-optical protocol for measuring atmospheric organic and elemental carbon: the EUSAAR protocol, Atmos. Meas. Tech., 3, 79-89, https://doi.org/10.5194/amt-3-792010, 2010.

Chappellaz, J. A., Fung, I. Y., and Thompson, A. M.: Atmospheric $\mathrm{CH}_{4}$ increase since the Last Glacial Maximum: 1. Source Estimates, Tellus B, 45, 228-241, 1993.

Cohen, J., Screen, J. A., Furtado, J. C., Barlow, M., Whittleston, D., Coumou, D., Francis, J., Dethloff, K., Entekhabi, D., Overland, J., and Jones, J.: Recent Arctic amplification and extreme midlatitude weather, Nat. Geosci., 7, 627-637, 2014.

Cole, J. J., Caraco, N. F., Kling, G. W., and Kratz, T. K.: Carbondioxide in the surface waters of lakes, Science, 265, 1568-1570, 1994.

Cuxart, J., Bougeault, P., and Redelsperger, J.-L. : A turbulence scheme allowing for mesoscale and large-eddy simulations, Q. J. Roy. Meteorol. Soc., 126, 1-30, 2000.

Dagsson-Waldhauserova, P., Arnalds, O., and Olafsson, H.: Longterm frequency and characteristics of dust storm events in Northeast Iceland (1949-2011), Atmos. Environ., 77, 117-127, 2013.

Dagsson-Waldhauserova, P., Arnalds, O., and Olafsson, H.: Longterm variability of dust events in Iceland, Atmos. Chem. Phys., 14, 13411-13422, https://doi.org/10.5194/acp-14-13411-2014, 2014a.

Dagsson-Waldhauserova, P., Arnalds, O., Olafsson, H., Skrabalova, L., Sigurdardottir, G. M., Branis, M., Hladil, J., Skala, R., Navratil, T., Chadimova, L., von Lowis of Menar, S., Thorsteinsson, T., Carlsen, H. K., and Jonsdottir, I.: Physical properties of suspended dust during moist and low-wind conditions in Iceland, Iceland. Agricult. Sci., 27, 25-39, 2014 b.

Dagsson-Waldhauserova, P., Arnalds, O., Olafsson, H., Hladil, J., Skala, R., Navratil, T., Chadimova, L., and Meinander, O.: Snowdust storm: A case study from Iceland, March 7th 2013, Aeolian Res., 16, 69-74, 2015. 
Dagsson-Waldhauserova, P., Magnusdottir, A. Ö., Olafsson, H., and Arnalds, O.: The spatial variation of dust particulate matter concentrations during two Icelandic dust storms in 2015, Atmosphere, 7, 77-88, 2016.

Decesari, S., Facchini, M. C., Fuzzi, S., and Tagliavini, E.: Characterization of water-soluble organic compounds in atmospheric aerosol: A new approach, J. Geophys. Res., 105, 1481-1489, https://doi.org/10.1029/1999JD900950, 2000.

Dee, D. P., Uppala, S. M., Simmons, A. J., Berrisford, P., Poli, P., Kobayashi, S., Andrae, U., Balmaseda, M. A., Balsamo, G., Bauer, P., Bechtold, P., Beljaars, A. C. M., van de Berg, L., Bidlot, J., Bormann, N., Delsol, C., Dragani, R., Fuentes, M., Geer, A. J., Haimberger, L., Healy, S. B., Hersbach, H., Hólm, E. V., Isaksen, L., Kållberg, P., Köhler, M., Matricardi, M., McNally, A. P., Monge-Sanz, B. M., Morcrette, J.-J., Park, B.-K., Peubey, C., de Rosnay, P., Tavolato, C., Thépaut, J.-N., and Vitart, F.: The ERA-interim reanalysis: configuration and performance of the data assimilation system, Q. J. Roy. Meteorol. Soc., 137, 553597, 2011

de Leeuw, G., Andreas, E. L., Anguelova, M. D., Fairall, C. W., Lewis, E. R., O'Dowd, C., Schulz, M., and Schwartz, S. E.: Production flux of sea spray aerosol, Rev. Geophys., 49, RG2001, https://doi.org/10.1029/2010RG000349, 2011.

Denfeld, B., Wallin, M. B., Sahlée, E., Sobek, S., Kovic, J., Chmiel, H. E., and Weyhenmeyer, G. A.: Temporal and spatial carbon dioxide concentration patterns in a small boreal lake in relation to ice cover dynamics, Boreal Environ. Res., 20, 679-692, 2015.

Denfeld, B., Kortelainen, P., Rantakari, M., Sobek, S., and Weyhenmeyer, G. A.: Regional variability and drivers of below ice $\mathrm{CO}_{2}$ in boreal and subarctic lakes, Ecosystems 19, 461-476, $2016 \mathrm{a}$.

Denfeld, B., Ricão Canelhas, A., Weyhenmeyer, G. A., Bertilsson, S., Eiler, A., and Bastviken, D.: Constrains on methane oxidation in ice-covered boreal lakes, J. Geophys. Res.-Biogeo., 121, 1924-1933, 2016b.

Di Liberto, L., Angelini, F., Pietroni, I., Cairo, F., Di Donfrancesco, G., Viola, A., Argentine, S., Fierli, F., Gobbi, G., Maturilli, M., Neuber, R., and Snels M.: Estimate of the Arctic Convective Boundary Layer Height from Lidar Observations: A Case Study, Hindawi Publishing Corporation, Adv. Meteorol., 2012, 851927, https://doi.org/10.1155/2012/851927, 2012.

DMI: Danmarks Meteorologiske Institute, available at: http://www. dmi.dk/vejr/ (last access: 4 February 2019), 2018.

Doherty, S. J., Warren, S. G., Grenfell, T. C., Clarke, A. D., and Brandt, R. E.: Light-absorbing impurities in Arctic snow, Atmos. Chem. Phys., 10, 11647-11680, https://doi.org/10.5194/acp-1011647-2010, 2010.

Domine, F., Salvatori, R., Legagneux, L., Salzano, R., Fily, M., and Casacchia, R.: Correlation between the specific surface area and the short wave infrared (SWIR) reflectance of snow, Cold Reg. Sci. Technol., 46, 60-68, 2006.

Dowdeswella, J. A., Hagen, J. O., Björnsson, H., Glazovsky, A. F., Harrison, W. D., Holmlund, P., Jania, J., Koerner, R. M., Lefauconnier, B., Ommanney, C. S. L., and Thomas, R. H.: The mass balance of Circum-Arctic glaciers and recent climate change, Quaternary Res., 48, 1-14, 1997.

Dragosics, M., Meinander, O., Jónsdóttir, T., Dürig, T., de Leeuw, G., Pálsson, F., Dagsson-Waldhauserová, P., and Thorsteinsson, T.: Insulation effects of Icelandic dust and volcanic ash on snow and ice, Arab. J. Geosci., 9, 126, https://doi.org/10.1007/s12517015-2224-6, 2016.

Dymarska, M., Murray, B. J., Sun, L., Eastwood, M. L., Knopf, D. A., and Bertram, A. K.: Deposition ice nucleation on soot at temperatures relevant for the lower troposphere, J. Geophys. Res.Atmos., 111, D04204, https://doi.org/10.1029/2005JD006627, 2006.

Ehn, M., Junninen, H., Petäjä, T., Kurtén, T., Kerminen, V.-M., Schobesberger, S., Manninen, H. E., Ortega, I. K., Vehkamäki, H., Kulmala, M., and Worsnop, D. R.: Composition and temporal behavior of ambient ions in the boreal forest, Atmos. Chem. Phys., 10, 8513-8530, https://doi.org/10.5194/acp-108513-2010, 2010.

Ehn, M., Thornton, J. A., Kleist, E., Sipilä, M., Junninen, H., Pullinen, I., Springer, M., Rubach, F., Tillmann, R., Lee, B., Lopez-Hilfiker, F., Andres, S., Acir, I.-H., Rissanen, M., Jokinen, T., Schobesberger, S., Kangasluoma, J., Kontkanen, J., Nieminen, T., Kurtén, T., Nielsen, L. B., Jørgensen, S., Kjaergaard, H. G., Canagaratna, M., Dal Maso, M., Berndt, T., Petäjä, T., Wahner, A., Kerminen, V.-M., Kulmala, M., Worsnop, D. R., Wildt, J., and Mentel, T. F.: A large source of lowvolatility secondary organic aerosol, Nature, 506, 476-479, https://doi.org/10.1038/nature13032, 2014.

Eisenmann, I. and Wettlaufer, J. S.: Nonlinear threshold behavior during the loss of Arctic sea ice, P. Natl. Acad. Sci. USA, 106, 28-32, 2009.

Eldering, A., Wennberg, P. O., Crisp, D., Schimel, D. S., Gunson, M. R., Chatterjee, A., Liu, J., Schwandner, F. M., Sun, Y., O’Dell, C. W., Frankenberg, D., Taylor, T., Fisher, B., Osterman, G. B., Wunch, D., Hakkarainen, J., Tamminen, J., and Weir, B.: The Orbiting Carbon Observatory-2 early science investigations of regional carbon dioxide fluxes, Science, 363, 6426, https://doi.org/10.1126/science.aam5745, 2017.

Eleftheriadis, K., Vratolis, S., and Nyeki, S.: Aerosol black carbon in the European Arctic: Measurements at Zeppelin station, Ny-Ålesund, Svalbard from 1998-2007, Geophys. Res. Lett., 36, L02809, https://doi.org/10.1029/2008GL035741, 2009.

Elmendorf, S. C., Henry, G. H. R., Hollister, R. D., Björk, R. G., Boulanger-Lapointe, N., Cooper, E. J., Cornelissen, J. H. C., Day, T. A., Dorrepaal, E,., Elumeeva, T. G., Gill, M., Gould, W. A., Harte, J., Hik, D. S., Hofgaard, A., Johnson, D. R., Johnstone, J. F., Jónsdóttir, I. S., Jorgenson, J. C., Klanderud, K., Klein, J. A., Koh, S., Kudo, G., Lara, M., Lévesque, E., Magnússon, B., May, J. L., Mercado-Díaz, J. A., Michelsen, A Molau, U., Myers-Smith, I. H., Oberbauer, S. F., Onipchenko, V. G., Rixen, C., Schmidt, N. M., Shaver, G. R., Spasojevic, M. J., Pórhallsdóttir, P. E., Tolvanen, A., Troxler, T., Tweedie, C. E., Villareal, S., Wahren, C.-H., Walker, X., Webber, P. J., Welker, J. M., and Wipf, S.: Plot-scale evidence of tundra vegetation change and links to recent summer warming, Nat. Clim. Change, 2, 453-457, https://doi.org/10.1038/NCLIMATE1465, 2012.

Elmquist, M., Cornelissen, G., Kukulska, Z., and Gustafsson, Ö.: Distinct oxidative stabilities of char versus soot black carbon: Implications for quantification and environmental recalcitrance, Global Biogeochem. Cy., 20, GB2009, https://doi.org/10.1029/2005GB002629, 2006.

Facchini, M. C., Mircea, M., Fuzzi, S., and Charlson, R. J.: Cloud albedo enhancement by surface-active organic solutes in growing droplets, Nature, 401, 257-259, 1999. 
Fang, K., Morris, J.L., Salonen, J. S., Miller, P. A., Renssen, H., Sykes, M. T., and Seppä, H.: How robust are the Holocene treeline simulations? A model-data comparison in the European Arctic treeline region, J. Quaternary Sci., 28, 595-604, https://doi.org/10.1002/jqs.2654, 2013.

Fang, K., Makkonen, R., Guo, Z., Zhao, Y., and Seppä, H.: An increase in the biogenic aerosol concentration as a contributing factor to the recent wetting trend in Tibetan Plateau, Scient. Rep., 5, 14628, https://doi.org/10.1038/srep14628, 2015.

Faubert, P., Tiiva, P., Rinnan, A., Michelsen, A., Holopainen, J. K., and Rinnan, R.: Doubled volatile organic compound emissions from subarctic tundra under simulated climate warming, New Phytol., 187, 199-208, 2010.

Faust, J. A., Junninen, H., Ehn, M., Chen, X., Ruusuvuori, K., Kieloaho, A.-J., Bäck, J., Ojala, A., Jokinen, T., Worsnop, D. R., Kulmala, M., and Petäjä, T.: Real-Time Detection of Arsenic Cations from Ambient Air in Boreal Forest and Lake Environments, Environ. Sci. Technol. Lett., 3, 42-46, https://doi.org/10.1021/acs.estlett.5b00308, 2016.

Fenger, M., Sorensen, L. L., Kristensen, K., Jensen, B., Nguyen, Q. T., Nojgaard, J. K., Massling, A., Skov, H., Becker, T., and Glasius, M.: Sources of anions in aerosols in northeast Greenland during late winter, Atmos. Chem. Phys., 13, 1569-1578, https://doi.org/10.5194/acp-13-1569-2013, 2013.

Flanner, M. G.: Arctic climate sensitivity to local black carbon, J. Geophys. Res., 118, 1840-1851, 2013.

Flanner, M. G. and Zender, C. S.: Linking snowpack microphysics and albedo evolution, J. Geophys. Res.-Atmos., 111, D12208, https://doi.org/10.1029/2005JD006834, 2006.

Flanner, M. G., Zender, C. S., Randerson, J. T., and Rasch, P. J.: Present day climate forcing and response from black carbon in snow, J. Geophys. Res., 112, D11202, https://doi.org/10.1029/2006JD008003, 2007.

Flanner, M. G., Zender, C. S., Hess, P. G., Mahowald, N. M., Painter, T. H., Ramanathan, V., and Rasch, P. J.: Springtime warming and reduced snow cover from carbonaceous particles, Atmos. Chem. Phys., 9, 2481-2497, https://doi.org/10.5194/acp9-2481-2009, 2009.

Friedman, B., Kulkarni, G., Beránek, J., Zelenyuk, A., Thornton, J. A., and Cziczo, D. J.: Ice nucleation and droplet formation by bare and coated soot particles, J. Geophys. Res.-Atmos., 116, D17203, https://doi.org/10.1029/2011JD015999, 2011.

Fuglestvedt, J. S., Dalsøren, S. B., Samset, B. H., Berntsen, T., Myhre, G., Hodnebrog, Ø., Eide, M. S., and Bergh, T. F.: Climate penalty for shifting shipping to the Arctic, Environ. Sci. Technol., 48, 13273-13279, 2014.

Garimella, S., Kristensen, T. B., Ignatius, K., Welti, A., Voigtländer, J., Kulkarni, G. R., Sagan, F., Kok, G. L., Dorsey, J., Nichman, L., Rothenberg, D. A., Rösch, M., Kirchgäßner, A. C. R., Ladkin, R., Wex, H., Wilson, T. W., Ladino, L. A., Abbatt, J. P. D., Stetzer, O., Lohmann, U., Stratmann, F., and Cziczo, D. J.: The SPectrometer for Ice Nuclei (SPIN): an instrument to investigate ice nucleation, Atmos. Meas. Tech., 9, 2781-2795, https://doi.org/10.5194/amt-9-2781-2016, 2016.

Gent, P. R., Danabasoglu, G., Donner, L. J., Holland, M. M., Hunke, E. C., Jayne, S. R., Lawrence, D. M., Neale, R. B., Rasch, P. J., Vertenstein, M., Worley, P. H., Yang, Z.-L., and Zhang, M.: The Community Climate System Model Version 4, J. Climate, 24, 4973-4991, 2011.
Georgsdóttir, G. I.: Sandfok á Íslandi 2002-2011, Tíðni, upptakasvæði og veðuraðstæður (Dust storms in Iceland 20022011), MS Thesis, University of Iceland, Reykjavik, 2012.

Gisladottir, F. O., Brink, S. H., and Arnalds, O.: Nytjaland (Icelandic Farmland Database), Report 54, Agricultural University of Iceland, Reykjavik, 2014.

Glantz, P., Bourassa, A. E., Herber, A., Iversen, T., Karlsson, J., Kirkevåg, A., Maturilli, M., Seland, Ø., Stebel, K., Struthers, H., Tesche, M., and Thomason, L.: Remote sensing of aerosols in the Arctic for an evaluation of global climate model simulations, J. Geophys. Res.-Atmos., 119, 8169-8188, 2013.

Glasius, M. and Goldstein, A. H.: Recent Discoveries and Future Challenges in Atmospheric Organic Chemistry, Environ. Sci. Technol., 50, 2754-2764, https://doi.org/10.1021/acs.est.5b05105, 2016.

Glasius, M., Hansen, A. M. K., Claeys, M., Henzing, J. S., Jedynska, A. D., Kasper-Giebl, A., Kistler, M., Kristensen, K., Martinsson, J., Maenhaut, W., Nøjgaard, J. K., Spindler, G., Stenström, K. E., Swietlicki, E., Szidat, S., Simpson, D., and Yttri, K. E.: Composition and sources of carbonaceous aerosols in Northern Europe during winter, Atmos. Environ., 173, 127-141, 2018.

Goldstein, A. H. and Galbally, I. E.: Known and Unexplored Organic Constituents in the Earth's Atmosphere, Environ. Sci. Technol., 41, 1514-1521, 2007.

Granier, C., Bessagnet, B., Bond, T., D’Angiola, A., van der Gon, H. D., Frost, G. J., Heil, A., Kaiser, J. W., Kinne, S., Klimont, Z., Kloster, S., Lamarque, J.-F., Liousse, C., Masui, T., Meleux, F., Mieville, A., Ohara, T., Raut, J.-C., Riahi, K. Schultz, M. G., Smith, S. J., Thompson, A., van Aardenne, J., van der Werf, G. R., and van Vuuren, D. P.: Evolution of anthropogenic and biomass burning emissions of air pollutants at global and regional scales during the 1980-2010 period, Climatic Change, 109, 163-190, 2011.

Graus, M., Müller, M., and Hansel, A.: High resolution PTR-TOF: quantification and formula confirmation of VOC in real time, $\mathrm{J}$. Am. Soc. Mass Spectrom., 21, 1037-1044, 2010.

Groot Zwaaftink, C. D., Grythe, H., Skov, H., and Stohl, A.: Substantial contribution of northern high-latitude sources to mineral dust in the Arctic, J. Geophys. Res.-Atmos., 121, 13678-13697, https://doi.org/10.1002/2016JD025482, 2016.

Groot Zwaaftink, C. D., Arnalds, Ó., Dagsson-Waldhauserova, P., Eckhardt, S., Prospero, J. M., and Stohl, A.: Temporal and spatial variability of Icelandic dust emissions and atmospheric transport, Atmos. Chem. Phys., 17, 10865-10878, https://doi.org/10.5194/acp-17-10865-2017, 2017.

Gryning, S. E., Larsen, S., and Mahrt, L.: Oscillating Nocturnal Slope Flow in a Coastal Valley, Tellus A, 37, 196-203, 1985.

Gustafsson, Ö., Haghseta, F., Chan, C., Macfarlane, J., and Gschwend, P. M.: Quantification of the dilute sedimentary soot phase: Implications for PAH speciation and bioavailability, Environ. Sci. Technol., 31, 203-209, 1997.

Gustafsson, Ö., Bucheli, T. D., Kukulska, Z., Andersson, M., Largeau, C., Rounzaud, J.-N., Reddy, C. M., and Eglinton, T. I.: Evaluation of a protocol for the quantification of black carbon in sediments, Global Biogeochem. Cy., 15, 881-890, 2001.

Hadley, O. and Kirchstetter, T.: Black-carbon reduction of snow albedo, Nat. Clim. Change, 2, 437-440, https://doi.org/10.1038/nclimate1433, 2012. 
Hakkarainen, J., Ialongom I., and Tamminen, J.: Direct spacebased observations of anthropogenic $\mathrm{CO}_{2}$ emission areas from OCO-2, Geophys. Res. Lett., 43, 11400-11406, https://doi.org/10.1002/2016GL070885, 2016.

Hall, D. K., Riggs, G. A., Salomonson, V. V., DiGirolamo, N. E., and Bayr, K. J.: MODIS snow-cover products, Remote Sens. Environ., 83, 181-194, 2002.

Hammes, K., Schmidt, M. W. I., Smernik, R. J., Currie, L. A., Ball, W. P., Nguyen, T. H., Louchouarn, P., Houel, S., Gustafsson, Ö., Elmquist, M., Cornelissen, G., Skjemstad, J. O., Masiello, C. A., Song, J., Peng, P., Mitra, S., Dunn, J. C., Hatcher, P. G., Hockaday, W. C., Smith, D. M., Hartkopf-Fröder, C., Böhmer, A., Lüer, B., Huebert, B. J., Amelung, W., Brodowski, S., Huang, L., Zhang, W., Gschwend, P. M., Flores-Cervantes, D. X., Largeau, C., Rouzaud, J.-N., Rumpel, C., Guggenberger, G., Kaiser, K., Rodionov, A., Gonzalez-Vila, F. J., GonzalezPerez, J. A., de la Rosa, J. M., Manning, D. A. C., LópezCapél, E., and Ding, L.: Comparison of quantification methods to measure fire-derived (black/elemental) carbon in soils and sediments using reference materials from soil, water, sediment and the atmosphere, Global Biogeochem. Cy., 21, GB3016, https://doi.org/10.1029/2006GB002914, 2007.

Hansen, A. M. K., Kristensen, K., Nguyen, Q. T., Zare, A., Cozzi, F., Nøjgaard, J. K., Skov, H., Brandt, J., Christensen, J. H., Ström, J., Tunved, P., Krejci, R., and Glasius, M.: Organosulfates and organic acids in Arctic aerosols: speciation, annual variation and concentration levels, Atmos. Chem. Phys., 14, 7807-7823, https://doi.org/10.5194/acp-14-7807-2014, 2014.

Hansen, A. M. K., Hong, J., Raatikainen, T., Kristensen, K., Ylisirniö, A., Virtanen, A., Petäjä, T., Glasius, M., and Prisle, N. L.: Hygroscopic properties and cloud condensation nuclei activation of limonene-derived organosulfates and their mixtures with ammonium sulfate, Atmos. Chem. Phys., 15, 14071-14089, https://doi.org/10.5194/acp-15-14071-2015, 2015.

Hari, P., Petäjä, T., Bäck, J., Kerminen, V.-M., Lappalainen, H. K., Vihma, T., Laurila, T., Viisanen, Y., Vesala, T., and Kulmala, M.: Conceptual design of a measurement network of the global change, Atmos. Chem. Phys., 16, 1017-1028, https://doi.org/10.5194/acp-16-1017-2016, 2016.

Hermansson, E., Roldin, P., Rusanen, A., Mogensen, D., Kivekäs, N., Väänänen, R., Boy, M., and Swietlicki, E.: Biogenic SOA formation through gas-phase oxidation and gas-to-particle partitioning - a comparison between process models of varying complexity, Atmos. Chem. Phys., 14, 11853-11869, https://doi.org/10.5194/acp-14-11853-2014, 2014.

Hickler, T., Vohland, K., Feehan, J., Miller, P. A., Smith, B., Costa, L., Giesecke, T., Fronzek, S., Carter, T. R., and Cramer, W.: Projecting the future distribution of European potential natural vegetation zones with a generalized, tree species-based dynamic vegetation model, Global Ecol. Biogeogr., 21, 50-63, 2012.

Hicks, S.: When no pollen does not mean no trees, Veg. Hist. Archaeobot., 15, 253-261, 2006.

Hirdman, D., Sodemann, H., Eckhardt, S., Burkhart, J. F., Jefferson, A., Mefford, T., Quinn, P. K., Sharma, S., Ström, J., and Stohl, A.: Source identification of short-lived air pollutants in the Arctic using statistical analysis of measurement data and particle dispersion model output, Atmos. Chem. Phys., 10, 669-693, https://doi.org/10.5194/acp-10-669-2010, 2010.
Hong, J., Häkkinen, S. A. K., Paramonov, M., Äijälä, M., Hakala, J., Nieminen, T., Mikkilä, J., Prisle, N. L., Kulmala, M., Riipinen, I., Bilde, M., Kerminen, V.-M., and Petäjä, T.: Hygroscopicity, $\mathrm{CCN}$ and volatility properties of submicron atmospheric aerosol in a boreal forest environment during the summer of 2010, Atmos. Chem. Phys., 14, 4733-4748, https://doi.org/10.5194/acp14-4733-2014, 2014.

Horn, H., Bonka, H., and Maqua, M.: Measured particle bound activity size-distribution, deposition velocity, and activity concentration in rainwater after the Chernobyl accident, J. Aerosol Sci., 18, 681-684, 1987.

Hoyle, C. R., Boy, M., Donahue, N. M., Fry, J. L., Glasius, M., Guenther, A., Hallar, A. G., Huff Hartz, K., Petters, M. D., Petäjä, T., Rosenoern, T., and Sullivan, A. P.: A review of the anthropogenic influence on biogenic secondary organic aerosol, Atmos. Chem. Phys., 11, 321-343, https://doi.org/10.5194/acp-11-3212011, 2011.

Hudson, S. R.: Estimating the global radiative impact of the sea ice-albedo feedback in the Arctic, J. Geophys. Res.-Atmos., 116, D16102, https://doi.org/10.1029/2011JD015804, 2011.

Huijnen, V., Eskes, H. J., Poupkou, A., Elbern, H., Boersma, K. F., Foret, G., Sofiev, M., Valdebenito, A., Flemming, J., Stein, O., Gross, A., Robertson, L., D’Isidoro, M., Kioutsioukis, I., Friese, E., Amstrup, B., Bergstrom, R., Strunk, A., Vira, J., Zyryanov, D., Maurizi, A., Melas, D., Peuch, V.-H., and Zerefos, C.: Comparison of $\mathrm{OMI} \mathrm{NO}_{2}$ tropospheric columns with an ensemble of global and European regional air quality models, Atmos. Chem. Phys., 10, 3273-3296, https://doi.org/10.5194/acp10-3273-2010, 2010.

Humborg, C., Mörth, C.-M., Sundbom, M., Borg, H., Blenckner, T., Giesler, R., and Ittekkot, V.: $\mathrm{CO}_{2}$ supersaturation along the aquatic conduit in Swedish watersheds as constrained by terrestrial respiration, aquatic respiration and weathering, Global Change Biol., 16, 1966-1978, 2010.

Iinuma, Y., Muller, C., Berndt, T., Boge, O., Claeys, M., and Herrmann, H.: Evidence for the existence of organosulfates from beta-pinene ozonolysis in ambient secondary organic aerosol, Environ. Sci. Technol., 41, 6678-6683, https://doi.org/10.1021/es070938t, 2007.

IPCC: Climate Change 2013: The Physical Science Basis, in: Contribution of Working Group I to the Fifth Assessment Report of the Intergovernmental Panel on Climate Change, edited by: Stocker, T. F., Qin, D., Plattner, G.-K., Tignor, M., Allen, S. K., Boschung, J., Nauels, A., Xia, Y., Bex, V., and Midgley, P. M., Cambridge University Press, Cambridge, UK and New York, NY, USA, 1535 pp., https://doi.org/10.1017/CBO9781107415324, 2013.

Istomina, L. G., von Hoyningen-Huene, W., Kokhanovsky, A. A., and Burrows, J. P.: The detection of cloud-free snow-covered areas using AATSR measurements, Atmos. Meas. Tech., 3, 10051017, https://doi.org/10.5194/amt-3-1005-2010, 2010.

Iversen, T., Bentsen, M., Bethke, I., Debernard, J. B., Kirkevåg, A., Seland, Ø., Drange, H., Kristjansson, J. E., Medhaug, I., Sand, M., and Seierstad, I. A.: The Norwegian Earth System Model, NorESM1-M - Part 2: Climate response and scenario projections, Geosci. Model Dev., 6, 389-415, https://doi.org/10.5194/gmd-6-389-2013, 2013.

Jenkin, M. E., Saunders, S. M., and Pilling, M. J.: The tropospheric degradation of volatile organic compounds: a proto- 
col for mechanism development, Atmos. Environ., 31, 81-104, https://doi.org/10.1016/S1352-2310(96)00105-7, 1997.

Jiao, C., Flanner, M. G., Balkanski, Y., Bauer, S. E., Bellouin, N., Berntsen, T. K., Bian, H., Carslaw, K. S., Chin, M., De Luca, N., Diehl, T., Ghan, S. J., Iversen, T., Kirkevåg, A., Koch, D., Liu, X., Mann, G. W., Penner, J. E., Pitari, G., Schulz, M., Seland, Ø., Skeie, R. B., Steenrod, S. D., Stier, P., Takemura, T., Tsigaridis, K., van Noije, T., Yun, Y., and Zhang, K.: An AeroCom assessment of black carbon in Arctic snow and sea ice, Atmos. Chem. Phys., 14, 2399-2417, https://doi.org/10.5194/acp14-2399-2014, 2014.

Johannessen, O. M., Bobylev, L., Pettersson, L., Sandven, S., and Shalina, E.: Sea ice in the Arctic: past, present and future, Springer-Praxis, in press, 2019.

Johansson, S. M., Kong, X., Thomson, E. S., Hallquist, M., and Pettersson, J. B. C.: The Dynamics and Kinetics of Water Interactions with a Condensed Nopinone Surface, J. Phys. Chem. A, 121, 6614-6619, https://doi.org/10.1021/acs.jpca.7b06263, 2017.

Jokinen, T., Sipilä, M., Junninen, H., Ehn, M., Lönn, G., Hakala, J., Petäjä, T., Mauldin III, R. L., Kulmala, M., and Worsnop, D. R.: Atmospheric sulphuric acid and neutral cluster measurements using CI-APi-TOF, Atmos. Chem. Phys., 12, 4117-4125, https://doi.org/10.5194/acp-12-4117-2012, 2012.

Jónsdóttir, I.: Drivis ved kysten av Island i det 20. Arhundre, in: AMS-Varia 24: Kilder for klimadata í Norden, fortrinnsvis i perioden 1860-1993, edited by: Selsing, L., Arkeologisk Museum i Stavanger, Stavanger, 1995.

Jónsdóttir, I. and Sveinbjörnsson, E.: Recent variations in sea-ice extent off Iceland. Jökull, Iceland. J. Earth Sci., 57, 61-70, 2007.

Junninen, H., Lauri, A., Keronen, P., Aalto, P., Hiltunen, V., Hari, P., and Kulmala, M.: Smart-SMEAR: on-line data exploration and visualization tool for SMEAR stations, Boreal Environ. Res., 14, 447-457, 2009.

Junninen, H., Ehn, M., Petäjä, T., Luosujärvi, L., Kotiaho, T., Kostiainen, R., Rohner, U., Gonin, M., Fuhrer, K., Kulmala, M., and Worsnop, D. R.: A high-resolution mass spectrometer to measure atmospheric ion composition, Atmos. Meas. Tech., 3, 10391053, https://doi.org/10.5194/amt-3-1039-2010, 2010.

Jylhä, K.: Empirical scavenging coefficients of radioactive substances released from Chernobyl, Atmos. Environ. A, 25, 263270, 1991.

Kaspari, S. D., Schwikowski, M., Gysel, M., Flanner, M. G., Kang, S., Hou, S., and Mayewski, P. A.: Recent increase in black carbon concentrations from a Mt. Everest ice core spanning 1860-2000 AD, Geophys. Res. Lett., 38, L04703, https://doi.org/10.1029/2010GL046096, 2011.

Kasurinen, V., Alfredsen, K., Ojala, A., Pumpanen, J., Weyhenmeyer, G. A., Futter, F. N., Laudon, H., and Berninger, F.: Modeling nonlinear responses of DOC transport in boreal catchments in Sweden, Water Resour. Res., 52, 4970-4989, https://doi.org/10.1002/2015WR018343, 2016.

Keegan, K. M., Albert, M. R., McConnell, J. R., and Baker, I.: Climate change and forest fires synergistically drive widespread melt events of the Greenland Ice Sheet, P. Natl. Acad. Sci. USA, 111, 7964-7967, https://doi.org/10.1073/pnas.1405397111, 2014.

King, J. C., Argentini, S., and Anderson, P. S.: Contrasts between the summertime surface energy balance and boundary layer structure at Dome C and Halley stations, Antarctica, J. Geophys. Res., 111, D02105, https://doi.org/10.1029/2005JD006130, 2006.

King, S. M., Butcher, A. C., Rosenoern, T., Coz, E., Lieke, K. I., de Leeuw, G., Nilsson, E. D., and Bilde, M.: Investigating Primary Marine Aerosol Properties: CCN Activity of Sea Salt and Mixed Inorganic-Organic Particles, Environ. Sci. Technol., 46, 10405-10412, 2012.

Kipling, Z., Stier, P., Johnson, C. E., Mann, G. W., Bellouin, N., Bauer, S. E., Bergman, T., Chin, M., Diehl, T., Ghan, S. J., Iversen, T., Kirkevåg, A., Kokkola, H., Liu, X., Luo, G., van Noije, T., Pringle, K. J., von Salzen, K., Schulz, M., Seland, Ø., Skeie, R. B., Takemura, T., Tsigaridis, K., and Zhang, K.: What controls the vertical distribution of aerosol? Relationships between process sensitivity in HadGEM3-UKCA and inter-model variation from AeroCom Phase II, Atmos. Chem. Phys., 16, 2221-2241, https://doi.org/10.5194/acp-162221-2016, 2016.

Kirillin, G., Leppäranta, M., Terzhevik, A., Bernhardt, J., Engelhardt, C., Granin, N., Golosov, S., Efremova, T., Palshin, N., Sherstyankin, P., Zdorovennova, G., and Zdorovennov, R.: Physics of seasonally ice-covered lakes: major drivers and temporal/spatial scales, Aquat. Ecol., 74, 659-682, https://doi.org/10.1007/s00027-012-0279-y, 2012.

Kirkevåg, A., Iversen, T., Seland, Ø., Debernard, J. B., Storelvmo, T., and Kristjánsson, J. E.: Aerosol-cloud-climate interactions in the climate model CAM-Oslo, Tellus A, 60, 492-512, 2008.

Kirkevåg, A., Iversen, T., Seland, Ø., Hoose, C., Kristjánsson, J. E., Struthers, H., Ekman, A. M. L., Ghan, S., Griesfeller, J., Nilsson, E. D., and Schulz, M.: Aerosol-climate interactions in the Norwegian Earth System Model - NorESM1-M, Geosci. Model Dev., 6, 207-244, https://doi.org/10.5194/gmd-6207-2013, 2013.

Kirkevåg, A., Acosta Navarro, J. C., Ekman, A. M. L., Hansson, H.-C., Iversen, T., Riipinen, I., Seland, $\varnothing$, Struthers, H., and Varma, V.: Reduced European sulfur emissions unleashes the Arctic greenhouse warming, in: Transboundary particulate matter, photo-oxidants, acidification and eutrophying components, EMEP Status Report 1/2016, MET - Norwegian Meteorological Institute, Oslo, ISSN 1504-6192, 2016.

Knudsen, K. L., Eiríksson, J., Jiang, H., and Jónsdóttir, I.: Palaeoceanography and climate changes off North Iceland during the last millennium: comparison of foraminifera, diatoms and icerafted debris with instrumental and documentary data, J. Quaternary Sci., 24, 457-468, 2009.

Koffi, B., Schulz, M., Breon, F.-M., Dentener, F., Steensen, B. M., Griesfeller, J., Winker, D., Balkanski, Y., Bauer, S. E., Bellouin, N., Berntsen, T., Bian, H., Chin, M., Diehl, T., Easter, R., Ghan, S., Hauglustaine, D., Iversen, T., Kirkevåg, A., Liu, X., Lohmann, U., Myhre, G., Rasch, P., Seland, Ø., Skeie, R. B., Steenrod, S. D., Stier, P., Tackett, J., Takemura, T., Tsigaridis, K., Vuolo, M. R., Yoon, J., and Zhang, K.: Evaluation of the aerosol vertical distribution in global aerosol models through comparison against CALIOP measurements: AeroCom phase II results, J. Geophys. Res.-Atmos., 121, 7254-7283, 2016.

Kong, X., Andersson, P. U., Thomson, E. S., and Pettersson, J. B. C.: Ice formation via deposition mode nucleation on bare and alcohol-covered graphite surfaces, J. Phys. Chem. C, 116, 8964 8974, 2012. 
Kong, X., Papagiannakopoulos, P., Thomson, E. S., Markovič, N., and Pettersson, J. B. C.: Water accommodation and desorption kinetics on ice, J. Phys. Chem. A, 118, 3973-3979, 2014a.

Kong, X., Thomson, E. S., Papagiannakopoulos, P., Johansson, S. M., and Pettersson, J. B. C.: Water accommodation on ice and organic surfaces: Insights from environmental molecular beam experiments, J. Phys. Chem. B, 118, 13378-13386, 2014b.

Kong, X., Wolf, M., Roesch, M., Thomson, E. S., Bartels-Rausch, T., Alpert, P., Ammann, M., Prisle, N., and Cziczo, D.: A Continuous Flow Diffusion Chamber Study of Sea Salt Particles Acting as Cloud Nuclei: Deliquescence and Ice Nucleation, Tellus B, 70, 1463806, https://doi.org/10.1080/16000889.2018.1463806, 2018.

Kouznetsov, R. and Sofiev, M.: A methodology for evaluation of vertical dispersion and dry deposition of atmospheric aerosols, J. Geophys. Res., 117, D01202, https://doi.org/10.1029/2011JD016366, 2012.

Kramshøj, M., Vedel-Petersen, I., Schollert, M., Rinnan, Å., Nymand, J., Ro-Poulsen, H., and Rinnan, R.: Large increases in arctic biogenic volatile emissions are a direct effect of warming, Nat. Geosci., 9, 349-352, 2016.

Kristensen, K. and Glasius, M.: Organosulfates and oxidation products from biogenic hydrocarbons in fine aerosols from a forest in North West Europe during spring, Atmos. Environ., 45, 45464556, https://doi.org/10.1016/j.atmosenv.2011.05.063, 2011.

Kristensen, K., Bilde, M., Aalto, P. P., Petaja, T., and Glasius, M.: Denuder/filter sampling of organic acids and organosulfates at urban and boreal forest sites: Gas/particle distribution and possible sampling artifacts, Atmos. Environ., 130, 36-53, https://doi.org/10.1016/j.atmosenv.2015.10.046, 2016.

Kristensen, T. B., Prisle, L. N., and Bilde, M.: Cloud droplet activation of mixed model HULIS and $\mathrm{NaCl}$ particles: Experimental results and $k$-theory, Atmos. Res., 137, 167-175, 2014.

Kulmala, M., Lappalainen, H. K., Petäjä, T., Kurten, T., Kerminen, V.-M., Viisanen, Y., Hari, P., Bondur, V., Kasimov, N., Kotlyakov, V., Matvienko, G., Baklanov, A., Guo, H., Ding, A., Hansson, H.-C., and Zilitinkevich, S.: Introduction: The Pan-Eurasian Experiment $(\mathrm{PEEX})$ - multi-disciplinary, multi-scale and multicomponent research and capacity building initiative, Atmos. Chem. Phys., 15, 13085-13096, https://doi.org/10.5194/acp-1513085-2015, 2015.

Kulmala, M., Lappalainen, H. K., Petäjä, T., Kerminen, V.-M., Viisanen, Y., Matvienko, G., Melnikov, V., Baklanov, A., Bondur, V., Kasimov, N., and Zilitinkevich, S.: Pan-Eurasian Experiment (PEEX) Program: Grant Challenges in the Arctic-boreal context, J. Geogr. Environ. Sustain., 2, 5-18, 2016.

Kürten, A., Jokinen, T.,Simon, M., Sipilä, M., Sarnela, N., Junninen, H., Adamov, A., Almeida, J., Amorim, A., Bianchi, F., Breitenlechner, M., Dommen, J., Donahue, N. M., Duplissy, J., Ehrhart, S., Flagan, R. C. Franchin, A., Hakala, J., Hansel, A., Heinritzi, M., Hutterli, M., Kangasluoma, J., Kirkby, J., Laaksonen, A., Lehtipalo, K., Leiminger, M., Makhmutov, V., Mathot, S., Onnela, A., Petäjä, T., Praplan, A. P., Riccobono, F., Rissanen, M. P., Rondo, L., Schobesberger, S., Seinfeld, J. H., Steiner, G., Tomé, A., Tröstl, J., Winkler, P. M., Williamson, C., Wimmer, D., Ye, P., Baltensperger, U., Carslaw, K. S., Kulmala, M., Worsnop, D. R., and Curtius, J.: Neutral molecular cluster formation of sulfuric aciddimethylamine observed in real time under atmospheric conditions, P. Natl Acad. Sci., USA, 111, 15019-15024, 2014.
Kyrö, E.-M., Väänänen, R., Kerminen, V.-M., Virkkula, A., Petäjä, T., Asmi, A., Dal Maso, M., Nieminen, T., Juhola, S., Shcherbinin, A., Riipinen, I., Lehtipalo, K., Keronen, P., Aalto, P. P., Hari, P., and Kulmala, M.: Trends in new particle formation in eastern Lapland, Finland: effect of decreasing sulfur emissions from Kola Peninsula, Atmos. Chem. Phys., 14, 4383-4396, https://doi.org/10.5194/acp-14-4383-2014, 2014.

Laj, P., Klausen, J., Bilde, M., Plass-Duelmer, C., Pappalardo, G., Clerbaux, C., Baltensperger., U., Hjorth, J., Simpson, D., Reimann, S., Coheur, P. F., Richter, A., De Maziere, M., Rudich, Y., McFiggans, G., Torseth, K., Wiedensohler, A., Morin, S., Schulz, M., Allan, J. D., Attie, J. L., Barnes, I., Birmili, W., Cammas, J. P., Dommen, J., Dorn, H. P., Fowler, D., Fuzzi, S., Glasius, M., Granier, C., Hermann, M., Isaksen, I. S. A., Kinne, S., Koren, I., Madonna, F., Maione, M., Massling, A., Moehler, O., Mona, L., Monks, P. S., Muller, D., Muller, T., Orphal, J., Peuch, V. H., Stratmann, F., Tanre, D., Tyndall, G., Riziq, A. A., Van Roozendael, A., Villani, P., Wehner, B., Wex, H., and Zardini, A. A.: Measuring atmospheric composition change, Atmos. Environ., 43, 5351-5414, 2009.

Lambert, F., Kug, J.-S., Park, R. J., Mahowald, N., Winckler, G., Abe-Ouchi, A., O'ishi, R., Takemura, T., and Lee, J.-H.: The role of mineral-dust aerosols in polar temperature amplification, Nat. Clim. Change, 3, 487-491, https://doi.org/10.1038/nclimate1785, 2013.

Lampert, A., Ström, J., Ritter, C., Neuber, R: Yoon, Y. J., Chae, N. Y., and Shiobara, M.: Inclined Lidar Observations of Boundary layer Aerosol Particles above the Kongsfjord, Svalbard, Acta Geophys., 60, 1287-1307, 2011.

Lappalainen, H. K., Petäjä, T., Kujansuu, J., Kerminen, V.-M., Shvidenko, A., and Bäck, J.: Pan-Eurasian Experiment (PEEX) - a research initiative meeting the grand challenges of the changing environment of the northern Pan-Eurasian arctic-boreal areas, J. Geogr. Environ. Sustain., 2, 13-48, 2014.

Lappalainen, H. K., Kerminen, V.-M., Petäjä, T., Kurten, T., Baklanov, A., Shvidenko, A., Bäck, J., Vihma, T., Alekseychik, P., Andreae, M. O., Arnold, S. R., Arshinov, M., Asmi, E., Belan, B., Bobylev, L., Chalov, S., Cheng, Y., Chubarova, N., de Leeuw, G., Ding, A., Dobrolyubov, S., Dubtsov, S., Dyukarev, E., Elansky, N., Eleftheriadis, K., Esau, I., Filatov, N., Flint, M., Fu, C., Glezer, O., Gliko, A., Heimann, M., Holtslag, A. A. M., Hõrrak, U., Janhunen, J., Juhola, S., Järvi, L., Järvinen, H., Kanukhina, A., Konstantinov, P., Kotlyakov, V., Kieloaho, A.-J., Komarov, A. S., Kujansuu, J., Kukkonen, I., Duplissy, E.-M., Laaksonen, A., Laurila, T., Lihavainen, H., Lisitzin, A., Mahura, A., Makshtas, A., Mareev, E., Mazon, S., Matishov, D., Melnikov, V., Mikhailov, E., Moisseev, D., Nigmatulin, R., Noe, S. M., Ojala, A., Pihlatie, M., Popovicheva, O., Pumpanen, J., Regerand, T., Repina, I., Shcherbinin, A., Shevchenko, V., Sipilä, M., Skorokhod, A., Spracklen, D. V., Su, H., Subetto, D. A., Sun, J., Terzhevik, A. Y., Timofeyev, Y., Troitskaya, Y., Tynkkynen, V.P., Kharuk, V. I., Zaytseva, N., Zhang, J., Viisanen, Y., Vesala, T., Hari, P., Hansson, H. C., Matvienko, G. G., Kasimov, N. S., Guo, H., Bondur, V., Zilitinkevich, S., and Kulmala, M.: PanEurasian Experiment (PEEX): towards a holistic understanding of the feedbacks and interactions in the land-atmosphere-oceansociety continuum in the northern Eurasian region, Atmos. Chem. Phys., 16, 14421-14461, https://doi.org/10.5194/acp-1614421-2016, 2016. 
Larsen, D., Miller, G. H., Geirsdóttir, Á., and Thordarson, T.: A 3000-year varved record of glacier activity and climate change from the proglacial lake Hvítárvatn, Iceland, Quaternary Sci. Rev., 20, 2715-2731, https://doi.org/10.1016/j.quascirev.2011.05.026, 2011.

Lavanchy, V. M. H., Gäggler, H. W., Schotterer, U., Schwikowski, M., and Baltensperger, U.: Historical record of carbonaceous particle concentrations from a European high-alpine glacier (Colle Gnifetti, Switzerland), J. Geophys. Res., 104, 21227-21236, https://doi.org/10.1029/1999JD900408, 1999.

Lei, R., Li, N., Li, C., and Jónsdóttir, I.: Seasonal changes in sea ice conditions along the Northeast Passage in 2007 and 2012, Adv. Polar Sci., 25, 300-309, 2014.

Lei, R., Xie, H., Wang, J., Leppäranta, M., Jónsdóttir, I., and Zhang, Z.: Changes in sea ice conditions along the Arctic Northeast Passage from 1979 to 2012, Cold Reg. Sci. Technol., 119, 132-144, 2015.

Lejonthun, L. S. E. R., Andersson, P. U., Hallquist, M., Thomson, E. S., and Pettersson, J. B. C.: Interactions of N2O5 and related nitrogen oxides with ice surfaces: Desorption kinetics and collision dynamics, J. Phys. Chem. B, 118, 13427-13434, 2014.

Leppäranta, M.: Freezing of lakes and the evolution of their ice cover, Springer-Praxis, Heidelberg, Germany, p. 301, 2015.

Liu, B. Y. H., Pui, D. Y. H., Whitby, K. T., Kittelson, D. B., Kousaka, Y., and McKenzie, R. L.: The aerosol mobility Chromatograph: A new detector for sulfuric acid aerosols, Atmos. Environ., 12, 99-104, 1978.

Lucht, W., Schaaf, C. F., and Strahler, A. H.: An algorithm for the retrieval of albedo from space using semiempirical BRDF models, IEEE T. Geosci. Remote, 38, 977-998, 2000.

Makkonen, R., Seland, Ø., Kirkevåg, A., Iversen, T., and Kristjánsson, J. E.: Evaluation of aerosol number concentrations in NorESM with improved nucleation parameterization, Atmos. Chem. Phys. 14, 5127-5152, https://doi.org/10.5194/acp-145127-2014, 2014.

Massling, A., Nielsen, I. E., Kristensen, D., Christensen, J. H., Sorensen, L. L., Jensen, B., Nguyen, Q. T., Nojgaard, J. K., Glasius, M., and Skov, H.: Atmospheric black carbon and sulfate concentrations in Northeast Greenland, Atmos. Chem. Phys., 15, 9681-9692, https://doi.org/10.5194/acp-15-9681-2015, 2015.

McClelland, J. W., Holmes, R. M., Peterson, B. J., and Stieglitz, M.: Increasing river discharge in the Eurasian Arctic: Consideration of dams, permafrost thaw, and fires as potential agents of change, J. Geophys. Res., 109, D18102, https://doi.org/10.1029/2004JD004583, 2004.

McConnell, J. R.: New Directions: Historical black carbon and other ice core aerosol records in the Arctic for GCM evaluation, Atmos. Environ., 44, 2665-2666, 2010.

McConnell, J. R. and Edwards, R.: Coal burning leaves toxic heavy metal legacy in the Arctic, P. Natl. Acad. Sci. USA, 105, 1214012144, 2008.

McConnell, J. R., Edwards, R., Kok, G. L., Flanner, M. G., Zender, C. S., Saltzman, E. S., Banta, J. R., Pasteris, D. R., Carter, M. M., and Kahl, J. D. W.: 20th century industrial black carbon emissions altered arctic climate forcing, Science, 317, 1381-1384, 2007.

Mei, L. L., Xue, Y., Kokhanovsky, A. A., von Hoyningen-Huene, W., Istomina, L., de Leeuw, G., Burrows, J. P., Guang, J., and
Jing, Y.: Aerosol optical depth retrieval over snow using AATSR data, Int. J. Remote Sens., 34, 5030-5041, 2013.

Meinander, O.: Effect of black carbon and Icelandic dust on snow albedo, melt and density, Finnish Meteorological Institute Contributions No. 125, ISBN 978-951-697-895-9, Erweko, Helsinki, p. $122,2016$.

Meinander, O., Kazadzis, S., Arola, A., Riihelä, A., Räisänen, P., Kivi, R., Kontu, A., Kouznetsov, R., Sofiev, M., Svensson, J., Suokanerva, H., Aaltonen, V., Manninen, T., Roujean, J.-L., and Hautecoeur, O.: Spectral albedo of seasonal snow during intensive melt period at Sodankylä, beyond the Arctic Circle, Atmos. Chem. Phys., 13, 3793-3810, https://doi.org/10.5194/acp13-3793-2013, 2013.

Meinander, O., Kontu, A., Virkkula, A., Arola, A., Backman, L., Dagsson-Waldhauserová, P., Järvinen, O., Manninen, T., Svensson, J., de Leeuw, G., and Leppäranta, M.: Brief communication: Light-absorbing impurities can reduce the density of melting snow, The Cryosphere, 8, 991-995, https://doi.org/10.5194/tc-8991-2014, 2014.

Meinander, O., Dagsson-Waldhauserova, P., and Arnalds, O.: Icelandic volcanic dust can have a significant influence on the cryosphere in Greenland and elsewhere, Polar Res., 35, 31313, https://doi.org/10.3402/polar.v35.31313, 2016.

Melnikov, V., Gennadinik, V., Kulmala, M., Lappalainen, H. K., Petäjä, T., and Zilitinkevich, S.: Cryosphere: a kingdom of anomalies and diversity, Atmos. Chem. Phys., 18, 6535-6542, https://doi.org/10.5194/acp-18-6535-2018, 2018.

Morrison, H., de Boer, G., Feingold, G., Harrington, J., Shupe, M. D., and Sulia, K.: Resilience of persistent arctic mixed-phase clouds, Nat. Geosci., 5, 11-17, https://doi.org/10.1038/ngeo1332, 2012.

Myhre, G., Shindell, D., Breon, F.-M., Collins, W., Fuglestvedt, J., Huang, J., Koch, D., Lamarque, J.-F., Lee, D., Mendoza, B., Nakajima, T., Robock, A., Stephens, G., Takemura, T., and Zhang, H.: Anthropogenic and Natural Radiative Forcing, in: Climate Change 2013: The Physical Science Basis, Contribution of Working Group I to the Fifth Assessment Report of the Intergovernmental Panel on Climate Change, edited by: Stocker, T. F., Qin, D., Plattner, G.-K., Tignor, M., Allen, S. K., Boschung, J., Nauels, A., Xia, Y., Bex, V., and Midgley, P. M., Cambridge University Press, Cambridge, UK and New York, NY, USA, 659740, 2013.

Myhre, G., Forster, P. M., Samset, B. H., Hodnebrog, Ø., Sillmann, J., Aalbergsjø, S. G., Andrews, T., Boucher, O., Faluvegi, G., Fläschner, D., Kasoar, M., Kharin, V., Kirkevåg, A., Lamarque, J.-F., Olivié, D., Richardson, T., Shindell, D., Shine, K. P., Stjern, C. W., Takemura, T., Voulgarakis, A., and Zwiers, F.: PDRMIP: A Precipitation Driver and Response Model Intercomparison Project, Protocol and preliminary results, B. Am. Meteorol. Soc., 98, 1185-1198, https://doi.org/10.1175/BAMS-D-160019.1, 2017.

Myhre, L. C., Ferré, B., Platt, S. M., Silyakova, A., Hermansen, O., Allen, G., Pisso, I., Schmidbauer, N., Stohl, A., Pitt, J., Jansson, P., Greinert, J., Percival, C., Fjaeraa, A. M., O’Shea, S. J., Gallagher, M., Le Breton, M., Bower, K. N., Bauguitte, S. J. B., Dalsøren, S., Vadakkepuliyambatta, S., Fisher, R. E., Nisbet, E. G., Lowry, D., Myhre, G., Pyle, J. A., Cain, M., and Mienert, J.: Extensive release of methane from Arctic seabed west of Svalbard 
during summer 2014 does not influence the atmosphere, Geophys. Res. Lett., 43, 4624-4631, 2016.

Mårtensson, E. M., Nilsson, E. D., de Leeuw, G., Cohen, L. H., and Hansson, H.-C.: Laboratory simulations and parameterization of the primary marine aerosol production, J. Geophys. Res., 108, 4297-4308, https://doi.org/10.1029/2002JD002263, 2003.

Najafi, M. R., Zwiers, F. W., and Gillett, N. P.: Attribution of Arctic temperature change to greenhouse-gas and aerosol influences, Nat. Clim. Change, 5, 246-249, https://doi.org/10.1038/NCLIMATE2524, 2015.

Ng, N. L., Herndon, S. C., Trimborn, A., Canagaratna, M. R., Croteau, P. L., Onasch, T. B., Sueper, D., Worsnop, D. R., Zhang, Q., Sun, Y. L., and Jayne, J. T.: An Aerosol Chemical Speciation Monitor (ACSM) for Routine Monitoring of the Composition and Mass Concentrations of Ambient Aerosol, Aerosol Sci. Tech., 45, 780-794, 2011.

Nguyen, Q. T., Skov, H., Sorensen, L. L., Jensen, B. J., Grube, A. G., Massling, A., Glasius, M., and Nojgaard, J. K.: Source apportionment of particles at Station Nord, North East Greenland during 2008-2010 using COPREM and PMF analysis, Atmos. Chem. Phys., 13, 35-49, https://doi.org/10.5194/acp-13-352013, 2013.

Nguyen, Q. T., Christensen, M. K., Cozzi, F., Zare, A., Hansen, A. M. K., Kristensen, K., Tulinius, T. E., Madsen, H. H., Christensen, J. H., Brandt, J., Massling, A., Nojgaard, J. K., and Glasius, M.: Understanding the anthropogenic influence on formation of biogenic secondary organic aerosols in Denmark via analysis of organosulfates and related oxidation products, Atmos. Chem. Phys., 14, 8961-8981, https://doi.org/10.5194/acp14-8961-2014, 2014a.

Nguyen, Q. T., Kristensen, T. B., Hansen, A. M. K., Skov, H., Bossi, R., Massling, A., Sørensen, L. L., Bilde, M., Glasius, M., and Nøjgaard, J. K.: Characterization of humic-like substances in Arctic aerosols, J. Geophys. Res.-Atmos., 119, 5011-5029, https://doi.org/10.1002/2013JD020144, 2014b.

Nguyen, Q. T., Kjær, K. H., Kling, K. I., Boesen, T., and Bilde, M.: Impact of fatty acid coating on the CCN activity of sea salt particles, Tellus B, 69, 1304064, https://doi.org/10.1080/16000889.2017.1304064, 2017.

Nilsson, E. D., Rannik, Ü., Swietlicki, E., Leck, C., Aalto, P. P., Zhou, J., and Norman, M.: Turbulent aerosol fluxes over the Arctic Ocean: 2. Wind-driven sources from the sea, J. Geophys. Res., 106, 32139-32154, https://doi.org/10.1029/2000JD900747, 2001.

Noilhan, J. and Mahfouf, J.-F.: The ISBA land surface parameterisation scheme, Global Planet. Change, 13, 145-159, 1996.

Nordic Climate Change Research: NordForsk Policy Briefs 2009-8, Mandag Morgen, 2009.

Norris, S. J., Brooks, I. M., de Leeuw, G., Sirevaag, A., Leck, C., Brooks, B. J., Birch, C. E., and Tjernström, M.: Measurements of bubble size spectra within leads in the Arctic summer pack ice, Ocean Sci., 7, 129-139, https://doi.org/10.5194/os-7-129-2011, 2011.

Nozière, B., Kalberer, M., Claeys, M., Allan, J., D’Anna, B., Decesari, S., Finessi, E., Glasius, M., Grgić, I., Hamilton, J. F., Hoffmann, T., Iinuma, Y., Jaoui, M., Kahnt, A., Kampf, C. J., Kourtchev, I., Maenhaut, W., Marsden, N., Saarikoski, S., Schnelle-Kreis, J., Surratt, J. D., Szidat, S., Szmigielski, R., and Wisthaler, A.: The Molecular Identi- fication of Organic Compounds in the Atmosphere: State of the Art and Challenges, Chem. Rev., 115, 3919-3983, https://doi.org/10.1021/cr5003485, 2015.

NSIDC: National Snow and Ice Data Center, available at: http:// nsidc.org/arcticseaicenews/ (last access: 4 February 2019), 2018.

Ogilvie, A. E. J. and Jónsdóttir, I.: Climatic and environmental history of Northern Europe and the North Atlantic Region over the past 1000 years, Veðurstofa Íslands Reports, 1997.

O'Reilly, C. M., Sharma, S., Gray, D. K., Hampton, S. E., Read, J. S., Rowley, R. J., Schneider, P., Lenters, J. D., McIntyre, P. B., Kraemer, B. M., Weyhenmeyer, G. A., Straile, D., Dong, B., Adrian, R., Allan, M. G., Anneville, O., Arvola, L., Austin, J., Bailey, J. L., Baron, J. S., Brookes, J. D., de Eyto, E., Dokulil, M. T., Hamilton, D. P., Havens, K., Hetherington, A. L., Higgins, S. N., Hook, S., Izmest'eva, L. R., Joehnk, K. D., Kangur, K., Kasprzak, P., Kumagai, M., Kuusisto, E., Leshkevich, G., Livingstone, D. M., MacIntyre, S., May, L., Melack, J. M., MuellerNavarra, D. C., Naumenko, M., Noges, P., Noges, T., North, R. P., Plisnier, P.-D., Rigosi, A., Rimmer, A., Rogora, M., Rudstam, L. G., Rusak, J. A., Salmaso, N., Samal, N. R., Schindler, D. E., Schladow, S. G., Schmid, M., Schmidt, S. R., Silow, E., Soylu, M. E., Teubner, K., Verburg, P., Voutilainen, A., Watkinson, A., Williamson, C. E., and Zhang, G.: Rapid and highly variable warming of lake surface waters around the globe, Geophys. Res. Lett., 42, 10773-10781, https://doi.org/10.1002/2015GL066235, 2015.

Öström, E., Zhou, P, Schurgers, G., Mishurov, M., Kivekäs, N., Lihavainen, H., Ehn, M., Rissanen, M. P., Kurtén, T., Boy, M., Swietlicki, E., and Roldin, P.: Model data for simulation of secondary organic aerosol formation over the boreal forest, link to NetCDF files in zip archieve, PANGAEA, https://doi.org/10. 1594/PANGAEA.877695, 2016.

Öström, E., Zhou, P, Schurgers, G., Mishurov, M., Kivekäs, N., Lihavainen, H., Ehn, M., Rissanen, M. P., Kurtén, T., Boy, M., Swietlicki, E., and Roldin, P: Modeling the role of highly oxidized multifunctional organic molecules for the growth of new particles over the boreal forest region, Atmos. Chem. Phys., 17, 8887-8901, https://doi.org/10.5194/acp-17-8887-2017, 2017.

Ovadnevaite, J., Zuend, A., Laaksonen, A., Sanchez, K. J., Roberts, G., Ceburnis, D., Decesari, S., Rinaldi, M., Hodas, N., Facchini, M. C., Seinfeld, J. H., and O'Dowd, C.: Surface tension prevails over solute effect in organic-influenced cloud droplet activation, Nature, 546, 637-641, 2017.

Painter, T. H., Flanner, M. G., Kaser, G., Marzeion, B., VanCuren, R. A., and Abdalati, W.: End of the Little Ice Age in the Alps forced by industrial black carbon, P. Natl. Acad. Sci. USA, 110, 15216-15221, https://doi.org/10.1073/pnas.1302570110, 2013.

Papagiannakopoulos, P., Kong, X., Thomson, E. S., Markovič, N., and Pettersson, J. B. C.: Surface transformations and water uptake on liquid and solid butanol near the melting temperature, J. Phys. Chem. C, 117, 6678-6685, 2013.

Papagiannakopoulos, P., Kong, X., Thomson, E. S., and Pettersson, J. B. C.: Water interactions with acetic acid layers on ice and graphite, J. Phys. Chem. B, 118, 13333-13340, 2014.

Peltoniemi, J. I., Gritsevich, M., Hakala, T., DagssonWaldhauserová, P., Arnalds, Ó., Anttila, K., Hannula, H.-R., Kivekäs, N., Lihavainen, H., Meinander, O., Svensson, J., Virkkula, A., and de Leeuw, G.: Soot on Snow experiment: bidirectional reflectance factor measurements of contaminated 
snow, The Cryosphere, 9, 2323-2337, https://doi.org/10.5194/tc9-2323-2015, 2015.

Penuelas, J., Asensio, D., Tholl, D., Wenke, K., Rosenkranz, M., Piechulla, B., and Schnitzler, J. P.: Biogenic volatile emissions from the soil, Plant Cell Environ., 37, 1866-1891, 2014.

Perovich, D. K. and Polashenski, C.: Albedo evolution of seasonal Arctic sea ice, Geophys. Res. Lett., 39, L08501, https://doi.org/10.1029/2012GL051432, 2012.

Peters, G. P., Nilssen, T. B., Lindholt, L., Eide, M. S., Glomsrød, S., Eide, L. I., and Fuglestvedt, J. S.: Future emissions from shipping and petroleum activities in the Arctic, Atmos. Chem. Phys., 11, 5305-5320, https://doi.org/10.5194/acp-11-5305-2011, 2011.

Petit, J. R., Jouzel, J., Raynaud, D., Barkov, N. I., Barnola, J.-M., Basile, I., Bender, M., Chappellaz, J., Davis, M., Delaygue, G., Delmotte, M., Kotlyakov, V. M., Legrand, M., Lipenkov, V. Y., Lorius, C., Pépin, L., Ritz, C., Saltzman, E., and Stievenard, M.: Climate and atmospheric history of the past 420,000 years from the Vostok ice core, Antarctica, Nature, 399, 429-436, https://doi.org/10.1038/20859, 1999.

Pithan, F. and Mauritsen, T.: Arctic amplification dominated by temperature feedbacks in contemporary climate models, Nat. Geosci., 7, 181-184, 2014.

Pirazzini, R.: Surface albedo measurements over Antarcticsites in summer, J. Geophys. Res., 109, D20118, https://doi.org/10.1029/2004JD004617, 2004.

Polashenski, C. M., Dibb, J. E., Flanner, M. G., Chen, J. Y., Courville, Z. R., Lai, A. M., Schauer, J. J., Shafer, M. M., and Bergin, M.: Neither dust nor black carbon causing apparent albedo decline in Greenland's dry snow zone, implications for MODIS C5 surface reflectance, Geophys. Res. Lett., 42, 93199327, https://doi.org/10.1002/2015GL065912, 2015.

Possner, A., Zubler, E., Lohmann, U., and Schär, C.: Realcase simulations of aerosol-cloud interactions in ship tracks over the Bay of Biscay, Atmos. Chem. Phys., 15, 2185-2201, https://doi.org/10.5194/acp-15-2185-2015, 2015

Prisle, N. L., Raatikanen, T., Sorjamaa, R., Svennigsson, B., Laaksonen, A., and Bilde, M.: Surfactant partitioning in cloud droplet activation: a study of $\mathrm{C} 8, \mathrm{C} 10, \mathrm{C} 12$ and C14 normal fatty acid sodium salts, Tellus B, 60, 416-431, https://doi.org/10.1111/j.1600-0889.2008.00352.x, 2008.

Prisle, N. L., Raatikainen, T., Laaksonen, A., and Bilde, M.: Surfactants in cloud droplet activation: mixed organicinorganic particles, Atmos. Chem. Phys., 10, 5663-5683, https://doi.org/10.5194/acp-10-5663-2010, 2010.

Prisme Media: Nordforsk CRAICC, available at: https://trotv. solidtango.com/video/nordforsk-craicc?locale=en, last access: 4 February 2019.

Quinn, P. K., Bates, T. S., Baum, E., Doubleday, N., Fiore, A. M., Flanner, M., Fridlind, A., Garrett, T. J., Koch, D., Menon, S., Shindell, D., Stohl, A., and Warren, S. G.: Shortlived pollutants in the Arctic: their climate impact and possible mitigation strategies, Atmos. Chem. Phys., 8, 1723-1735, https://doi.org/10.5194/acp-8-1723-2008, 2008.

Rasmussen, B. B., Nguyen, Q. T., Kristensen, K., Nielsen, L. S., and Bilde, M.: What controls volatility of sea spray aerosol? Results from laboratory studies using artificial and real seawater samples, J. Aerosol Sci., 107, 134-141, 2017.

Raymond, P., Hartmann, J., Lauerwald, R., Sobek, S., McDonald, C., Hoover, M., Butman, D., Striegl, R., Mayorga, E., Humborg,
C., Kortelainen, P., Dürr, H., Meybeck, M., Ciais, P., and Guth, P.: Global carbon dioxide emissions from inland waters, Nature, 503, 355-359, 2013.

Ricão Canelhas, M., Denfeld, B. A., Weyhenmeyer, G. A., Bastviken, D., Bertilsson, S.: Methane oxidation at the water-ice interface of an ice-covered lake, Limnol. Oceanogr., 61, 78-90, 2016.

Roberts, G. C. and Nenes, A.: A Continuous-Flow Streamwise Thermal-Gradient CCN Chamber for Atmospheric Measurements, Aerososol Sci. Tech., 39, 206-221, 2005.

Roldin, P., Swietlicki, E., Schurgers, G., Arneth, A., Lehtinen, K. E. J., Boy, M., and Kulmala, M.: Development and evaluation of the aerosol dynamics and gas phase chemistry model ADCHEM, Atmos. Chem. Phys., 11, 5867-5896, https://doi.org/10.5194/acp11-5867-2011, 2011.

Roldin, P., Eriksson, A. C., Nordin, E. Z., Hermansson, E., Mogensen, D., Rusanen, A., Boy, M., Swietlicki, E., Svenningsson, B., Zelenyuk, A., and Pagels, J.: Modelling non-equilibrium secondary organic aerosol formation and evaporation with the aerosol dynamics, gas- and particle-phase chemistry kinetic multilayer model ADCHAM, Atmos. Chem. Phys., 14, 7953-7993, https://doi.org/10.5194/acp-14-7953-2014, 2014.

Roldin, P., Liao, L., Mogensen, D., Dal Maso, M., Rusanen, A., Kerminen, V. M., Mentel, T. F., Wildt, J., Kleist, E., KiendlerScharr, A., Tillmann, R., Ehn, M., Kulmala, M., and Boy, M.: Modelling the contribution of biogenic volatile organic compounds to new particle formation in the Julich plant atmosphere chamber, Atmos. Chem. Phys., 15, 10777-10798, https://doi.org/10.5194/acp-15-10777-2015, 2015.

Rose, N. L. and Ruppel, M. M.: Environmental archives of contaminant particles, in: Environmental Contaminants, Developments in Paleoenvironmental Research 18, edited by: Blais, J. M., Rosen, M. R., and Smol, J. P., Springer, Dordrecht, 187-221, 2015.

Rothrock, D. A. and Maykut, G. A.: Thinning of the Arctic sea-ice cover, Geophys. Res. Lett., 26, 3469-3472, 1999.

Ruehl, C. R., Davies, J. F., and Wilson, K. R.: An interfacial mechanism for cloud droplet formation on organic aerosols, Science, 351, 1447-1450, 2016.

Ruppel, M. M., Isaksson, E., Ström, J., Beaudon, E., Svensson, J., Pedersen, C. A., and Korhola, A.: Increase in elemental carbon values between 1970 and 2004 observed in a 300year ice core from Holtedahlfonna (Svalbard), Atmos. Chem. Phys., 14, 11447-11460, https://doi.org/10.5194/acp-14-114472014, 2014.

Ruppel, M. M., Gustafsson, Ö., Rose, N. L., Pesonen, A., Yang, H., Weckström, J., Palonen, V., and Korhola, A.: Spatial and temporal patterns in Black Carbon (BC) deposition in dated Fennoscandian Arctic lake sediments from 1830 to 2010, Environ. Sci. Technol., 49, 13954-13963, 2015.

Ruppel, M. M., Soares, J., Gallet, J.-C., Isaksson, E., Martma, T., Svensson, J., Kohler, J., Pedersen, C. A., Manninen, S., Korhola, A., and Ström, J.: Do contemporary (1980-2015) emissions determine the elemental carbon deposition trend at Holtedahlfonna glacier, Svalbard?, Atmos. Chem. Phys., 17, 12779-12795, https://doi.org/10.5194/acp-17-12779-2017, 2017.

Salter, M. E., Nilsson, E. D., Butcher, A., and Bilde, M.: On the seawater temperature dependence of the sea spray aerosol gener- 
ated by a continuous plunging jet, J. Geophys. Res.-Atmos., 119, 9052-9072, 2014.

Salter, M. E., Zieger, P., Acosta Navarro, J. C., Grythe, H., Kirkevåg, A., Rosati, B., Riipinen, I., and Nilsson, E. D.: An empirically derived inorganic sea spray source function incorporating sea surface temperature, Atmos. Chem. Phys., 15, 1104711066, https://doi.org/10.5194/acp-15-11047-2015, 2015.

Salter, M. E., Hamacher-Barth, E., Leck, C., Werner, J., Johnson, C. M., Riipinen, I., Nilsson, E. D., and Zieger, P.: Calcium enrichment in sea spray aerosol particles, Geophys. Res. Lett., 43, 8277-8285, 2016.

Samset, B. H., Myhre, G., Forster, P. M., Hodnebrog, Ø., Andrews, T., Fulavegi, G., Flashner, D., Kasoar, M., Kharin, V., Kirkevåg, A., Lamarque, J.-F., Olivie, D., Richardson, T., Schindell, D., Shine, K. P., Takemura, T., and Voulgarakis, A.: Fast and slow precipitation responses to individual climate forcers: A PDRMIP multimodel study, Geophys. Res. Lett., 43, 2782-2791, 2016.

Sand, M., Berntsen, T. K., Seland, Ø., and Kristjánsson, J. E.: Arctic surface temperature change to emissions of black carbon within Arctic or midlatitudes, J. Geophys. Res.-Atmos., 118, 111, 2013a.

Sand, M., Berntsen, T. K., Kay, J. E., Lamarque, J. F., Seland, Ø., and Kirkevåg, A.: The Arctic response to remote and local forcing of black carbon, Atmos. Chem. Phys., 13, 211-224, https://doi.org/10.5194/acp-13-211-2013, 2013b.

Sand, M., Iversen, T., Bohlinger, P., Kirkevåg, A., Seierstad, I. A., Seland, Ø., and Sorteberg, A.: A standardized global climate model study showing unique properties for the climate response to black carbon aerosols, J. Climate, 28, 2512-2526, https://doi.org/10.1175/JCLI-D-14-00050.1, 2015a.

Sand, M., Berntsen, T. K., von Salzen, K., Flanner, M. G., Langner, J., and Victor, D. G.: Response of Arctic temperature to changes in emissions of short-lived climate forcers, Nat. Clim. Change, 6 , 286-289, 2015b.

Saunders, S. M., Jenkin, M. E., Derwent, R. G., and Pilling, M. J.: Protocol for the development of the Master Chemical Mechanism, MCM v3 (Part A): tropospheric degradation of nonaromatic volatile organic compounds, Atmos. Chem. Phys., 3, 161-180, https://doi.org/10.5194/acp-3-161-2003, 2003.

Savre, J. and Ekman, A. M. L.: A theory-based parameterization for heterogeneous ice nucleation and implications for the simulation of ice processes in atmospheric models, J. Geophys. Res.-Atmos., 120, 4937-4961, https://doi.org/10.1002/2014JD023000, 2015a.

Savre, J. and Ekman, A. M. L.: Large-eddy simulation of three mixed-phase cloud events during ISDAC: Conditions for persistent heterogeneous ice formation, J. Geophys. Res.-Atmos., 120, 7699-7725, https://doi.org/10.1002/2014JD023006, 2015 b.

Schaaf, C. B., Gao, F., Strahler, A. H., Lucht, W., Li, X., Tsang, T., Strugnell, N. C., Zhang, X., Jin, Y., Muller, J.-P., Lewis, P., Barnsley, M., Hobson, P., Disney, M., Roberts, G., Dunderdale, M., Doll, C., d'Entremont, R., Hu, B., Liang, S., and Privette, J. L.: First operational BRDF, albedo and nadir reflectance products from MODIS, Remote Sens. Environ., 83, 135-148, 2002.

Schill, G. P., Jathar, S. H., Kodros, J. K., Levin, E. J. T., Galang, A. M., Friedman, B., Link, M. F., Farmer, D. K., Pierce, J. R., Kreidenweis, S. M., and DeMott, P. J.: Icenucleating particle emissions from photochemically aged diesel and biodiesel exhaust. Geophysi. Res. Lett., 43, 5524-5531, https://doi.org/10.1002/2016GL069529, 2016.

Schmidt, M. W. I., Skejstadt, J. O., Czimczic, C. I., Glaser, B., Prentice, K. M., Gelinas, Y., and Kuhlbusch, T. A. J.: Comparative analysis of black carbon in soils, Global Biogeochem. Cy., 15, 163-167, 2001.

Schobesberger, S., Junninen, H., Bianchi, F., Lönn, G., Ehn, M., Lehtipalo, K., Dommen, J., Ehrhart, S., Ortega, I. K., Franchin, A., Nieminen, T., Riccobono, F., Hutterli, M., Duplissy, J., Almeida, J., Amorim, A., Breitenlechner, M., Downard, A. J., Dunne, E. M., Flagan, R. C., Kajos, M., Keskinen, H., Kirkby, J., Kupc, A., Kürten, A., Kurtén, T., Laaksonen, A., Mathot, S., Onnela, A., Praplan, A. P., Rondo, L., Santos, F. D., Schallhart, S., Schnitzhofer, R., Sipilä, M., Tomé, A., Tsagkogeorgas, G., Vehkamäki, H., Wimmer, D., Baltensperger, U., Carslaw, K. S., Curtius, J., Hansel, A., Petäjä, T., Kulmala, M., Donahue, N., and Worsnop, D. R.: Molecular understanding of atmospheric particle formation from sulfuric acid and large oxidized organic molecules, P. Natl. Acad. Sci., USA, 110, 17223-17228, https://doi.org/10.1073/pnas.1306973110, 2013.

Schollert, M., Kivimäenpää, M., Michelsen, A., Blok, D., and Rinnan, R.: Leaf anatomy, BVOC emission and $\mathrm{CO}_{2}$ exchange of arctic plants following snow addition and summer warming, Ann. Bot., 119, 433-445, https://doi.org/10.1093/aob/mcw237, 2016.

Schrod, J., Danielczok, A., Weber, D., Ebert, M., Thomson, E. S., and Bingemer, H. G.: Re-evaluating the Frankfurt isothermal static diffusion chamber for ice nucleation, Atmos. Meas. Tech., 9, 1313-1324, https://doi.org/10.5194/amt-9-1313-2016, 2016.

Schurgers, G., Arneth, A., Holzinger, R., and Goldstein, A. H.: Process-based modelling of biogenic monoterpene emissions combining production and release from storage, Atmos. Chem. Phys., 9, 3409-3423, https://doi.org/10.5194/acp-9-3409-2009, 2009.

Schwinger, J., Tjiputra, J., Goris, N., Six, K., Kirkevåg, A., Seland, Ø., Heinze, C., and Ilyina, T.: Amplification of global warming through $\mathrm{pH}$-dependence of DMS-production simulated with a fully coupled Earth system model, Biogeosciences, 14, 36333648, https://doi.org/10.5194/bg-14-3633-2017, 2017.

Seland, Ø., Iversen, T., Kirkevåg, A., and Storelvmo, T.: Aerosolclimate interactions in the CAM-Oslo atmospheric GCM and investigations of associated shortcomings, Tellus A, 60, 459-491, 2008.

Seppä, H. and Hicks, S.: Integration of modern and past pollen accumulation rate (PAR) records across the arctic tree-line: a method for more precise vegetation reconstructions, Quaternary Sci. Rev., 25, 1501-1516, 2006.

Serreze, M. C. and Barry, R. G.: Processes and impacts of Arctic amplification: A research synthesis, Global Planet. Change, 77, 85-96, 2011.

Serreze, M. C., Walsh, J. E., Chapin, F. S., Osterkamp, T., Dyurgerov, M., Romanovsky, V., Oechel, W. C., Morison, J., Zhang, T., and Barry, R. G.: Observational Evidence of Recent Change in the Northern High-Latitude Environment, Climatic Change, 46, 159-207, 2000.

Shakhova, N., Semiletov, I., Leifer, I., Salyuk, A., Rekant, P., and Kosmach, D.: Geochemical and geophysical evidence of methane release over the East Siberian Arctic Shelf, J. Geophys. 
Res., 115, C08007, https://doi.org/10.1029/2009JC005602, 2010.

Sharma, S., Lavoue, D., Cachier, H., Barrie, L. A., and Gong, S. L.: Long-term trends of the black carbon concentrations in the Canadian Arctic, J. Geophys. Res.-Atmos., 109, D15203, https://doi.org/10.1029/2003JD004331, 2004.

Simpkins, G.: Extreme Arctic heat, Nat. Clim. Change, 7, 95, 2017. Sitch, S., Smith, B., Prentice, I. C., Arneth, A., Bondeau, A., Cramer, W., Kaplan, J. O., Levis, S., Lucht, W., and Sykes, M. T.: Evaluation of ecosystem dynamics, plant geography and terrestrial carbon cycling in the LPJ dynamic global vegetation model, Global Change Biol., 9, 161-185, 2003.

Smith, B., Prentice, I. C., and Sykes, M. T.: Representation of vegetation dynamics in the modelling of terrestrial ecosystems: comparing two contrasting approaches within European climate space, Global Ecol. Biogeogr., 10, 621-637, 2001.

Smith, F. B. and Clark, M. J.: The transport and deposition of radioactive debris from the Chernobyl nuclear power plant accident with special emphasis on consequences to the United Kingdom, Meteorological Office Scientific Paper no. 42, HMSO, London, 1989.

Soares, J., Sofiev, M., Gaire, S., Ruppel, M. M., Langner, J., Geels, C., Kurgansky, R., Nuterman, A., Mahura, A., Kaas, E., and Tsyro, S.: Impact of black carbon on Arctic, a multi-modelling study, in preparation, 2019.

Sofiev, M., Siljamo, P., Valkama, I., Ilvonen, M., and Kukkonen, J.: A dispersion modelling system SILAM and its evaluation against ETEX data, Atmos. Environ., 40, 674-685, 2006.

Sofiev, M., Vira, J., Prank, M., Soares, J., and Kouznetsov, R.: An outlook of System for Integrated modeLling of Atmospheric coMposition SILAM v.5, in: Air Pollution Modeling and its Application XXII, edited by: Steyn, D. G., Builtjes, P. J., and Timmermans, R. M., Springer Netherlands, Dordrecht, 397-400, 2014.

Solazzo, E., Bianconi, R., Pirovan, G. Matthias, V., Vautard, R., Morann, M. D., Appel, W., Bessagnet, B., Brand, J., Christensen, J. H., Chemel, C., Collo, I., Ferreira, J., Forkel, R., Francis, X. V., Grell, G., Grossi, P., Hansen, A. P., and Galmarinia, S.: Operational model evaluation for particulate matter in Europe and North America in the context of AQMEII, Atmos. Environ., 53, 75-92, 2012.

Sorjamaa, R., Svenningsson, B., Raatikainen, T., Henning, S., Bilde, M., and Laaksonen, A.: The role of surfactants in Köhler theory reconsidered, Atmos. Chem. Phys., 4, 2107-2117, https://doi.org/10.5194/acp-4-2107-2004, 2004.

Stendel, M., Christensen, J. H., and Petersen, D.: Arctic climate and climate change with a focus on Greenland, Adv. Ecol. Res., 40, 13-43, 2008.

Stetzer, O., Baschek, B., Lüönd, F., and Lohmann, U.: The Zurich Ice Nucleation Chamber (ZINC) - A new instrument to investigate atmospheric ice nucleation, Aerosol Sci. Tech., 42, 64-74, https://doi.org/10.1080/02786820701787944, 2008.

Stohl, A.: Characteristics of atmospheric transport into the arctic troposphere, J. Geophys. Res., 111, D11306, https://doi.org/10.1029/2005JD006888, 2006.

Stohl, A., Andrews, E., Burkhart, J. F., Forster, C., Herber, A., Hoch, S. W., Kowal, D., Lunder, C., Mefford, T., Ogren, J. A., Sharma, S., Spichtinger, N., Stebel, K., Stone, R., Stroem, J., Toerseth, K., Wehrli, C., and Yttri, K. E.: Pan-Arctic enhancements of light absorbing aerosol concentrations due to North American boreal forest fires during summer 2004, J. Geophys. Res., 111, D22214, https://doi.org/10.1029/2006JD007216, 2006.

Stohl, A., Berg, T., Burkhart, J. F., Fjæraa, A. M., Forster, C., Herber, A., Hov, Ø., Lunder, C., McMillan, W. W., Oltmans, S., Shiobara, M., Simpson, D., Solberg, S., Stebel, K., Ström, J., Tørseth, K., Treffeisen, R., Virkkunen, K., and Yttri, K. E.: Arctic smoke - record high air pollution levels in the European Arctic due to agricultural fires in Eastern Europe in spring 2006, Atmos. Chem. Phys., 7, 511-534, https://doi.org/10.5194/acp-7511-2007, 2007.

Stohl, A., Klimont, Z., Eckhardt, S., Kupiainen, K., Shevchenko, V. P., Kopeikin, V. M., and Novigatsky, A. N.: Black carbon in the Arctic: the underestimated role of gas flaring and residential combustion emissions, Atmos. Chem. Phys., 13, 8833-8855, https://doi.org/10.5194/acp-13-8833-2013, 2013.

Stohl, A., Aamaas, B., Amann, M., Baker, L. H., Bellouin, N., Berntsen, T. K., Boucher, O., Cherian, R., Collins, W., Daskalakis, N., Dusinska, M., Eckhardt, S., Fuglestvedt, J. S., Harju, M., Heyes, C., Hodnebrog, Ø., Hao, J., Im, U., Kanakidou, M., Klimont, Z., Kupiainen, K., Law, K. S., Lund, M. T., Maas, R., MacIntosh, C. R., Myhre, G., Myriokefalitakis, S., Olivié, D., Quaas, J., Quennehen, B., Raut, J.-C., Rumbold, S. T., Samset, B. H., Schulz, M., Seland, Ø., Shine, K. P., Skeie, R. B., Wang, S., Yttri, K. E., and Zhu, T.: Evaluating the climate and air quality impacts of short-lived pollutants, Atmos. Chem. Phys., 15, 10529-10566, https://doi.org/10.5194/acp-15-105292015, 2015.

Struthers, H., Ekman, A. M. L., Glantz, P., Iversen, T., Kirkevåg, A., Mårtensson, E. M., Seland, Ø., and Nilsson, E. D.: The effect of sea ice loss on sea salt aerosol concentrations and the radiative balance in the Arctic, Atmos. Chem. Phys., 11, 3459-3477, https://doi.org/10.5194/acp-11-3459-2011, 2011.

Struthers, H., Ekman, A. M. L., Glantz, P., Iversen, T., Kirkevåg, A., Seland, Ø, Mårtensson, E. M., Noone, K., and Nilsson, E. D.: Climate-induced changes in sea salt aerosol number emissions: 1870 to 2100, J. Geophys. Res.-Atmos., 118, 670-682, https://doi.org/10.1002/jgrd.50129, 2013.

Surratt, J. D., Kroll, J. H., Kleindienst, T. E., Edney, E. O., Claeys, M., Sorooshian, A., Ng, N. L., Offenberg, J. H., Lewandowski, M., Jaoui, M., Flagan, R. C., and Seinfeld, J. H.: Evidence for Organosulfates in Secondary Organic Aerosol, Environ. Sci. Technol., 41, 517-527, 2007.

Svensson, J., Virkkula, A., Meinander, O., Kivekäs, N., Hannula, H.-R., Järvinen, O., Peltoniemi, J. I., Gritsevich, M., Heikkilä, A., Kontu, A., Neitola, K., Brus, D., Dagsson-Waldhauserova, P., Anttila, K., Vehkamäki, M., Hienola, A., de Leeuw, G., and Lihavainen, H.: Soot-doped natural snow and its albedo - results from field experiments, Boreal Environ. Res., 21, 481-503, 2016.

Tedesco, M., Doherty, S., Fettweis, X., Alexander, P., Jeyaratnam, J., and Stroeve, J.: The darkening of the Greenland ice sheet: trends, drivers, and projections (1981-2100), The Cryosphere, 10, 477-496, https://doi.org/10.5194/tc-10-477-2016, 2016.

Thomson, E. S., Kong, X., Marković, N., Papagiannakopoulos, P., and Pettersson, J. B. C.: Collision dynamics and uptake of water on alcohol-covered ice, Atmos. Chem. Phys., 13, 2223-2233, https://doi.org/10.5194/acp-13-2223-2013, 2013.

Thomson, E. S., Kong, X., Papagiannakopoulos, P., and Pettersson, J. B. C.: Deposition-mode ice nucleation reexamined at tem- 
peratures below $200 \mathrm{~K}$, Atmos. Chem. Phys., 15, 1621-1632, https://doi.org/10.5194/acp-15-1621-2015, 2015.

Thomson, E. S., Weber, D., Bingemer, H. G., Tuomi, J., Ebert, M., and Pettersson, J. B. C.: Intensification of ice nucleation observed in ocean ship emissions, Scient. Rep., 8, 1111, https://doi.org/10.1038/s41598-018-19297-y, 2018.

Thordarson, T. and Höskuldsson, Á: Iceland: Second Edition (Classic Geology in Europe 3), Edinburgh, Dunedin, 256 pp., ISBN13: 978-1780460215, 2014.

Thorsteinsson, T., Gísladóttir, G., Bullard, J., and McTainsh, G.: Dust storm contributions to airborne particulate matter in Reykjavík, Iceland, Atmos. Environ., 45, 5924-5933, 2011.

Thorsteinsson, T., Jóhannsson, T., Stohl, A., and Kristiansen, N. I.: High levels of particulate matter in Iceland due to direct ash emissions by the Eyjafjallajökull eruption and resuspension of deposited ash, J. Geophys. Res., 117, B00C05, https://doi.org/10.1029/2011JB008756, 2012.

Tiiva, P., Faubert, P., Michelsen, A., Holopainen, T., Holopainen, J. K., and Rinnan, R.: Climatic warming increases isoprene emission from a subarctic heath, New Phytol., 180, 853-863, 2008.

Tomasi, C., Kokhanovsky, A. A., Lupi, A., Ritter, C., Smirnov, A., O’Neill, N. T., Stone, R. S., Holben, B. N., Nyeki, S., Wehrli, C., Stohl, A., Mazzola, M., Lanconelli, C., Vitale, V., Stebel, L., Aaltonen, V., de Leeuw, G., Rodriguez, E., Herber, A. B., Radionov, V. F., Zielinski, T., Petelski, T., Sakerin, S. M., Kabanov, D. M., Xue, Y., Mei, L.-L., Istomina, L., Wagener, R., McArthur, B., Sobolewski, P. S., Kivi, R., Courcoux, Y., Larouche, P., Broccardo, S., and Piketh, S. J.: Aerosol remote sensing in polar regions, Earth-Sci. Rev., 140, 108-157, 2015.

Tsigaridis, K., Daskalakis, N., Kanakidou, M., Adams, P. J., Artaxo, P., Bahadur, R., Balkanski, Y., Bauer, S. E., Bellouin, N., Benedetti, A., Bergman, T., Berntsen, T. K., Beukes, J. P., Bian, H., Carslaw, K. S., Chin, M., Curci, G., Diehl, T., Easter, R. C., Ghan, S. J., Gong, S. L., Hodzic, A., Hoyle, C. R., Iversen, T., Jathar, S., Jimenez, J. L., Kaiser, J. W., Kirkevåg, A., Koch, D., Kokkola, H., Lee, Y. H., Lin, G., Liu, X., Luo, G., Ma, X., Mann, G. W., Mihalopoulos, N., Morcrette, J.-J., Müller, J.-F., Myhre, G., Myriokefalitakis, S., Ng, N. L., O’Donnell, D., Penner, J. E., Pozzoli, L., Pringle, K. J., Russell, L. M., Schulz, M., Sciare, J., Seland, Ø., Shindell, D. T., Sillman, S., Skeie, R. B., Spracklen, D., Stavrakou, T., Steenrod, S. D., Takemura, T., Tiitta, P., Tilmes, S., Tost, H., van Noije, T., van Zyl, P. G., von Salzen, K., Yu, F., Wang, Z., Wang, Z., Zaveri, R. A., Zhang, H., Zhang, K., Zhang, Q., and Zhang, X.: The AeroCom evaluation and intercomparison of organic aerosol in global models, Atmos. Chem. Phys., 14, 10845-10895, https://doi.org/10.5194/acp-14-108452014, 2014.

Unden, P., Jarvinen, H., Rodriguez, E., and Cats, G.: Hirlam-5 Final Report, Tech. Rep., SMHI, Norrkoping, Sweden, p. 69, available at: http://www.hirlam.org/ (last access: 4 February 2019), 2003.

Vali, G., DeMott, P. J., Möhler, O., and Whale, T. F.: Technical note: A proposal for ice nucleation terminology, Atmos. Chem. Phys., 15, 10263-10270, https://doi.org/10.5194/acp-15-102632015, 2015.

Valolahti, H., Kivimäenpää, M., Faubert, P., Michelsen, A., and Rinnan, R.: Climate change-induced vegetation change as a driver of increased subarctic biogenic volatile organic compound emissions, Global Change Biol., 21, 3478-3488, 2015.
Verpoorter, C., Kutser, T., Seekell, D. A., and Tranvik, L. J.: A global inventory of lakes based on high-resolution satellite imagery, Geophy. Res. Lett., 41, 6396-6402, 2014.

Wadhams, P.: Fairwell to ice, Penguin Books Ltd, ISBN 9780241009437, 2016.

Wagner, R., Kaufmann, J., Möhler, O., Saathoff, H., Schnaiter, M., Ullrich, R., and Leisner, T.: Heterogeneous ice nucleation ability of $\mathrm{NaCl}$ and sea salt aerosol particles at cirrus temperatures, J. Geophys. Res.-Atmos., 123, 2841-2860, https://doi.org/10.1002/2017JD027864, 2018.

Wanninkhof, R., Park, G.-H., Takahashi, T., Sweeney, C., Feely, R., Nojiri, Y., Gruber, N., Doney, S. C., McKinley, G. A., Lenton, A., Le Quéré, C., Heinze, C., Schwinger, J., Graven, H., and Khatiwala, S.: Global ocean carbon uptake: magnitude, variability and trends, Biogeosciences, 10, 1983-2000, https://doi.org/10.5194/bg-10-1983-2013, 2013.

Watson, J. G., Chow, J. C., and Chen, L.-W. A.: Summary of organic and elemental carbon/black carbon analysis methods and intercomparisons, Aerosol Air Qual. Res., 5, 65-102, 2005.

Weyhenmeyer, G. A., Kosten, S., Wallin, M. B., Tranvik, L. J., Jeppesen, E., and Roland, F.: Significant fraction of $\mathrm{CO}_{2}$ emissions from boreal lakes derived from hydrologic inorganic carbon inputs, Nat. Geosci., 8, 933-936, 2015.

Wiedensohler, A., Birmili, W., Nowak, A., Sonntag, A., Weinhold, K., Merkel, M., Wehner, B., Tuch, T., Pfeifer, S., Fiebig, M., Fjäraa, A. M., Asmi, E., Sellegri, K., Depuy, R., Venzac, H., Villani, P., Laj, P., Aalto, P., Ogren, J. A., Swietlicki, E., Williams, P., Roldin, P., Quincey, P., Hüglin, C., Fierz-Schmidhauser, R., Gysel, M., Weingartner, E., Riccobono, F., Santos, S., Grüning, C., Faloon, K., Beddows, D., Harrison, R., Monahan, C., Jennings, S. G., O’Dowd, C. D., Marinoni, A., Horn, H.-G., Keck, L., Jiang, J., Scheckman, J., McMurry, P. H., Deng, Z., Zhao, C. S., Moerman, M., Henzing, B., de Leeuw, G., Löschau, G., and Bastian, S.: Mobility particle size spectrometers: harmonization of technical standards and data structure to facilitate high quality long-term observations of atmospheric particle number size distributions, Atmos. Meas. Tech., 5, 657-685, https://doi.org/10.5194/amt-5-657-2012, 2012.

Wiscombe, W. J. and Warren, S. G.: A model for the spectral albedo of snow. I: Pure snow, J. Atmos. Sci., 37, 2712-2733, 1980.

Wittmann, M., Groot Zwaaftink, C. D., Steffensen Schmidt, L., Guðmundsson, S., Pálsson, F., Arnalds, O., Björnsson, H., Thorsteinsson, T., and Stohl, A.: Impact of dust deposition on the albedo of Vatnajökull ice cap, Iceland, The Cryosphere, 11, 741-754, https://doi.org/10.5194/tc-11-741-2017, 2017.

Wu, Y., Brasseur, Z., Castarède, D., Aalto, P., Hao, L., Heikkinen, L., Heikkilä, P., Kulmala, M., Petäjä, T., Thomson, E. S., and Duplissy, J.: Can new particle formation affect ice-nucleating particle concentration in Boreal forest? in: The Centre of Excellence in Atmospheric Science - From Molecular and Biological processes to The Global Climate, Annual Seminar, 27-29 November 2018, Kuopio, Finland, 2018.

Xu, B., Cao, J., Hansen, J., Yao, T., Joswia, D. R., Wang, N., Wu, G., Wang, M., Zhao, H., Yang, W., Liu, X., and He, J.: Black soot and the survival of Tibetan glaciers, P. Natl. Acad. Sci. USA, 106, 22114-22118, https://doi.org/10.1073/pnas.0910444106, 2009.

Yang, Y., Cheng, B., Kourzeneva, E., Semmler, T., Rontu, L., Leppäranta, M., Shirasawa, K., and Li, Z.: Modelling experiments on 
air-snow interactions over Kilpisjärvi, a lake in northern Finland, Boreal Environ. Res., 18, 341-358, 2013.

Yang, Y., Leppäranta, M., Li, Z., Cheng, B., Zhai, M., and Demchev, D.: Model simulations of the annual cycle of the landfast ice thickness in the East Siberian Sea, Adv. Polar Sci., 26, 168178,2015

Yttri, K. E., Lund Myhre, C., Eckhardt, S., Fiebig, M., Dye, C., Hirdman, D., Ström, J., Klimont, Z., and Stohl, A.: Quantifying black carbon from biomass burning by means of levoglucosan - a one-year time series at the Arctic observatory Zeppelin, Atmos. Chem. Phys., 14, 6427-6442, https://doi.org/10.5194/acp14-6427-2014, 2014.

Zábori, J., Krejci, R., Ekman, A. M. L., Mårtensson, E. M., Ström, J., de Leeuw, G., and Nilsson, E. D.: Wintertime Arctic Ocean sea water properties and primary marine aerosol concentrations, Atmos. Chem. Phys., 12, 10405-10421, https://doi.org/10.5194/acp-12-10405-2012, 2012.
Zachos, J., Pagani, M., Sloan, L., Thomas, E., and Billups, K.: Trends, rhythms, and aberrations in global climate $65 \mathrm{Ma}$ to present, Science, 292, 686-693, 2001.

Zhang, X., He, J., Zhang, J., Polyakov, I., Gerdes, R, Inoue, J., and $\mathrm{Wu}, \mathrm{P}$. : Enhanced poleward moisture transport and amplified northern high-latitude wetting trend, Nat. Clim. Change, 3, 47-51, https://doi.org/10.1038/nclimate1631, 2013.

Zhang, Y., Renssen, H., Seppä, H., and Valdes, P. J.: Holocene temperature evolution in the northern Hemisphere high latitudes data-model comparisons, Quaternary Sci. Rev., 173, 101-113, 2017.

Zieger, P., Väisänen, O., Corbin, J., Partridge, D. G., Bastelberger, S., Mousavi-Fard, M., Rosati, B., Gysel, M., Krieger, U., Leck, C., Nenes, A., Riipinen, I., Virtanen, A., and Salter, M.: Revising the hygroscopicity of inorganic sea salt particles, Nat. Commun., 8, 15883, https://doi.org/10.1038/ncomms15883, 2017. 